\title{
A Guide to the Formulation of Water Resources Strategy
}

Edited by Guy Le Moigne, Ashok Subramanian, Mei Xie, and Sandra Giltner

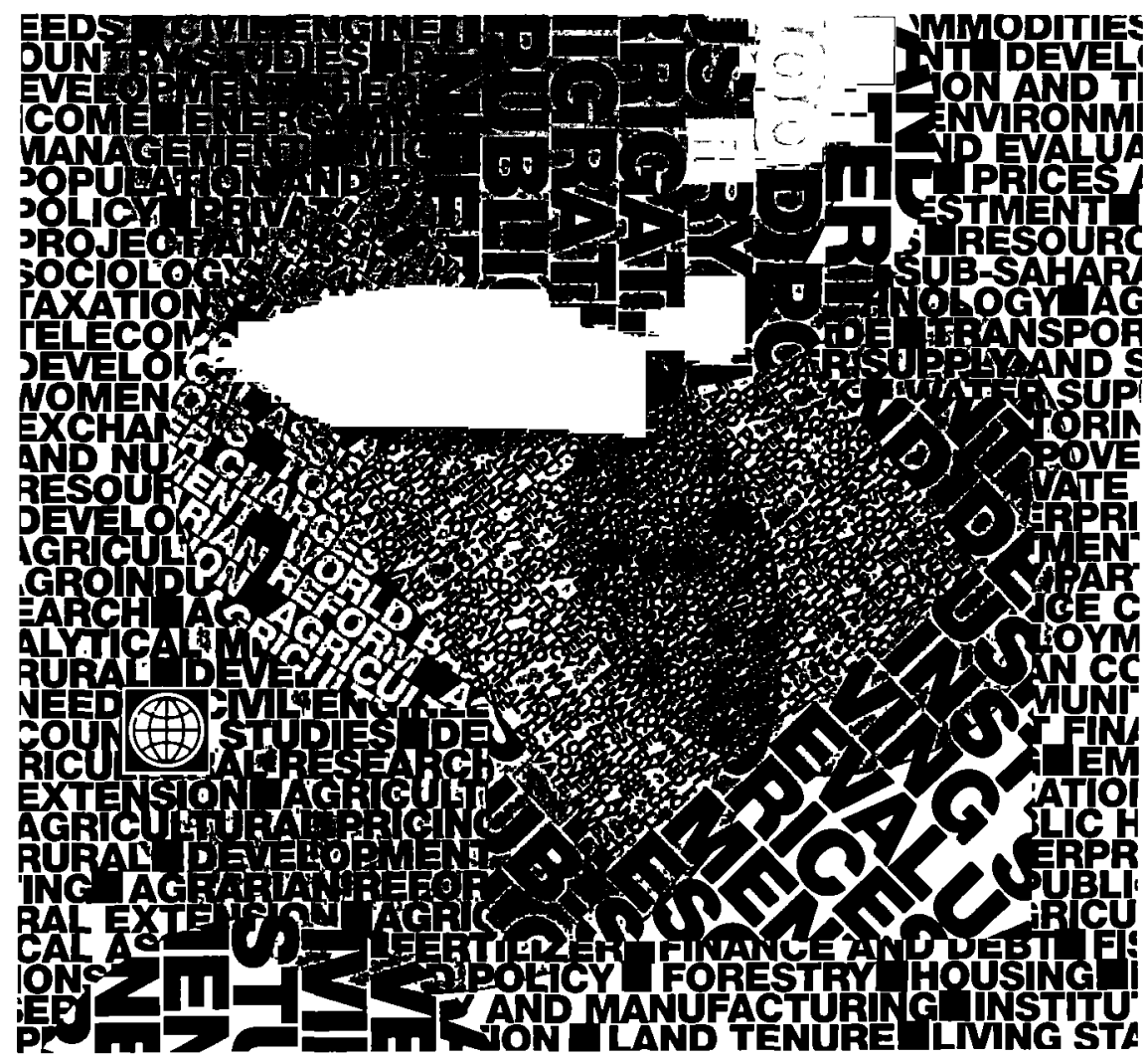




\section{RECENT WORLD BANK TECHNICAL PAPERS}

No. 189 Frederick, Balancing Water Demands with Supplies: The Role of Management in a World of Increasing Scarcity

No. 190 Macklin, Agricultural Extension in India

No. 191 Frederiksen, Water Resources Institutions: Some Principles and Practices

No. 192 McMillan, Painter, and Scudder, Settlement and Development in the River Blindness Control Zone

No. 193 Braatz, Conserving Biological Diversity: A Strategy for Protected Areas in the Asia-Pacific Region

No. 194 Saint, Universities in Africa: Strategies for Stabilization and Revitalization

No. 195 Ochs and Bishay, Drainage Guidelines

No. 196 Mabogunje, Perspective on Urban Land and Land Management Policies in Sub-Saharan Africa

No. 197 Zymelman, editor, Assessing Engineering Education in Sub-Saharan Africa

No. 198 Teerink and Nakashima, Water Allocation, Rights, and Pricing: Examples from Japan and the United States

No. 199 Hussi, Murphy, Lindberg, and Brenneman, The Development of Cooperatives and Other Rural Organizations: The Role of the World Bank

No. 200 McMillan, Nana, and Savadogo, Settlement and Development in the River Blindness Control Zone: Case Study Burkina Faso

No. 201 Van Tuijl, Improving Water Use in Agriculture: Experiences in the Middle East and North Africa

No. 202 Vergara, The Materials Revolution: What Does It Mean for Developing Asia?

No. 203 Cleaver, A Strategy to Develop Agriculture in Sub-Saharan Africa and a Focus for the World Bank

No. 204 Barghouti, Cromwell, and Pritchard, editors, Agricultural Technologies for Market-Led Development Opportunities in the 1990s

No. 205 Xie, Küffner, and Le Moigne, Using Water Efficiently: Technological Options

No. 206 The World Bank/FAO/UNIDO/Industry Fertilizer Working Group, World and Regional Supply and Demand Balances for Nitrogen, Phosphate, and Potash, 1991/92-1997/98

No. 207 Narayan, Participatory Evaluation: Tools for Managing Change in Water and Sanitation

No. 208 Bindlish and Evenson, Evaluation of the Performance of T\&V Extension in Kenya

No. 209 Keith, Property Tax: A Practical Manual for Anglophone Africa

No. 210 Bradley and McNamara, editors, Living with Trees: Policies for Forestry Management in Zimbabwe

No. 211 Wiebers, Integrated Pest Management and Pesticide Regulation in Developing Asia

No. 212 Frederiksen, Berkoff, and Barber, Water Resources Management in Asia, Volume I: Main Report

No. 213 Srivastava and Jaffee, Best Practices for Moving Seed Technology: New Approaches to Doing Business

No. 214 Bonfiglioli, Agro-pastoralism in Chad as a Strategy for Survival: An Essay on the Relationship between Anthropology and Statistics

No. 215 Umali, Irrigation-Induced Salinity: A Growing Problem for Development and the Environment

No. 216 Carr, Improving Cash Crops in Africa: Factors Influencing the Productivity of Cotton, Coffee, and Tea Grown by Smallholders

No. 217 Antholt, Getting Ready for the Twenty-First Century: Technical Change and Institutional Modernization in Agriculture

No. 218 Mohan, editor, Bibliography of Publications: Technical Department, Africa Region, July 1987 to December 1992

No. 219 Cercone, Alcohol-Related Problems as an Obstacle to the Development of Human Capital: Issues and Policy Options

No. 220 Kingsley, Ferguson, Bower, and Dice, Managing Urban Environmental Quality in Asia

No. 221 Srivastava, Tamboli, English, Lal, and Stewart, Conserving Soil Moisture and Fertility in the Warm Seasonally Dry Tropics

No. 222 Selvaratnam, Innovations in Higher Education: Singapore at the Competitive Edge

No. 223 Piotrow, Treiman, Rimon, Yun, and Lozare, Strategies for Family Planning Promotion

No. 224 Midgley, Urban Transport in Asia: An Operational Agenda for the 1990s

No. 225 Dia, A Governance Approach to Civil Service Reform in Sub-Saharan Africa 


\section{A Guide to the Formulation of Water Resources Strategy}

Edited by Guy Le Moigne, Ashok Subramanian, Mei Xie, and Sandra Giltner

The World Bank

Washington, D.C. 
Copyright (C) 1994

The International Bank for Reconstruction

and Development/THE WORLD BANK

1818 H Street, N.W.

Washington, D.C. 20433, U.S.A.

All rights reserved

Manufactured in the United States of America

First printing November 1994

Technical Papers are published to communicate the results of the Bank's work to the development community with the least possible delay. The typescript of this paper therefore has not been prepared in accordance with the procedures appropriate to formal printed texts, and the World Bank accepts no responsibility for errors. Some sources cited in this paper may be informal documents that are not readily available.

The findings, interpretations, and conclusions expressed in this paper are entirely those of the author(s) and should not be attributed in any manner to the World Bank, to its affiliated organizations, or to members of its Board of Executive Directors or the countries they represent. The World Bank does not guarantee the accuracy of the data included in this publication and accepts no responsibility whatsoever for any consequence of their use. The boundaries, colors, denominations, and other information shown on any map in this volume do not imply on the part of the World Bank Group any judgment on the legal status of any territory or the endorsement or acceptance of such boundaries.

The material in this publication is copyrighted. Requests for permission to reproduce portions of it should be sent to the Office of the Publisher at the address shown in the copyright notice above. The World Bank encourages dissemination of its work and will normally give permission promptly and, when the reproduction is for noncommercial purposes, without asking a fee. Permission to copy portions for classroom use is granted through the Copyright Clearance Center, Inc., Suite 910, 222 Rosewood Drive, Danvers, Massachusetts 01923, U.S.A.

The complete backlist of publications from the World Bank is shown in the annual Index of Publications, which contains an alphabetical title list (with full ordering information) and indexes of subjects, authors, and countries and regions. The latest edition is available free of charge from the Distribution Unit, Office of the Publisher, The World Bank, 1818 H Street, N.W., Washington, D.C. 20433, U.S.A., or from Publications, The World Bank, 66, avenue d'Iéna, 75116 Paris, France.

ISSN: 0253-7494

All of the editors work in the Agriculture and Natural Resources Department of the World Bank. Guy Le Moigne is a senior adviser on water resources, Ashok Subramanian is an institutions specialist, Mei $X i e$ is a water resources engineer, and Sandra Giltner is a consultant.

\section{Library of Congress Cataloging-in-Publication Data}

A guide to the formulation of water resources strategy / edited by Guy

Le Moigne ... [et al.].

p. cm - (World Bank technical paper; no. 263)

Includes bibliographical references.

ISBN 0-8213-3038-1

1. Water resources development-Developing countries-Planning.

I. Le Moigne, Guy J. M., 1932- II. Series.

HD1702.G85 1994

$333.91^{\prime} 009172^{\prime} 4-\mathrm{dc} 20$

94-37850 


\section{Contents}

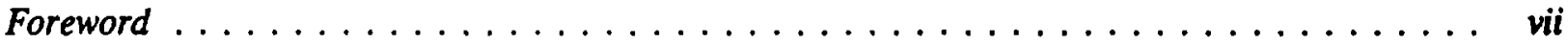

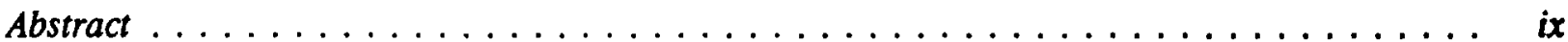

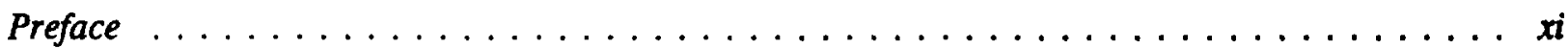

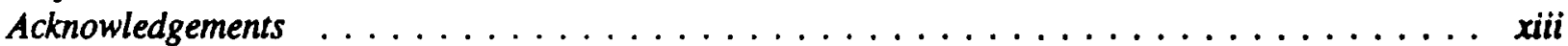

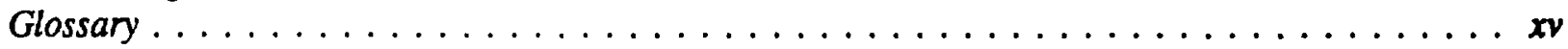

PART I: THE PROCESS OF WATER RESOURCES STRATEGY FORMULATION . . . . . 1

CHAPTER 1 THE PROCESS OF WATER RESOURCES

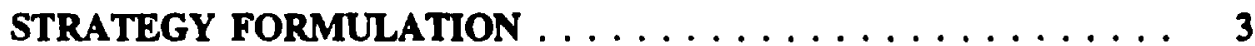

PURPOSE OF THE GUIDE $\ldots \ldots \ldots \ldots \ldots \ldots \ldots \ldots \ldots \ldots \ldots \ldots$

WATER RESOURCES MANAGEMENT STRATEGY $\ldots \ldots \ldots \ldots \ldots \ldots \ldots \ldots$

THE PROCESS OF STRATEGY FORMULATION $\ldots \ldots \ldots \ldots \ldots \ldots$

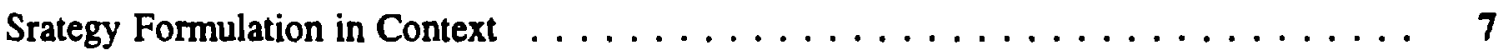

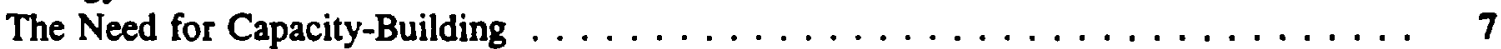

Stakeholder Participation $\ldots \ldots \ldots \ldots \ldots \ldots \ldots \ldots \ldots \ldots \ldots$

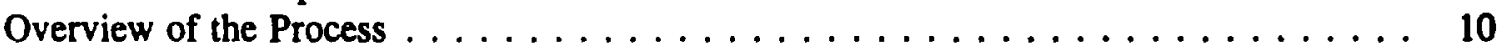

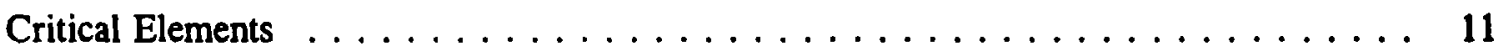

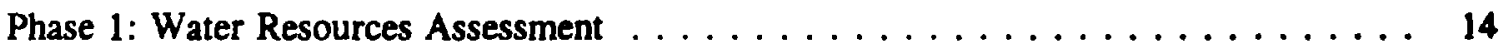

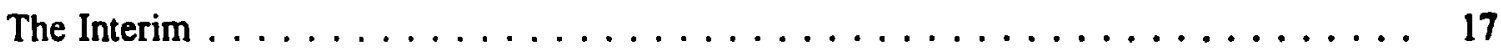

Phase 2: Formulating Strategic Options $\ldots \ldots \ldots \ldots \ldots \ldots \ldots \ldots$

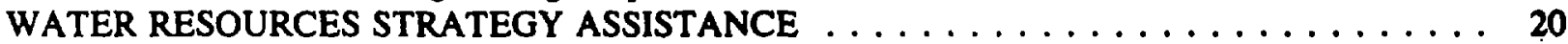

KEY AREAS FOR ASSESSMENT AND STRATEGY INTEGRATION . . . . . . . . . 20

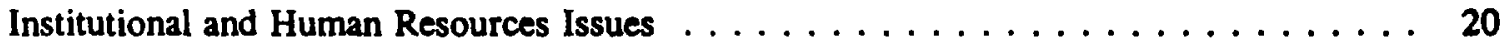

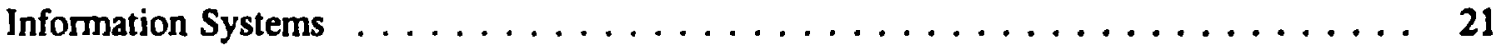

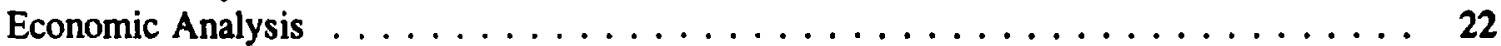

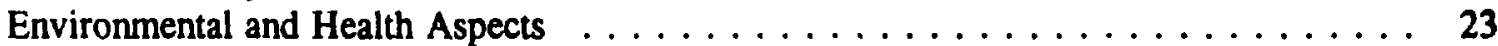

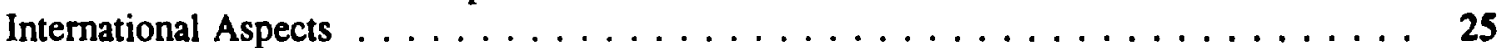

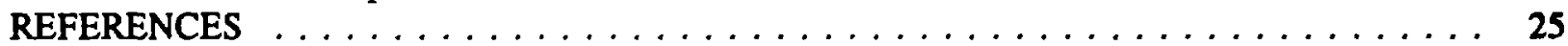

PART II: ISSUES IN COMPREHENSIVE WATER RESOURCES

MANAGEMENT

CHAPTER 2 INSTITUTIONAL AND HUMAN RESOURCES ISSUES $\ldots \ldots \ldots$

ASSESSMENT AND INSTITUTIONAL ANALYSIS $\ldots \ldots \ldots \ldots \ldots \ldots \ldots \ldots$

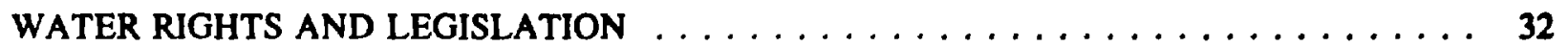

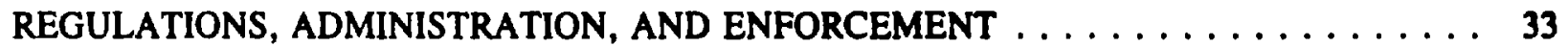


ORGANIZATIONAL ARRANGEMENTS $\ldots \ldots \ldots \ldots \ldots \ldots \ldots \ldots \ldots$

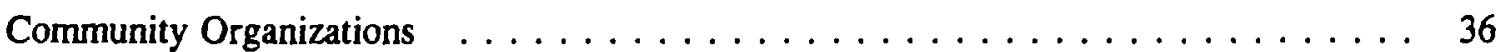

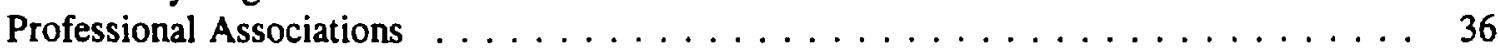

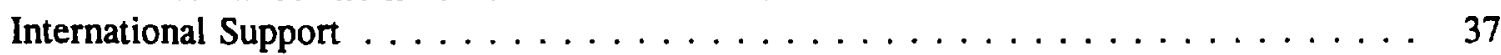

HUMAN RESOURCES DEVELOPMENT $\ldots \ldots \ldots \ldots \ldots \ldots \ldots \ldots \ldots \ldots \ldots$

FURTHER INFORMATION $\ldots \ldots \ldots \ldots \ldots \ldots \ldots \ldots \ldots \ldots \ldots$

CHAPTER 3 STAKEHOLDER PARTICIPATION $\ldots \ldots \ldots \ldots \ldots \ldots \ldots$

DEFINITION AND BENEFITS OF STAKEHOLDER PARTICIPATION $\ldots \ldots \ldots \ldots$

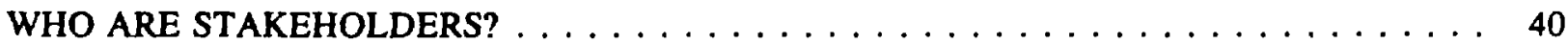

LEVELS AND TECHNIQUES OF PARTICIPATION $\ldots \ldots \ldots \ldots \ldots \ldots \ldots \ldots \ldots \ldots$

STAKEHOLDER PARTICIPATION DURING STRATEGY FORMULATION $\ldots \ldots \ldots \ldots$

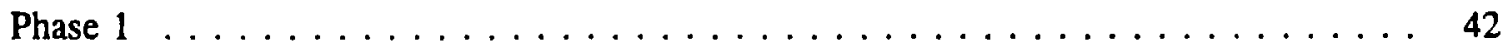

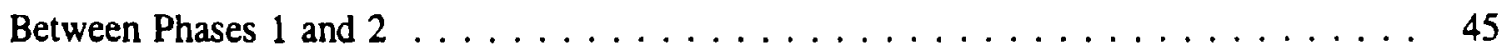

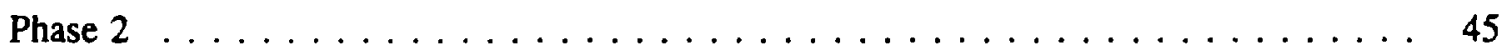

PRINCIPLES FOR PARTICIPATION $\ldots \ldots \ldots \ldots \ldots \ldots \ldots \ldots$

FURTHER INFORMATION $\ldots \ldots \ldots \ldots \ldots \ldots \ldots \ldots \ldots \ldots$

CHAPTER 4 INFORMATION SYSTEM ISSUES $\ldots \ldots \ldots \ldots \ldots \ldots \ldots$

JUSTIFICATION AND RATIONALE $\ldots \ldots \ldots \ldots \ldots \ldots \ldots \ldots$

ELEMENTS OF AN ASSESSMENT OF A WATER RESOURCES MANAGEMENT

INFORMATION SYSTEM $\ldots \ldots \ldots \ldots \ldots \ldots \ldots \ldots \ldots \ldots$. . . . . . . . . 50

AN EXAMPLE OF TERMS OF REFERENCE FOR THE DESIGN OF WATER RESOURCES

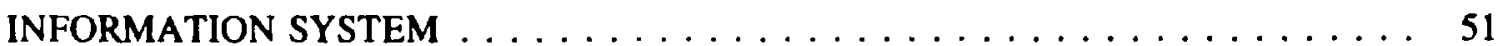

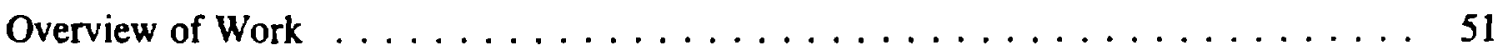

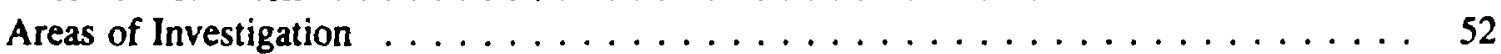

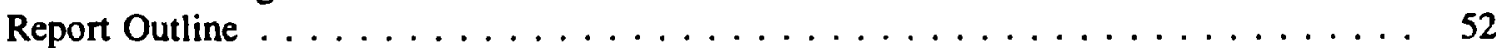

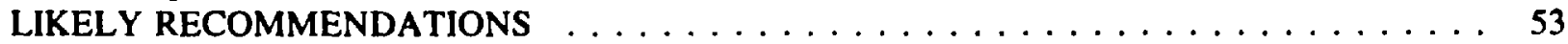

THE EFFECT OF TECHNOLOGY ON INSTITUTIONS $\ldots \ldots \ldots \ldots \ldots \ldots \ldots \ldots$

FURTHER INFORMATION $\ldots \ldots \ldots \ldots \ldots \ldots \ldots \ldots \ldots \ldots \ldots \ldots$

CHAPTER 5 THE ROLE OF ECONOMICS $\ldots \ldots \ldots \ldots \ldots \ldots \ldots$

APPLYING ECONOMIC CONCEPTS IN STRATEGY FORMULATION $\ldots \ldots \ldots$

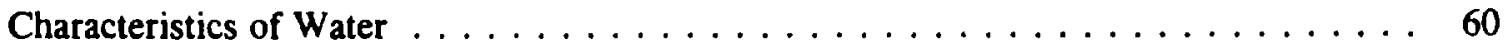

Economic Efficiency and the Value of Water $\ldots \ldots \ldots \ldots \ldots \ldots \ldots$

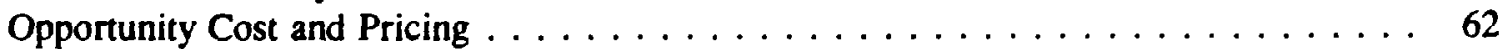

Other Economic Incentives $\ldots \ldots \ldots \ldots \ldots \ldots \ldots \ldots$

Economic Analysis of Alternative Courses of Action and Investments . . . . . . . 63

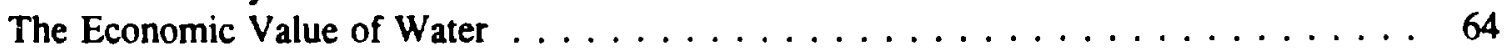

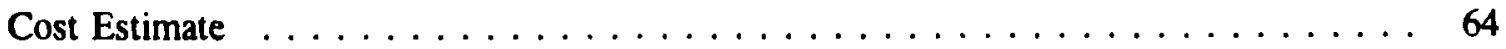




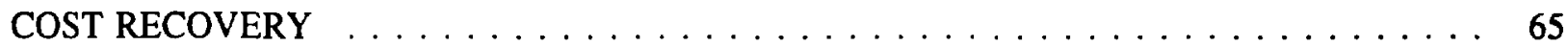

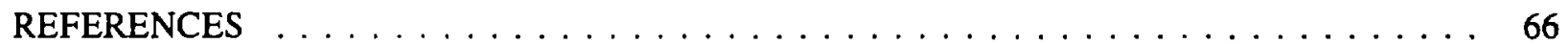

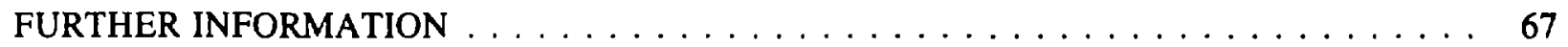

CHAPTER 6 ENVIRONMENTAL AND HEALTH CONSIDERATIONS $\ldots \ldots \ldots$

PUBLIC HEALTH AND WATER RESOURCES $\ldots \ldots \ldots \ldots \ldots \ldots$

EXISTING ENVIRONMENTAL ISSUES FOR WATER RESOURCES ASSESSMENT . . . . . 70

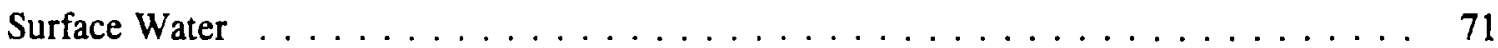

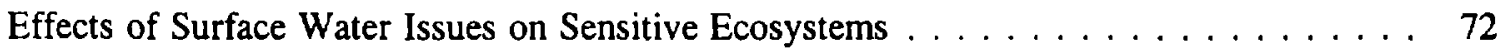

Effects on Public Health $\ldots \ldots \ldots \ldots \ldots \ldots \ldots \ldots \ldots \ldots$

Groundwater . . . . . . . . . . . . . . . . . . . . . . 74

WATER RESOURCES ASSESSMENT: ENVIRONMENTAL INSTITUTIONS $\ldots \ldots \ldots$. . 75

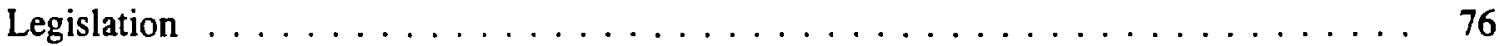

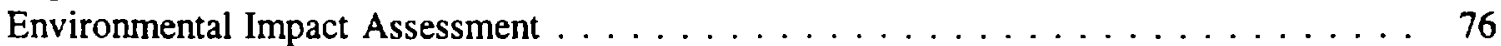

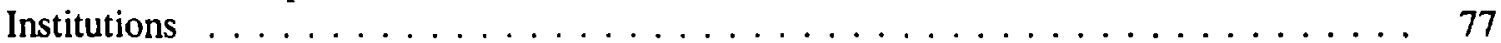

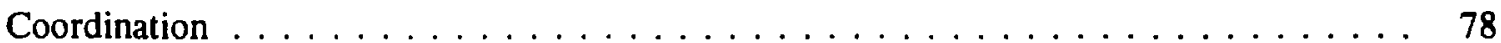

WATER RESOURCES MANAGEMENT STRATEGY $\ldots \ldots \ldots \ldots \ldots \ldots \ldots \ldots$

Priority Environmental Issues . . . . . . . . . . . . . . . . . . . . . . 79

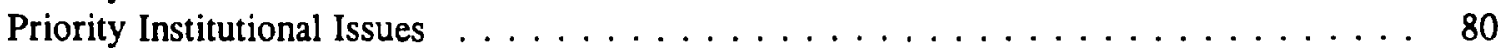

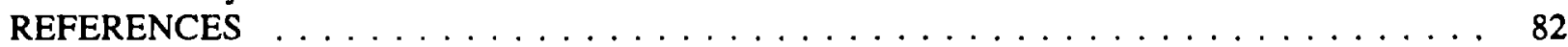

FURTHER INFORMATION $\ldots \ldots \ldots \ldots \ldots \ldots \ldots \ldots \ldots \ldots$

CHAPTER 7 INTERNATIONAL ISSUES $\ldots \ldots \ldots \ldots \ldots \ldots$

INTERNATIONAL ASPECTS OF WATER RESOURCES STRATEGY $\ldots \ldots \ldots$

INTERNATIONAL WATER LAW $\ldots \ldots \ldots \ldots \ldots \ldots \ldots$

OBJECTIVES OF COLLABORATION $\ldots \ldots \ldots \ldots \ldots \ldots \ldots \ldots \ldots$

ASSESSING THE DATA BASE $\ldots \ldots \ldots \ldots \ldots \ldots \ldots \ldots$

WATER SHARING AND ALLOCATION $\ldots \ldots \ldots \ldots \ldots \ldots \ldots \ldots$

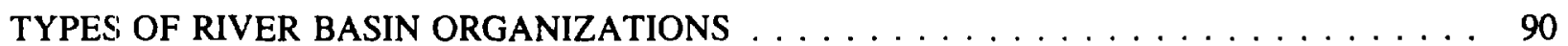

FACTORS CONTRIBUTING TO THE SUCCESS OF A RIVER BASIN ORGANIZATION . . . 91

FURTHER INFORMATION $\ldots \ldots \ldots \ldots \ldots \ldots \ldots \ldots \ldots$

ANNEX SUGGESTED TERMS OF REFERENCE FOR WATER RESOURCES STRATEGY FORMULATION $\ldots \ldots \ldots \ldots . \ldots \ldots$

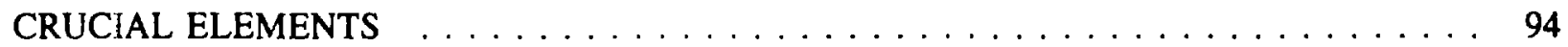

SCOPE OF WORK . . . . . . . . . . . . . . . . . . . . . . . . . . . . 94

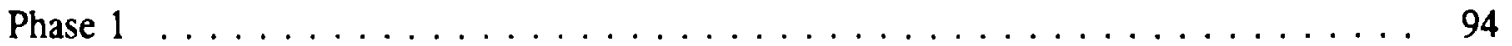

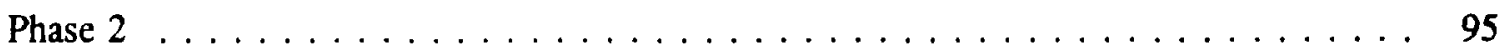

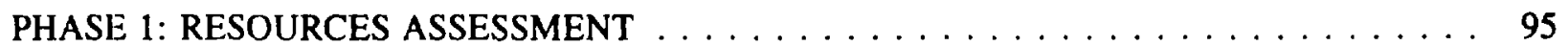

Examination of National Development Goals and Key Water-Related Policies . . . . . . . . . . . . . . . . 95

Inventory .......................... 95 
Key Issues: Selection, Analysis (Projections), and Ranking . . . . . . . . . . . . . 99

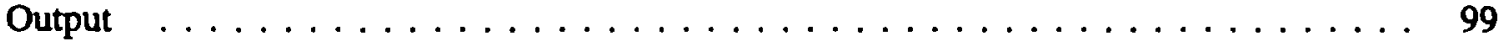

PHASE 2: STRATEGY DEFINITION $\ldots \ldots \ldots \ldots \ldots \ldots \ldots \ldots \ldots \ldots$

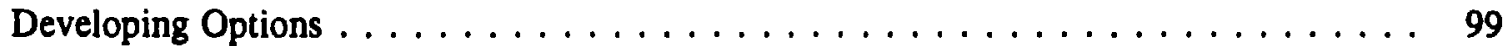

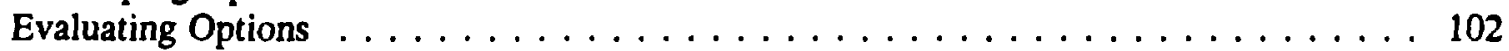

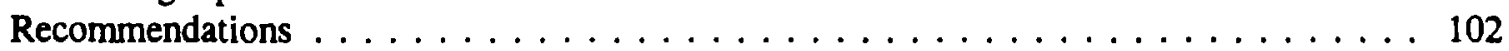

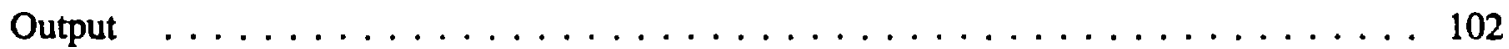

\section{TABLES}

Table 3.1 Information and Stakeholder Participation . . . . . . . . . . . . 44

Table 4.1 Need for Selected Meteorologic and

Climatologic Data . . . . . . . . . . . . . . . . . . 56

Table 4.2 Need for Selected Hydrometric Data for Water Resources Assessment . . . . . . . . . . . . . . . . . 57

Table 4.3 Need for Selected Groundwater Data for Water Resources Management . . . . . . . . . . . . . 58

\section{FIGURES}

Figure 1.1 The Strategic Planning Cycle $\ldots \ldots \ldots \ldots \ldots \ldots \ldots$

Figure 1.2 Levels and Roles of Stakeholder Participation

in Water Resources Management . . . . . . . . . . . . . . 10

Figure 1.3 Key Points

in Water Strategy Formulation $\ldots \ldots \ldots \ldots 11$

Figure 3.1 Levels of Stakeholder Participation

and Examples of Participation Techniques . . . . . . . . . . . 42 
In its 1993 policy paper Water Resources Management, the World Bank committed itself to assisting countries in the development of a systematic framework for incorporating cross-sectoral and ecosystem interdependencies into the formulation of policies, regulations, and public investment plans that are suitable to the particular country's situation. Elsewhere in that document, the Bank recognized two factors associated with incorporating these elements of comprehensive water resources management. First, one of the major requirements for long-term, sustainable economic development, and for successful management of water resources, is building a country's capacity to plan and manage its resources. This capacity-building must occur on many levels, but particularly on the levels of developing the proper individual and institutional abilities to plan and manage resources. Second, implementing water resources policies that incorporate principles such as water conservation, cost-recovery, and poverty alleviation requires a national water resources strategy. The Bank made a commitment in the policy paper to preparing, in collaboration with the United Nations Development Programme (UNDP), a guide on capacity-building for countries interested in forming strategies for managing water resources.

This volume on strategy formulation is the result of well over a year's effort by water resources professionals under the leadership of Guy Le Moigne. Since the Bank's commitment was clearly a guide for countries, the authors have aimed the volume at policymakers in the developing world. Many countries have prepared water resources plans and the like, but often these have not been prepared principally by the countries themselves. One central element the authors wished to address was building the capacity to manage water resources through the process of strategy formulation.

Political, economic, social, and environmental circumstances are different among developing countries, especially concerning the availability of water. It would have been most difficult to extrapolate from actual experiences to develop a "best practices" guide or a rigorous step-by-step guide on how to formulate a strategy. Moreover, water resources planning and management in the past rarely sought to incorporate the comprehensive or "holistic" principles that have been recently adopted at numerous international conferences including the 1992 United Nations Conference on Environment and Development (UNCED) in Rio de Janeiro. These elements are elaborated in the volume.

This volume, then, describes the process of strategy formulation and relates the major aspects of comprehensive water resources management to that process. While the description is based on experience, the process has rarely been undertaken as described. Like the major issues in comprehensive water resources management, the process is meant to be adapted to each country's circumstances. There are, however, several elements that should be included if the process of formulating water resources strategy is to contribute to a country's ability to manage and sustain the resource.

Water is a crucial element in economic development, and in maintaining or improving the health of a country's people and of its natural environment. Investments in managing water resources can be among the most fruitful that a country can make for its future, provided that they are made within the framework of a comprehensive strategy. We hope that this volume will contribute to this critical endeavor.

MICHEL PETIT

Director

Agriculture and Natural Resources

Department 



\section{Abstract}

This volume outlines the process of formulating a water resources management strategy. It is intended for decisionmakers in developing countries. The process that is outlined, while drawn from experience, is general; moreover, it can be used for regional, national, or international strategy formulation. Going through process of formulating a water resources strategy can contribute to a country's ability or capacity to manage its water resources. The process outlined in this volume incorporates the elements of comprehensive or "holistic" water resources management that have been endorsed by numerous international conferences. These elements include (a) institutional and human resources issues (including laws, regulations, and organizations), (b) the development of adequate information systems, (c) the participation of those concerned with or having an interest in water resources-"stakeholders"-in the strategy formulation process, (d) the use of economic principles (including cost-recovery) in water resources management, (e) consideration of the environmental and public health aspects of water resources management, and (f) working with other countries or regions to manage international resources successfully. 

Renewed interest in water resources management in the wake of several recent international conferences and meetings has prompted a number of developing countries to formulate policies, undertake water resources assessments, and prepare associated strategies or action programs. Increasingly, the World Bank, the UNDP, and other organizations are called upon to provide support in the formulation of water resources strategies. The principles and recommendations endorsed at the international conferences and in the 1993 World Bank policy paper on water resources management provide a framework for the translation of these policies into action. This guide describes a process for formulating water resources strategies and outlines major issues in comprehensive water resources management that need to be considered in strategy formulation.

The primary purpose of this volume is to assist developing countries in formulating water resource management strategies by outlining a general process. The paper also suggests ways for countries to build capacity through the process of formulating and implementing such strategies. Water resources management is a daunting task, especially given complex institutional and human resources issues and competing demands for resources. Management of water resources is, however, essential for long-term, environmentally sustainable human and economic development.

Many developing countries and external support agencies (ESAs) have already adopted water resources development policies. In suggesting a process for translating such policies into action, this guide complements other efforts to develop strategies. These include water resources master plans and "rapid assessments," the latter often used for solution of immediate problems and for evaluating shortterm investments. This guide stresses the need for long-term water resources management, which entails building a national capacity to manage resources by involving all stakeholders in decisionmaking. The process of assessment and strategy formulation should be collaborative, consultative, and transparent.

There are many fine technical guidelines (cited in the text) for water assessments and other components of preparing a strategy. This guide is not meant to explain the process of strategy formulation or its concepts in fine detail. Part I, "The Process of Strategy Formulation," covers the purpose and process of strategy formulation. The latter is a two-phase process consisting basically of a water resources assessment and then the formulation and choice of options. Part II, "Issues in Comprehensive Water Resources Management," covers such main concepts as institutional and human resources aspects, stakeholder participation, information systems, economic aspects, environmental and health aspects, and international issues. General terms of reference for formulating water resources management strategy are included as the appendix. As can be seen, a conscious effort has been made to bring together disciplines that all too often are addressed separately.

This paper has benefited substantially from review and discussion by over 160 participants in the World Bank-sponsored Tenth Water Resources Seminar (formerly the Irrigation and Drainage Seminar) in December 1993 in Richmond, Virginia. Seminar participants included representatives of international agencies such as the World Bank, the United Nations (UN)-including UNDP, the UN Secretariat, the UN Food and Agriculture Organization (FAO), the UN Educational, Scientific, and Cultural Organization (UNESCO), and the World Meteorological Organization (WMO)-professional associations (such as the International Water Resources Association (IWRA), the International Commission on Irrigation and 
Drainage, the International Irrigation Management Institute), non-government organizations (NGOs), donor agencies, and governments of industrial and developing countries.

The volume is weighted toward the comprehensive water resources management issues that cut across traditional water sectors such as water supply and sanitation, irrigation and drainage, and hydropower. These traditional areas will in most cases be the main substance and focus of strategies. Although broad strategy cannot address all of the specific issues within these sectors, it can articulate where the emphases should be placed among them and how the considerations of comprehensive water resources management can affect these areas. In our view, this guide is ready to be shared with our colleagues in developing countries and external support agencies with an invitation to use it in "real life" situations and to help us to improve any future versions.

The comprehensive approach to water resources management challenges countries to find new ways of providing environmentally sound social and economic development and of managing these resources to achieve this. Circumstances in countries vary so widely that it would not be fruitful to prescribe one method for strategy formulation. It is clear, however, that throughout the world water is a limited and critical resource, that strategies to manage and conserve it are necessary, and that countries need and want to build their capacities to manage it successfully.

FRANK HARTVELT

Deputy Director

Division for Science, Technology, and

the Private Sector

United Nations Development Programme
GUY LE MOIGNE

Senior Adviser, Water Resources

The World Bank 
This volume benefitted from the contributions of many people. The text of chapter 1 was prepared by Guy Le Moigne, Ashok Subramanian, Mei Xie, and Sandra Giltner. Chapters 2-7 were prepared by Jerome Delli Priscoli, Geoffrey Matthews, Ashok Subramanian, Daniel Okun, K. William Easter, Rafik Hirji, Alfred M. Duda, and Robert Rangeley. Significant contributions were also made by UNDP's Frank Hartvelt and Anthony Edwards of the UN Secretariat as well as by the World Bank's Janusz Kindler, Harald Frederiksen, François-Marie Patorni, Gershon Feder, Ariel Dinar, and the staff of the Bank's Water and Sanitation Division in the Transport, Water, and Urban Development Department (TWUWS) under John Briscoe. Many of the individuals who commented on early drafts were among the 160 or so who attended the World Bank's Tenth Water Resources Seminar (formerly the Irrigation and Drainage Seminar) in December 1993. Drafts of the guide were distributed to the seminar participants, who came from governments, the World Bank, the UN, professional associations, and nongovernment organizations, and who provided valuable comments on the focus and content of this volume. The editors would also like to thank Dennis Warner of the World Health Organization (WHO) and John Rodda of the World Meterorological Association (WMO) for reviewing and commenting on a later draft and both Robert Rangeley and Janusz Kindler for careful review of several drafts. Finally, the work of many individuals on the World Bank's water policy paper Water Resources Management laid the foundation for this paper. 

Aquifer

Assessment (water resources assessment)

Capacity-building

Comprehensive water resources management

Cost recovery

Decentralization

Demand management

Ecosystem

ESA

Externality

FAO

Financial autonomy

Human resources development

IHE

Institutions
A stratum or zone below the surface of the earth capable of producing water

An examination of the aspects of the supply and demand for water and of the factors affecting the management of water resources

The process of building organizations, human resources, and the legal and regulatory framework needed for effective and efficient water resources management

Water resources planning, development, and control that incorporates physical, social, economic, and environmental interdependencies

Fee structures that cover the cost of providing the service or investment

The distribution of responsibilities for decisionmaking and operations to lower levels of government, community organizations, the private sector, and nongovernment organizations

The use of price, quantitative restrictions, and other devices to limit the demand for water

A complex system formed by the interaction of a community of organisms with its environment

External support agency (generally an agency that provides support, monetary or nonmonetary for economic or social development). These organizations may be bilateral, multilateral, or non-government agencies

The unintended real (generally nonmonetary) side effect of one party's actions on another party that is ignored in decisions made by the party causing the effects

\section{Food and Agriculture Organization of the United Nations}

The ability of an entity to operate and sustain its activities for a long period based on the revenue it collects from the users of its services

The enhancement of knowledge and skills plus the creation of optimum conditions to use these

International Institute for Hydraulic and Environmental Engineering

Organizational arrangements and the legal and regulatory framework (the "enabling environment") in which organizations operate 
IWRA

Market failure

NGOs

O\&M

Opportunity cost

RBO

Riparian state

River basin

Sensitivity analysis

Sewage

Sewerage

Stakeholder

Strategy (water resources strategy)

UN

UNCED

UNDP

UNEP

UNESCO

UNDDSMS

Watercourse
International Water Resources Association

A divergence between the market outcome (without intervention) and the economically efficient solution

Non-government organizations

Operations and maintenance

The value of goods or services foregone, including environmental goods and services, when a scarce resource is used for one purpose instead of for its next best alternative use

River basin organization

A state through or along which a portion of a river flows or a lake lies

A geographical area determined by the watershed limits of a system of water, including surface and underground water, flowing into a common terminus

Assessment of the response of some factors as a result of changes in others

Liquid refuse or waste matter carried off by sewers

The removal and disposal of sewage and surface water by sewer systems

Organization or individual that is concerned with or has an interest in water resources and that would be affected by decisions about water resources management

A set of medium- to long-term action programs to support the achievement of development goals and to implement water-related policies

United Nations

United Nations Conference on Environment and Development (Rio de Janeiro 1992)

United Nations Development Programme

United Nations Environment Programme

United Nations Educational, Scientific, and Cultural Organization

United Nations Department of Development Support and Management Services

A system of surface and underground waters that constitute, by virtue of their physical relationship, a unitary whole and that flow into a common terminus 
Watershed

Wetlands

WHO

WMO
An area drained by a river or stream system; also referred to as a catchment area

Areas of marsh, fen, peat land, or water that include natural, artificial, permanent, and temporary areas with static or flowing water that is fresh, brackish, or marine

\section{World Health Organization}

World Meteorological Association 



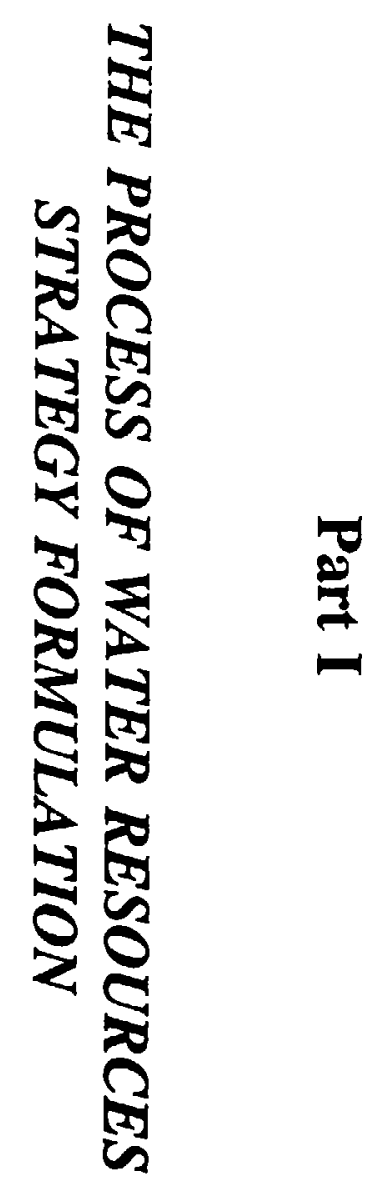





\section{CHAPTER 1 THE PROCESS OF WATER RESOURCES STRATEGY FORMULATION}

1.1 An adequate supply of affordable water of suitable quality makes a major contribution to economic and social development. More than a billion people, mostly the poor, still have no access to clean water.' Almost 1.7 billion people are without adequate sanitation. Many parts of the world are constantly struggling with drought and floods; in addition, many countries face the problems of fastgrowing populations, rapid urbanization, rising costs of providing water, and pollution of fresh water. Ail of these problems have increased the urgency of formulating policies and associated strategies that will ultimately lead to effective measures to manage water as a social and economic resource with emphasis on its conservation.

1.2 Numerous international conferences have called for medium- to long-term policy measures to protect and conserve water. These measures include:

- The adoption of policies based on a comprehensive approach to planning and management that takes physical, economic, social, and environmental factors into account

- Increased participation by "stakeholders"2 in both decisionmaking and operations

- Decentralized responsibility (at the lowest feasible level) for the management and delivery of water

- Greater reliance on managing demand for water

- Protection of water quality and preservation of aquatic ecosystems.

Many of these policy measures were articulated in the UNDP global consultation on safe water and sanitation for the 1990s held in New Delhi in 1990 (UNDP 1990). The 1991 UNDP symposium entitled "A Strategy for Water Sector Capacity Building" in Delft and the UN's 1992 International Conference on Water and the Environment in Dublin both played a leading role in promoting comprehensive water resources policy measures, many of which were endorsed by world leaders at the 1992 UNCED in Rio de Janeiro. ${ }^{3}$ These measures are also reflected in the World Bank's 1993 water resources management policy (World Bank 1993a).

'The World Health Organization (WHO) defines "reasonable access" to safe drinking water in an urban areas as access to piped water or a public standpipe within 200 meters of a dwelling or housing unit. In rural areas, reasonable access implies that a family member need not spend a disproportionate part of the day fetching water. "Safe" drinking water includes treated surface water and untreated water from protected springs, boreholes, and sanitary wells (World Resources 1993, p. 258).

${ }^{2}$ Stakeholders are institutions and individuals that are concerned with or have an interest in water resources and that would be affected by decisions about water resources management. Stakeholders inciude people who may have little knowledge of such effects and lack the means to participate.

${ }^{3}$ Please see the references at the end of this chapter for the Delft Declaration and the Dublin Statement; the results of UNCED are included in Earth Summit 1993. In order to find ways of implementing the portions of UNCED related to freshwater resources (chapter 18 of Agenda 21), a ministerial conference on drinking water and environmental sanitation was held in March 1994 in Noordwijk, the Netherlands. Among other measures, the conference encouraged the development of strategies for drinking water and sanitation "in the context of broader strategies for sustainable water resources management and environmental protection..." (Noordwijk 1994). 
1.3 While the elements of the comprehensive approach mentioned above have been endorsed and adopted by many countries, the difficulty remains of how to best implement them in a cost-effective and sustainable manner within reasonable time. Many countries, particularly those with acute shortages of clean water, have recognized the need to review their water policies and to develop comprehensive water resources management strategies. The new concepts in water resources management-all aimed at sustaining the resource-will take a long time to implement and may call for deep changes in national culture. ${ }^{4}$ A number of countries have requested World Bank and UNDP guidance and assistance in translating broad development goals and key water-related policies into country strategies for the water resources sector. ${ }^{5}$ Professional associations such as the IWRA have indicated their willingness to provide support for such endeavors.

1.4 Water's vital role in economic and social development makes it essential to have a strategy to develop and manage this resource. The classic definition of strategy is "the science and art of employing the political, economic, psychological and military forces of a nation or group of nations to afford the maximum support to adopted policies in peace or war." employed to obtain a goal. In short, strategy is a means of translating policy into action. The practical application of the concept of strategy for water resources management (as in other areas) varies widely. In some countries "strategy" has been deemed to cover every aspect of water resources management from formulating national policies to defining roles and responsibilities for implementation to selecting and financing water sector projects. In other cases, strategy has been treated as synonymous with "master plans" or "water action plans" that often encompass specific projects. This guide defines a water resources management strategy as a set of medium- to long-term action programs to support the achievement of development goals and to implement water-related policies. This definition of strategy does not include project identification, ranking, or financing; in this sense it is between policies and projects, but is certainly connected to them. Although this guide refers to national strategies throughout, the concepts and processes described can apply to different levels of government organization, such as regions or provinces. The concept of strategy is described further in the following section.

1.5 The formulation and implementation of a strategy for the water sector can help sustain economic and social development and can help build a country's capacity to manage its resources. Capacitybuilding can be one of a country's goals. In fact, building capacity can be one of the direct benefits of undergoing the process of strategy formulation. Formulating a water resources management strategy begins by examining a country's development goals and its existing water-related policies. These must be articulated clearly before the process begins. Formulating a water resources management strategy will also test the feasibility of existing development objectives and policies. Although this guide describes a general process, strategy formulation is not a one-time effort. Countries need to test, refine, and update

"See the chapter "A Water Ethic" in Postel 1993.

sAlthough the terminology is a matter of great debate, in this guide the terms "water sector" and "water resources" are used interchangeably. Both terms are meant to include all water uses (environmental, domestic, and production) from both the demand and supply sides. Both terms are also meant to include water quality considerations and the water needed to sustain aquatic ecosystems.

${ }^{6}$ Encyclopedia Americana, Webster's New Collegiate Dictionary, both s.v. "strategy, "La Grande Encyclopédie, s.v. "strategie." 
their strategies and to adapt them to new circumstances and challenges. ${ }^{7}$ They need to be able to do these things themselves in order to sustain economic and social development. In this sense, formulating strategy is a long-term, iterative process.

\section{PURPOSE OF THE GUIDE}

1.6 The purpose of this guide, which is sponsored by the World Bank and the UNDP, is to assist countries in preparing national, provincial, or regional water resources management strategies by outlining for policymakers a general process of formulating such strategies and suggesting ways for countries to build management capacity through the process of formulating these strategies. It is primarily directed to countries that have made the necessary commitment at the highest political levels to formulating and pursuing a strategy.

1.7 It can hardly be emphasized enough that conditions vary significantly from one country to another as well as within countries. This guide offers a general framework for formulating medium- to long-term water sector strategies; some aspects should be adapted to circumstances, and some that are essential to building capacity (such as participation of a wide variety of institutions and individuals concerned about water issues) should be applied by all countries that wish to undertake the exercise.

1.8 Many donor agencies and interested parties may find the framework set forth in this guide helpful in forming their approach to assistance in the water sector. If so, the guide may serve the additional purpose of facilitating communications between such organizations and developing countries.

\section{WATER RESOURCES MANAGEMENT STRATEGY}

1.9 As mentioned earlier, a water resources management strategy is a set of medium- to long-term action programs to support the achievement of development goals and to implement water-related policies. Development goals might concern, for example, aspects of food security, population growth, development of poor regions, rural and urban development, and the role of public and private sectors. Goals may also be specific, for example providing safe water supply and sanitation to a high percentage of the population by a certain date. Water-related policies might include government decisions about the preservation and protection of ecosystems, water rights, and the role of pricing. The objective of formulating a national water resources management strategy is to provide measures to manage this vital resource in accordance with adopted goals and policies. Developing such a strategy will also test whether these goals and policies are realistic. For example, there may simply not be enough water available to meet the goal selfsufficiency in food production. In such cases, existing goals and policies may need to be modified. A strategy should be developed with the idea of the best or most efficient use of existing or emerging resources to achieve goals. Otherwise, the strategy could be unrealistic and may not achieve its aims as quickly.

1.10 A national strategy need not identify specific investment projects, although it may outline or provide broad directions for an investment program. A water resources management strategy should

\footnotetext{
'For officials charged with program oversight, strategy can mean "simply addressing rigorous logic to the allocation of the scarce resources available to carry out the tasks assigned us by national strategy" (Lehman 1988).
} 
emphasize such aspects of water development as the necessary institutional and human resources framework, and should address the medium- to long-term (5-30 years) issue of building or enhancing a country's water management capacity. Such a strategy should incorporate the views of water resources stakeholders by including them in the formulation process. Moreover, a strategy should be developed principally by national experts. Foreign technical assistance might be offered as appropriate, but if at all possible, it should be kept to a minimum. The final strategy should be a domestic product that encourages the commitment and "ownership" necessary for sustained economic development as well as for the implementation of the water strategy and the success of individual projects and investments.

1.11 A water resources management strategy differs from the "master plans" that many countries have developed. A master plan is usually investment- or project-oriented; the product of a master plan is often a specific set of investments to be made or projects to be undertaken. Master plans have a role to play in water resources management if they are viewed as an investment plan that follows the accepted strategy. Master plans should be placed firmly within the context of development goals and key waterrelated policies and strategies. Some of the best plans already do this; investments, however, should include capacity-building measures. The principle of community or stakeholder participation, which is missing from many master plans, needs to be included in project planning.

1.12 Many countries' master plans have not adequately considered the institutional and human resources frameworks that are important to water management. Master plans have often neglected the long-term issue of building a country's water management capacity. Also, many such plans have been developed with considerable expatriate involvement. Capacity-building of institutions and individuals has often been inadequate. Most master plans have been made without taking into account the views of water resources stakeholders. Some master plans have been developed without adequate consideration of national development objectives or the acceptability of the plan to government decisionmakers and water resources stakeholders.

1.13 In contrast to master plans, which often take a long time to develop, "quick assessments" or "rapid assessments" have been used to justify immediate investments. The objective of these assessments is to determine critical issues for prompt consideration while longer-term needs are being examined. Quick assessments may be necessary in the short term; they have the merit of rapidly bringing the major issues that need to be addressed to the attention of decisionmakers. One of the most valuable contributions of a quick assessment is the identification of the limits of what is known. Quick assessments do not, however, address the long-term issue of building a country's ability to manage its resources in a sustainable manner.

1.14 A number of elements in the approach suggested in this guide have been drawn from the experience of countries in formulating water resources strategies and from approaches to (and experience with) country water resources strategies developed by external support agencies such as the World Bank and the UNDP. The World Bank's Asia and Middle East and North Africa regions, for example, have developed approaches to strategy that emphasize comprehensive analysis and include institution-building and training (World Bank $1993 \mathrm{~b}$ and 1993c). Some external approaches, however, rely on initiative by the external support agency because of the urgency of problems in an area; countries can ill afford to further delay action on some emerging water crises. Such approaches, which often favor the quick or rapid assessments referred to above, argue that in most cases there is sufficient information to formulate a water sector strategy and to define critical programs and actions. 
1.15 The emphasis in this document is on medium- to long-term issues and on building a country's capacity to formulate and implement its water resources strategies. The product of strategy formulation as envisaged here is not a specific set of development projects or a summation of various river basin development plans. Just as policies are usually set at a high level of government, the kind of guidance needed for water resources management strategies needs to be set at a high level to ensure political commitment.

\section{THE PROCESS OF STRATEGY FORMULATION}

1.16 Each country has a set of unique legal, institutional, economic, social, physical, and environmental conditions that influence its water management policies and strategies. While experience worldwide is useful to generate options for action, solutions to a country's problems must be tailored to that country's needs. The formulation of national strategies for integrated water management can be complex, depending on many factors such as the size and political organization of the country, its hydrological conditions, its regional milieu, and the diversity of stakeholders. In some countries in the Middle East, Africa, and Central Asia, water scarcity is the main issue. For other countries in Asia and North and South America, floods are a major concern. For much of Central and Eastern Europe, pollution is the chief problem.

\section{Strategy Formulation in Context}

1.17 Figure 1.1 illustrates an overall strategic planning cycle in a country. Development objectives and key water policies provide the platform from which to launch an assessment and analysis of issues. Evaluating options and presenting choices is the next step. Both the examination of major issues and the evaluation of options may reflect back on development objectives, as illustrated by the dotted lines in figure 1.1. The options chosen by policymakers constitute a strategy; with a strategy in place, a country should have ample criteria to develop an investment or project plan. It may be necessary to change development objectives and water policies in light of discoveries made during strategy formulation or during implementation of a water resources strategy.

1.18 An important step in the strategic planning cycle is implementation of the strategy. Part of formulating a strategy should be to specify the entity that will be responsible for monitoring or followingup the implementation of strategy. Depending on the country, this entity might be a professional "think tank", outside experts, or a standing committee. It is important that this entity has both the authority and capability to oversee implementation of strategy, and that the commitment to review progress is not just an exercise on paper. Implementation itself may expose unrealistic portions of strategy or of original development goals.

\section{The Need for Capacity-Building}

1.19 There is mounting evidence that in the near future the major constraint a water resources development and protection will be the limited capacity of the institutions in many countries to absorb financial resources and convert them into worthwhile and sustainable actions and project (Alaerts and others 1991). Capacity-building is a major aspect of formulating a water resources management strategy. It further distinguishes a water resources management strategy from master plans or quick sector 
Figure 1.1 The Strategic Planning Cycle

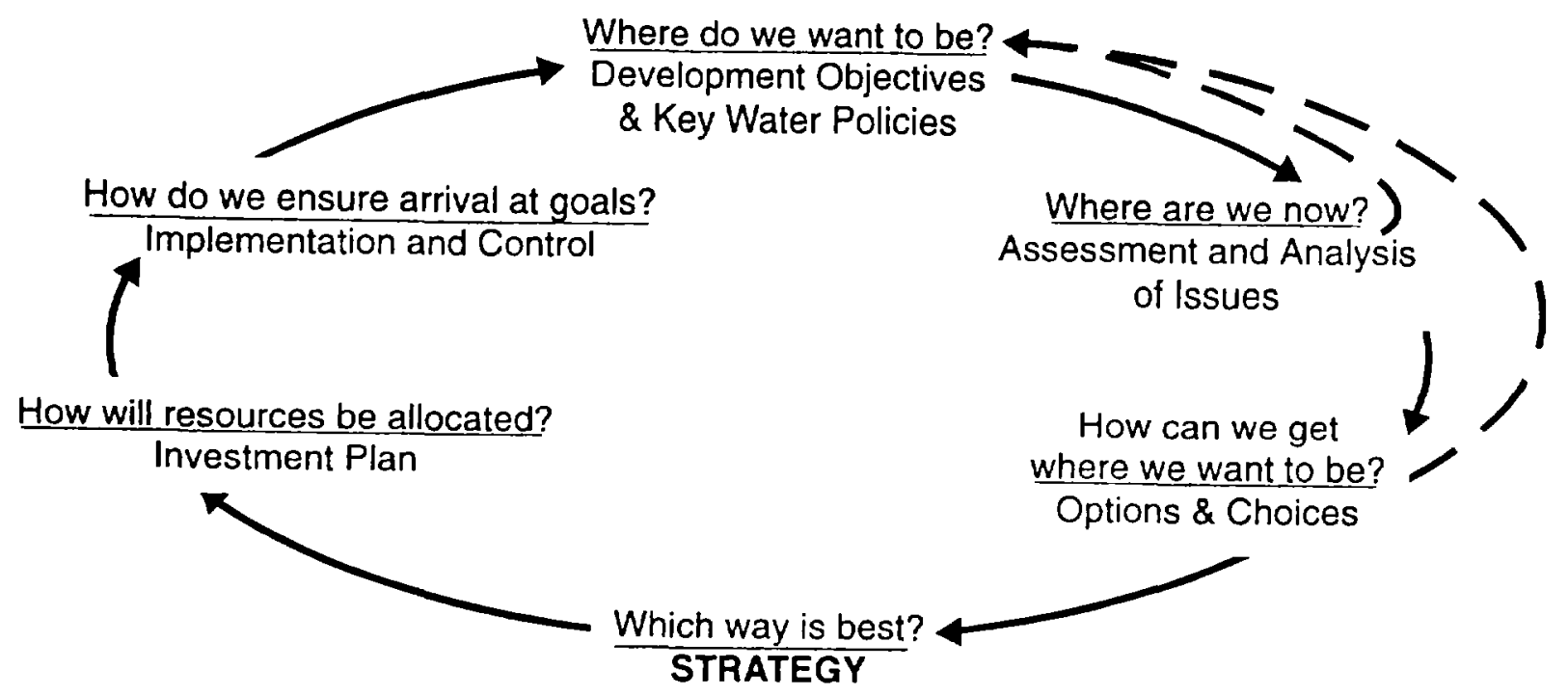

Source: Adapted from Hennessy 1993

assessments. The Delft Declaration (1991) describes capacity-building as a global concept and a strategic element in the sustainable development of water resources, and identifies the three basic elements of capacity-building as:

- Creating an enabling environment with appropriate policy and legal frameworks

- Institutional development, including community participation

- Human resources development and strengthening of managerial systems.

Many failures in water resources management are the result of lack of trained staff and weak institutions. Capacity-building has been identified as the missing link in African development (Jaycox 1993).

1.20 Real long-term success in water resources management depends on the ability of nationals to identify problems and formulate and implement policies and strategies. As mentioned earlier, strategy formulation is not a one-time effort. Rather, it is a long-term, iterative process. Countries constantly need to adapt their policies and associated strategies to new circumstances and challenges. For building capacity, the process of formulating a water sector strategy is perhaps as important as the resulting strategy. The outcomes of strategy formulation may be improved in the future; the immediate and difficult challenge is for the government to both make the commitment and put in the effort to develop its own strategy. The participation of national staff in this effort may give individuals the sense of ownership that is at the core of successful policy implementation.

\section{Stakeholder Participation}

1.21 Adequate stakeholder participation is another important aspect that distinguishes further the process of strategy formulation from quick sector assessments or from most master plans (please see paragraphs 1.11 and 1.12). Too many development strategies, whether in water or in other areas, have 
not fully involved the people affected by them (see Sandstrom 1994). Stakeholder participation involves those who are concerned with or have an interest in water resources and who will be affected by water resource decisions in the process of decisionmaking. It is similar to the idea of community participation in decisions at a project level. Decisions regarding water resources can affect nearly every sector of the economy and the public as a whole. Stakeholder participation should be established in a form that will elicit responses from those concerned with water resources development at appropriate levels.

1.22 Involving stakeholders ensures representation of a variety of views, but offers benefits far beyond this:

- It can help foster commitment to the final options chosen. This is an important element of success in managing water resources. By creating an environment that rewards the discussion and debate of risks, benefits and costs, participation leads to informed consent to chosen options. This contributes to acceptance of the resulting water strategies and creates ownership of the strategy or accompanying policies.

- It ensures transparency and accountability regarding decisions and the process by which decisions are made.

- It enhances creativity. Policymakers not only get a variety of views during the process, but can also identify organizations and individuals that can effectively implement policies at various levels.

1.23 The strategy formulation exercise would fail to win public support and necessary political and financial backing if it is perceived as merely an exclusive and technocratic task without the involvement of key constituencies-including professional associations, private sector agencies, and nongovernment organizations. The press and media are important channels to raise public awareness of issues and options in water resources management (UNESCO 1987).

1.24 Stakeholder participation in strategy formulation has two major aspects: identifying stakeholders, and securing their participation. Chapter 3 provides a variety of methods of identifying and involving stakeholders. The strategy formulation team (discussed below) should address which level of involvement at which point in the strategy process is appropriate to the stakeholders they identify. Stakeholders might be included on the team itself. Some might be engaged as decisionmakers, originators, advisors, reviewers, observers, or listeners. The forms of participation can range from information programs to structured meetings or processes designed to produce consensus or agreement or to resolve conflict. The levels of stakeholder participation in strategy formulation are illustrated in figure 1.2. Participation in the strategy formulation process should help the policy goal endorsed by many countries of giving stakeholders as much responsibility as possible for water resources management.

1.25 Many governments and development institutions understand that participation will lead to effective development. One of the risks of stakeholder participation, however is over-politicization of issues (technical or non-technical). Some technical issues might be better left to the expert team or its advisors, particularly in the early stages of strategy formulation. One key aspect of devising a program of stakeholder participation is to involve stakeholders at appropriate levels and times (please see the annex). 
Figure 1.2 Levels and Roles of Stakeholder Participation in Water Resources Management Decisions

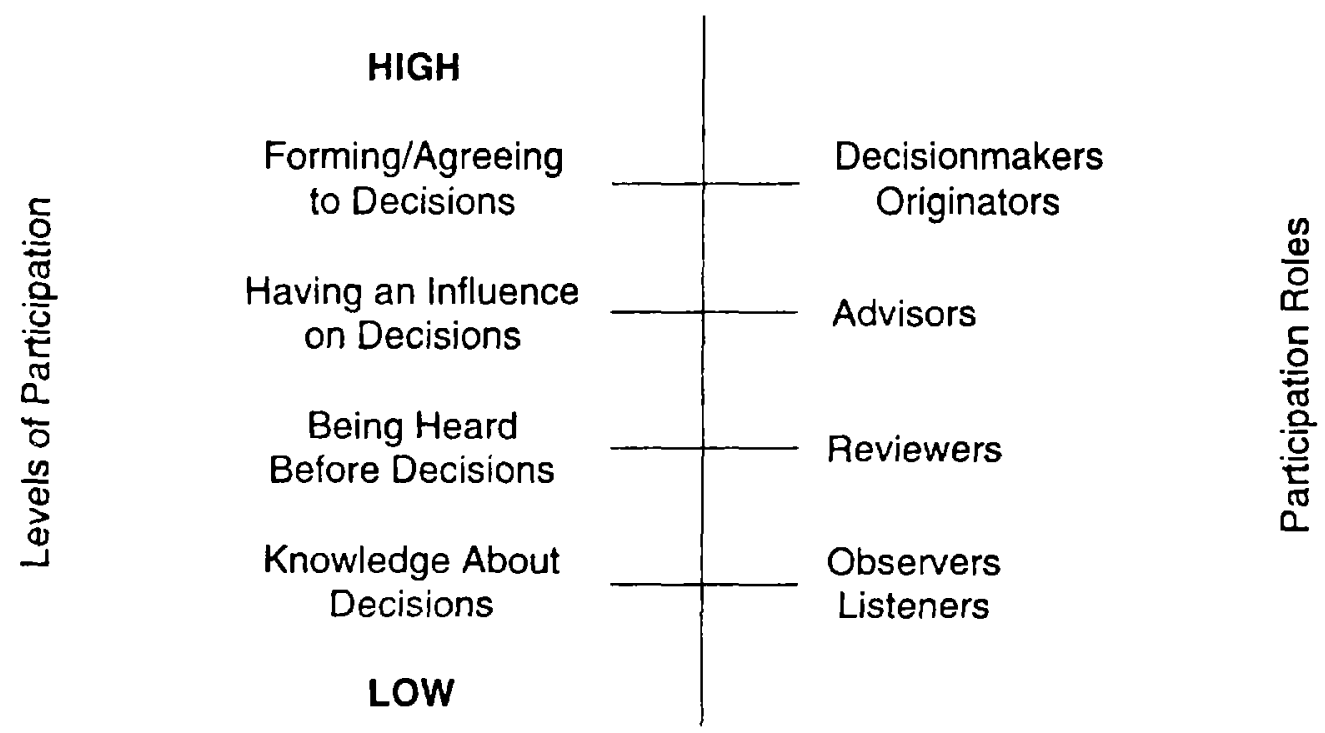

Source: Authors

\section{Overview of the Process}

1.26 There are several critical elements that should be in place prior to the beginning to formulate a water sector strategy. Strategy formulation itself has two main phases. The main critical elements and points in the process are illustrated in figure 1.3 and discussed in the following sections. Countries may initiate forming or adopting policies prior to strategy formulation; in fact, an interministerial steering committee or some other high-level authority (see paragraph 1.30) may be appointed and may convene to articulate or adopt policies before the process of strategy formulation begins. While it is important that policies be in place to guide the formulation of strategy, the iterative nature of strategy formulation means that policies both guide the process and can be revised by it, as illustrated in figure 1.1. During either phase 1 or phase 2 , or even after a strategy has been adopted (in, say, the implementation phase), policies may need to be adopted or clarified. The options presented to decisionmakers may include revising impractical or unrealistic policies.

\section{Critical Elements}

1.27 Several elements are critical for successful strategy formulation.

- The broad development objectives and key water policies should be articulated as clearly as possible. 
Figure 1.3 Key Points in Water Strategy Formulation

\begin{tabular}{|c|c|}
\hline Critical Elements & $\begin{array}{l}\text { Development Objectives and Key Water-Related Policies } \\
\text { Government Commitment } \\
\text { Appointment of Oversight Body } \\
\quad \text { (Interministerial Committee) } \\
\text { Recruitment of Expert Team } \\
\text { Determination of Partners and Process }\end{array}$ \\
\hline $\begin{array}{c}\text { Phase 1 } \\
\text { Water Resources } \\
\text { Assessment }\end{array}$ & $\begin{array}{l}\text { Review of Objectives and Policies } \\
\text { Inventory of Resources } \\
\text { Key Issues: Selection } \\
\text { Analysis (Projections) } \\
\text { Ranking }\end{array}$ \\
\hline Interim & $\begin{array}{l}\text { Review Process } \\
\text { Decisions on Proceeding }\end{array}$ \\
\hline $\begin{array}{l}\text { Phase } 2 \\
\text { Strategy } \\
\text { Definition }\end{array}$ & $\begin{array}{l}\text { Develop Options } \\
\text { Evaluate Options } \\
\text { Recommendations } \\
\text { Choice of Options } \\
\end{array}$ \\
\hline
\end{tabular}

Source: Authors

- At the highest levels the government must commit itself to the process of formulating a water strategy and to water sector management using a comprehensive approach. This commitment can take various forms-for example, the head of state or top government leaders endorse the approach in a declaration, written statement, or letter.

- The government should appoint an oversight body -an interministerial steering committee or other high-level authority-to whom the team of experts responsible for strategy formulation should report. One individual from this oversight body should be assigned the responsibility of coordinating the strategy effort.

- The government should recruit a team of national experts responsible for the process and content of strategy formulation.

- The expert team should determine the partners and the process for strategy formulation and agree with its oversight body on terms of reference for strategy formulation.

1.28 Government commitment also means the commitment of resources to undertake what could be a long process of strategy formulation suggested here. While some foreign technical assistance and other support may be available, building capacity means undertaking an effort largely staffed by a country's nationals who should be provided adequate financial and other resources. A substantial portion of these resources should be furnished by the country itself. 
1.29 The government should also make a commitment that the process will be collaborative, consultative, and transparent. "Collaborative" means generating a sense of partnership among key stakeholders within the country and the invited external support agencies that are willing to assist. "Consultative" means fostering debate and discussions among stakeholders on the issues and options that arise in formulating strategies. "Transparent" means both that the process itself should be articulated and that communication through periodic public reports on progress should be encouraged.

1.30 The Oversight Body and the Expert Team. The government should first appoint an interministerial committee or name some other responsible body with the authority to appoint an expert team to develop strategy (in most cases this will be an interministerial committee, so that term is used throughout the rest of this chapter). Too often the work of developing water resources plans has been left to one ministry without the genuine participation of other areas of government. What matters is not so much the structure as that strategy formulation has a genuinely intersectoral, multidisciplinary approach that can be implemented successfully.

1.31 It is appropriate for an interministerial committee to act as a steering committee during the course of the work program, reviewing progress and approving the course of work. In some countries, an interministerial committee will also be the authority that will choose among the options presented by the expert team; in others, it may present the recommendations of the expert team to the executive or to the legislative authority to enable either of them (or both) to choose the options that will constitute a strategy. The responsibilities for final choice among the options presented and for oversight of strategy formulation should be made explicit at the beginning of the process .

1.32 The budget for strategy formulation should be designated in general terms prior to choosing a team of experts. The government will no doubt wish to analyze the costs of preparing a water resources management strategy before committing the necessary funds to do so. While estimates can be made, the budget will probably not be finalized and funds will probably not be committed until the team has agreed with its oversight body on the work to be done.

1.33 The interministerial committee should recruit a team of experts. The size and composition of the expert team will vary according to the terms of reference, which will depend on the size of the area to be studied, the complexity of the water resources issues to be addressed, and the quality and level of the existing knowledge. Members of the expert team should be chosen primarily for their expertise, professional competence, and ability to appreciate cross-sectoral water issues. The members should be drawn from a variety of institutions that may include government, public and private agencies, academic institutions, professional associations, and NGOs. The team may include members of the public or other interested parties. If necessary, foreign technical experts could be included. Team members should be chosen for their professional competence and their capacity to appreciate cross-sectoral water issues. Most members would be full-time although not in all cases for the full duration of the study period.

1.34 Depending on the political structure of the country, the interministerial committee may wish to keep the parliament or legislative body abreast of the progress of strategy formulation. Since a legislature will often make the resource allocations to implement strategy and investment plans, it would be wise to at least inform, and possibly involve, legislators. For example, they could be included in the review workshops suggested in paragraph 1.54 .

1.35 Determining the Partners and the Process: Preparing Terms of Reference. Terms of reference for the national expert team should be prepared before beginning the water resources assessment that 
constitutes phase 1 . The supervisory body or interministerial committee will probably have a general idea of the work to be done prior to selecting the expert team; the final terms, however, should be prepared in consultation with the team members after they have had the opportunity to suggest the scope and process of the work and to determine the resources they will require.

1.36 The expert team should determine the partners and resources it will have and the process it will follow. Partners are individuals, firms or organizations that will be involved directly in the process, for example government departments, consulting firms, university faculties, or professional associations. In choosing the partners, the expert team will no doubt wish to avoid charges of bias; on the other hand, the choice of water resources expertise may be limited. Some guidance on these items will doubtless come from the expert team's oversight body. Tasks in this area include:

- Identifying partners

- Identifying and meeting stakeholders

- Defining stakeholder roles

- Determining the work management structure

- Agreeing on and communicating work and consultation procedures and a work program.

1.37 The need to include stakeholders and defining their roles are discussed in the section above on stakeholder participation. Determining the work management structure involves defining the tasks, structure, and schedules to be followed in the process. There are many guidelines upon which the team can draw to define their tasks (see Tiffen 1993, WMO 1992, Delft 1991, UN 1989, and UNESCO 1987) The expert team may wish to form ad hoc or standing groups to cover various issues. They should be able to draw on necessary expertise or resources within the government or elsewhere to complete the tasks outlined in the following section.

1.38 Areas of water resources management that should be considered in the strategy formulation process are summarized in the section "Key Areas for Assessment and Strategy Integration" in this chapter. Part II, "Issues in Comprehensive Water Resources Management," provides a general introduction to each of the following topics.

- Institutional and Human Resources Arrangements are perhaps the cornerstones of sustainable water resources management. "Institutions" are defined to include organizations, laws, regulations, and customs.

- Stakeholder Participation should be an element of strategy formulation as well as of project planning and management of water-related services.

- Information Systems, includes the availability, collection, and dissemination of waterrelated information. In the long run, it is both the availability of information and the integrity of the information system that are important in managing water resources.

- Economic Aspects of water are increasingly important if the finite resource is to be managed efficiently. The task of valuing water is complex in most countries; some notion of value should be established during the strategy formulation process. Economic concepts are crucial for sorting through the issues and making recommendations. 
- Environment and Health Aspects, including the sources and effects of pollution, are major problems in many countries. The team specialists in charge of these aspects should contribute to the other areas. The environment specialist could, for example, contribute to information systems by, for example, defining ways to identify and monitor sources of pollution, and to economic aspects by indicating appropriate ways of valuing environmental and health aspects of water resources management.

- International Arrangements can be crucial to the process of formulating a strategy. It should be immediately obvious to the expert team whether international aspects deserve significant, perhaps even primary, attention. Riparian states may wish to undertake jointly some aspects of strategy formulation.

\section{Phase 1: Water Resources Assessment}

1.39 The term "assessment" has been used in various ways in water resources literature $e^{8}$. Here, it means a process that includes, in general, the following components: describing development goals and water-related policies, preparing an inventory of information in several key areas mentioned in paragraph 1.38, and identifying, analyzing, and ranking major issues in water resources management. Preparing water resources assessments are an important way to build capacity.

1.40 The water resources assessment (phase 1) is an examination of the physical aspects and wide variety of factors that influence the development of water resources. It starts with a full appreciation of the stated policies and the existing and on-going developments. This provides the basic platform upon which strategies can be built. Preparing an inventory and identifying and analyzing major issues in water resources management includes covering the key areas mentioned in paragraph 1.38.

1.41 In some cases, international considerations will dominate the process of formulating a water resources management strategy. Countries need to establish collaborative arrangements with other states influencing (or influenced by) their decisions on water resources management. It may be impossible to proceed without international discussions or contact under the auspices of the expert team. Since resource assessments are generally made on the basis of a whole river basin or drainage area, it may be appropriate for several countries to undertake a joint water resources assessment.

1.42 Review of Policy Goals. The assessment should begin with a review of the country's development goals and key water-related policies. Goals might include, for instance, achievement of food security, development of heavy industry (including its location), or economic development of the poorest regions of a country (rural or urban). Water-related policies may include government decisions on environmental protection, water rights, pricing, the degree of decentralization of authority, and social issues (such as access to potable water supply and sanitation services). These policies should guide the entire process of formulating a strategy. For example, in a country that has chosen food security as a high priority, the

\footnotetext{
"For instance, UNESCO and WMO stress "water resources assessment" in terms of database and related analysis of collection, review, and dissemination (UNESCO/WMO 1988). The annex to the Delft Declaration (1991) introduces assessments as an instrument for country capacity-building. A report by the Canadian International Development Agency (CIDA) on institutional arrangements has used the term "thematic evaluation" instead of "assessment" for an approach that is comparable to that articulated in the Delft Declaration (Grover 1992).
} 
assessment will probably focus on agricultural uses of water. The water-related policy measures endorsed by many countries taking a comprehensive approach to water resources management are listed in paragraph 1.2. If goals and policies have not been adequately established it will be necessary to defer formulating a strategy.

1.43 Preparing an Inventory. Most water resources developments are long term, extending over 20 to 40 years or more. Transitions occur slowly. This is particularly important for irrigation, where existing arrangements are often a firmly established part of the local culture and the economy of a region. A detailed appreciation of the existing water resources management system, including the manner in which organizations function and the standards of service provided to the users, will help the expert team to understand the main issues and the paths and time any changes will take. This involves collecting information and experience in five key areas-water-related data, institutions and human resources, the economic treatment of water, the environment, and international water affairs. The process of preparing an inventory generates a list of the major water-related issues.

1.44 The preparation of an inventory of information and experience in the five key areas mentioned above should help to bring major issues to be addressed and any gaps in information to the fore. In the first area mentioned above, information systems, the expert team could begin the inventory by examining the availability and quality of data on water supply and demand. This might start from hydrologic, meteorologic, and water quality data. Data on the actual physical resource (its location, quantity, and quality) are fundamental to a water resources assessment. The inventory should be done for each major river basin. Far from merely generating a physical description of the resources or a checklist of available data, however, the inventory should examine how data are collected, stored, disseminated, analyzed, and used. Among institutional arrangements, the expert team will probably wish to review existing laws and regulations and the organizational arrangements for implementing them, together with identifying national trends. For example, studies might involve identifying those institutions (or the lack of them) responsible for resources planning, pollution enforcement, or operations and maintenance (O\&M) in irrigation systems. In the area of economic analysis, the team should study how water and its delivery is priced, the quality of demand forecasts, and the analytical techniques used in pricing and economic analysis. The environmental and health aspects of water resources might include an inventory of the state of major drainage areas and sensitive ecosystems as well as the incidence of waterborne diseases. Finally, the expert team will probably wish to briefly catalogue and evaluate international treaties and arrangements.

1.45 All of the aspects of water resources management mentioned in the paragraph above have an institutional and human resources aspect. Again, "institutions" include organizations, laws, regulations, and customs. In this sense, institutional and human resources aspects pervade all of the physical aspects of water resources management. Whether organizations for implementing policies exist or not, whether they are public or private, and how they function can be examined at the inventory stage. Similarly, almost every major issue identified and analyzed, and every option or solution suggested will have an institutional and human resources complement.

1.46 Selecting, Analyzing, and Ranking Issues. Phase 1 concludes by selecting and analyzing the major issues to be addressed in the water sector. During the inventory discussed above, major issues will naturally present themselves; the analysis should further help to identify issues to be addressed both at the local (basin) and national or international levels. Selection of key issues is crucial if strategy formulation is to remain a manageable activity. In the case of international waters, it would be useful to identify priorities to be handled at the country level, and those that would require dialogue with other countries, possibly through regional river basin organizations. 
1.47 Major issues may need to be addressed in different time frames. Some issues need to be addressed quickly before they become catastrophes. These issues may include dams or flood protection, dike safety, over-pumping of water, resettlement practices, or dangerous levels of pollution of drinking water. Other issues, if not addressed in the context of strategy formulation, will jeopardize sustainable development and may cause practically irreversible damage to the environment. These issues may include the intrusion of pollutants or of salt in underground water, soil salinization, erosion, and waterborne diseases.

1.48 In the course of analyzing major issues, it may be useful to develop both quantitative and qualitative projections in a number of areas. The most basic of the quantitative projections are for the demand and supply of water; from these, a number of other needs, such as the demand for a variety of services in the water sector, can be indicated. The projections should reflect the dynamic nature of potential water demand; indeed, projecting demand is a formidable challenge. Hydrological and meteorologic factors, population and economic growth, urban development, diversified agriculture, water pricing policies, environmental concerns, changes in technologies, and improved demand management are all factors that can effect the nature of water supply and demand. Some of the concepts of demand management are discussed in Chapter 5. The expert team should include clean water to preserve the environment, especially water-based ecosystems, as a new use or demand in such projections. The participation of stakeholders can help make projections realistic.

1.49 This is not to suggest that a great deal of time should be taken to produce sectoral or national water balances. Developing the necessary basin-level models for complex projections may be something a country wishes to undertake, but considering the amounts of data and the time required, it may be a project undertaken separately from strategy development. Indicative projections can identify trends in water use and supply, and may highlight issues or help to rank them in order of importance. It is important that the expert team set limits on the amount or complexity of the projections. In many cases, basic forecasts already exist. Sensitivity analysis-assessing the response of some factors as a result of changes in others-can also have a place at this stage of the process.

1.50 Along with quantitative projections, qualitative or descriptive forecasts of the future should be made. These might cover basic views of what the future will be like, or how it will be affected by impending socio-political developments. For example, the expert team might postulate the effects of trade agreements on water resources issues. Such agreements may cause shifts in agricultural production that will change the characteristics of demand for water and attendant products and services. Another example is a change in the domestic legal or administrative environment such as decentralization or privatization of water services. These factors will of course influence the quantitative projections mentioned above.

1.51 Ranking key issues in the order of importance is the final task of this portion of the strategy formation process. This will help the expert team focus on developing a variety of options that may cover several issues at once.

1.52 Timeframe. Depending on the size of the country and complexity of the issues, a water resources assessment along the lines suggested above may take anywhere from 6-18 months. 


\section{The Interim}

1.53 Review. It is useful to review the process at this point. If there are data gaps or serious conflicts among stakeholders, efforts to fill the gaps or address the conflicts may be necessary before moving on to selection of strategic options. In some countries, completing phase $1 \mathrm{can}$ lead directly to formulation of strategic options. In others, particularly in larger countries with many big river basins and complex institutional arrangements, or where international waters are involved, water management strategies may not be easily formulated from the assessment completed in phase 1 . In such cases, this phase should point to gaps in data collection, institutional functioning, policy enforcement, and action necessary before proceeding with strategy formulation.

1.54 Conducting Review Wbrkshops. At the end of phase 1, a series of workshops could be organized to evaluate the outcome of the assessment, to review progress, and to plan the next steps. Participants could include the country's decisionmakers, key stakeholders, members of the expert team mentioned above, and representatives of external support agencies. Before undertaking the next phase, the workshops could identify major gaps in the assessment. In cases where the country is ready to proceed with the second phase, specific terms of reference could be agreed at the workshop.

\subsection{Timeframe. The interim period may be 1-3 months.}

\section{Phase 2: Formulating Strategic Options}

1.56 During the second phase, the expert team develops and evaluates options, and presents recommendations to decisionmakers (the interministerial committee or other body). The options chosen constitute the water resources management strategy.

1.57 In developing options and analyzing options and in making recommendations, the expert team must strike a balance between the ideal and practical forms of water resources management for a country. Without becoming overly concerned with political ramifications, the expert team should nonetheless be aware of the feasibility of recommendations. Interchange with the executive branch or legislative body throughout the process of developing a strategy can help to inform the team and build support. The team should in any event avoid producing a list of options and recommendations that is a "wish list" divorced from practical consideration of the resources available to implement a water resources strategy.

1.58 Developing Options. On the basis of the work done in phase 1, the expert team should have some answers to the question "What are the major water resources issues or problems to be dealt with in order to achieve our development goals and support our water policies?" Identifying and evaluating options essentially answers the question "What are the best ways to deal with the issues or solve the problems?" For each issue considered, there will usually be several physical and institutional or human resources options. For example, if the option being considered is further development of groundwater resources in order to meet, say, growing urban demands, there must be a series of institutional measures that will enable specific physical or technical solutions to be designed and implemented. If pumping more groundwater is the best solution, the expert team should consider who should develop the resource (perhaps existing modes of development are satisfactory), which institution should regulate the development, and whether adequate environmental safeguards, especially considering aquifer pollution, are in place. In short the institutional and human resources options are necessary adjuncts of any 
technical or physical options. Developing technical solutions is an empty exercise without suggesting how to implement them.

1.59 Evaluating Options. Feasible options should be compared on technical, sociological, environmental, and economic grounds in order to arrive at recommendations. Evaluating options, both technical and institutional, should involve (to the greatest extent possible) analysis of the costs and benefits of each alternative. In this process, the extent to which options respond to original policy objectives should again receive attention. At this point, as in phase 1, analysis may show that some policies are unrealistic. As with analyzing the major issues, evaluating options needs to remain a manageable task. Many sophisticated analytical techniques can be applied, but if these techniques cannot be applied consistently by a country's water resources professionals they may not immediately serve the goal of sustaining water resources management.

1.60 Evaluating options should begin by establishing the criteria to be used. An evaluation criterion is a rule used to measure the extent to which an objective has been achieved (Kindler 1990). Criteria should to the greatest extent possible be quantifiable and limited in number. Moreover, a criterion should not be confused with a goal. As a basic example, country may have a goal of supplying a large percentage of the population with safe drinking water and a policy of decentralization of water supply services. Two of the options to be considered might be a rapid decentralization or a gradual devolution of responsibilitjes. Criteria used to choose between them might be cost, the quality of service that could be provided immediately, and acceptability to water resources stakeholders.

1.61 There are a variety of statistical techniques and models that can help to analyze options. Basically, however, analysis of options is a process of evaluating the available and necessary inputs (human, material, natural, and financial) in pursuing a strategy, and an assessment of the output, or response, that will arise from each strategic option. Finally, the team should compare these responses to the criteria set forth. Analysis should consider all aspects of implementing an option, including (broadly) not only the an allocation of financial, physical, and human resources but also cultural, ideological, and legal constraints. Progress in meeting strategic goals (for example, more efficient use of developed water, improved public health, improved water quality, and increased environmental protection) will affect the demand for water, and such progress can be assumed in the analysis.

1.62 The options should consider various means of matching supply and demand, and of satisfying environmental concerns. The strategic options should include:

- Broad technical arrangements needed to meet physical development of water resources

- Options for institutional and human resources arrangements, highlighting the potential of involving water users, nongovernment organizations, professional and trade associations, private sector service providers, and local governments in water resources management (criteria used to choose among options might include reducing the load on the public sector, or minimizing the need for complex interagency coordination)

- Requirements and alternative means for capacity-building in institutions and skills for water sector management

- Regulations that should be enforced or reformulated 
- Demand management possibilities, including the use of (a) pricing and non-pricing instruments, (b) appropriate technologies for water delivery, conservation, reuse, and pollution control, and (c) innovative educational means of motivating present and future users of water to monitor consumption and conserve water

- Environmental and health protection measures, in particular regulations concerning the monitoring and management of surface and groundwater, pollution control in all water subsectors, and incentives for wastewater reuse.

For each option, the expert team may wish to give an indication of the broad economic efficiency of the option and an indication of its multi-sectoral effects.

1.63 Finally, evaluating the options should include careful consideration and mention of the risks involved. For example, formalizing property water rights and legalizing water trading may raise the potential for monopolization of water supplies, possibly raising rural inequity. Some measures might be suggested to lessen such risks. Some risks, however, may remain part of necessary change.

1.64 A workshop prior to finalizing and presenting recommendations could be useful to inform or involve key stakeholders or to develop suggestions about how they should be informed or involved in the final phases of strategy formulation and implementation.

1.65 Recommendations. On the basis of evaluations, the expert team will provide a list of recommendations. The interministerial committee (or another authority empowered to do so) will eventually choose among the options presented. These choices will constitute a strategy.

1.66 In making recommendations, the expert team will doubtless wish to bear political acceptability in mind. The options a country chooses must be politically acceptable. This is because resources will ultimately have to be allocated to implement both the strategy and any resulting investment or project plan. All too often, elaborate master plans or investment plans have been developed and put aside because countries lacked the commitment to the process of managing water resources or because the plans were developed in isolation from political reality. An economically optimal solution does not equal a politically acceptable one. To a large extent, participation of a wide range of stakeholders in strategy formulation increases the acceptability of politically sensitive approaches.

1.67 There has been an unfortunate tendency for water assessments, strategic plans, and master plans to fail during (or even before) the implementation. There are several reasons for such failures, one of which is lack of follow-up action. The recommendations should include naming the body or group responsible for overseeing implementation of strategy. If stakeholders are included in the strategy formulation exercise, they may be a part of strategy implementation as well.

1.68 Timeframe. This second component could take 6-18 months, depending on the country.

1.69 Choice of Options. The urgency of water resources management notwithstanding, it will probably take some time for a government to make choices and allocate resources to implement the strategy. Debate in the legislature or discussion among executive departments will no doubt prove a lengthy but necessary process. 


\section{WATER RESOURCES STRATEGY ASSISTANCE}

1.70 A number of external support agencies (ESAs) may wish to offer assistance in helping countries formulate a water management strategy; in some circumstances a considerable amount of the work necessary to formulate a strategy may already have been completed. Putting work done in the past together with the process outlined herein could be a useful step toward sustainable and successful water resources management.

1.71 The cooperation and support of ESAs, NGOs, universities, and professional societies will depend partly on a country's demonstrated commitment to the process of developing and implementing a realistic strategy. The adoption of unrealistic and overly optimistic policies and strategies can fail to mobilize full donor support and may be seen by donors and stakeholders alike as merely a list of wishes. This should be avoided.

1.72 Developing countries may need technical assistance to build their capacity for the sector work required to develop the strategies and investment programs for integrated water resources management. One possibility to provide such assistance would be through a multilateral program for capacity-building work in the water sector. The primary objective of such a program might be to assist countries in building their capacity so that they may develop the knowledge, analyze the issues, and formulate the policies and strategies for comprehensive management of the resource. Capacity-building through water strategy formulation and water sector work would represent a new initiative; any multilateral effort in this area should initially be considered a pilot program. A program entitled "Capacity-Building for Sustainable Water Sector Development" has been initiated by the UNDP in close cooperation with the World Bank and the United Nations Department of Development Support and Management Services (UNDDSMS).

\section{KEY AREAS FOR ASSESSMENT AND STRATEGY INTEGRATION}

1.73 The following sections describe approaches to the issues and relate them to the water resources strategy assessment process.

\section{Institutional and Human Resources Issues}

1.74 Institutions ${ }^{9}$ include both the set of basic rules (laws, regulations and customs) as well as the organizational arrangements that govern water resources management. No matter how well-designed the laws, regulations, and organizations, however, they may be ineffective without well-trained and motivated individuals to enforce or administer them. Two objectives are served by analyzing institutions and human

\footnotetext{
'Some authors and water resources professionals prefer a broad definition of "institution." Fox (1976) states that an institution may refer to "either to an entity; an organization or an individual, or a rule, a law, regulation, or established custom. An institutional arrangement is defined as an interrelated set of entities and rules that serve to organize societies' activities so as to achieve social goals. Each nation has an institutional arrangement for managing water resources ..." The narrower definition in this paper is meant to highlight human resources development, a key aspect of capacity-building (see Alaerts 1991 and Okun and Lauria 1991. See also Kindler 1990).
} 
resources: assessing existing rules and organizational arrangements and matching them to the demands of program implementation, and identifying means of strengthening capacity to undertake strategy formulation on a continuing basis. Institutional and human resources analysis would examine the areas mentioned below.

1.75 The Basic Rules. Laws and customs govern water rights, principles of water allocation, water pricing, water quality, and public and private sector roles in the development and management of water resources. The legal environment for the water sector comprises constitutional provisions, legislation, government orders, reservoir rules, and long-term practices.

1.76 Regulations and Enforcement. Regulations are concerned with aquifer and groundwater management, pollution control and reuse, land use rights related to water, watershed development, environmental quality and pollution control standards, dam safety standards, service norms for water supply, and financial and management standards. The effectiveness of regulations will depend on the enforcement machinery, but also on their flexibility. Some degree of differentiated enforcement, exemptions, delegation of enforcement, and self-regulation by stakeholders should be considered. Due consideration must be given to alternatives to administrative measures such as pollution permits and incentives for compliance. It is important to separate the functions of management and regulation of water resources.

1.77 Structures. Organizational arrangements concern mechanisms for decisionmaking, coordination, and implementation at the national and local levels. The arrangements for deciding on and changing policies, rules, and regulations (including social and environmental action) should be among the first to be considered. Other organizational arrangements may specify the responsibility for the physical or technical aspects of water resources management (including operations), and a system of human resources development that includes training and incentives for improved service orientation. Several countries are considering changes in the public and private-sector arrangements so that central governments can deal with necessary overall policy, supervisory, and enabling functions while local public agencies, local government, private companies, nongovernment agencies and user groups can own and manage parts of the water resources system. Strategy formulation is an opportunity to review the respective roles of the government and the private sector.

1.78 The process of strategy formulation will require analyzing the institutional and human resources capacity of agencies in the country-the government at all levels, private and nongovernment agencies, professional and community organizations. Institutional and human resources analysis should identify needs and opportunities for capacity-building so that the country can effectively manage its water resources.

\section{Information Systems}

1.79 To form policies, strategies, and investment plans decisionmakers need information on water and land use for various sectors (such as water supply and sanitation, health, industry, energy generation, and agriculture). Decisionmakers also need information about the environmental and social aspects of these sectors. Determining the availability or need for a wide variety of information is an important part of phase 1 of the strategy formulation process. Far more important in the long run, however, is the system by which information is collected, analyzed, and disseminated. Chapter 4 concentrates on guidelines for 
an information system assessment and for designing an information system for water. It also presents a list of selected meteorologic and climatologic data necessary for development projects. ${ }^{10}$

1.80 In order to assess and improve an information system, the ultimate requirements as well as many other aspects should be established. This involves considering

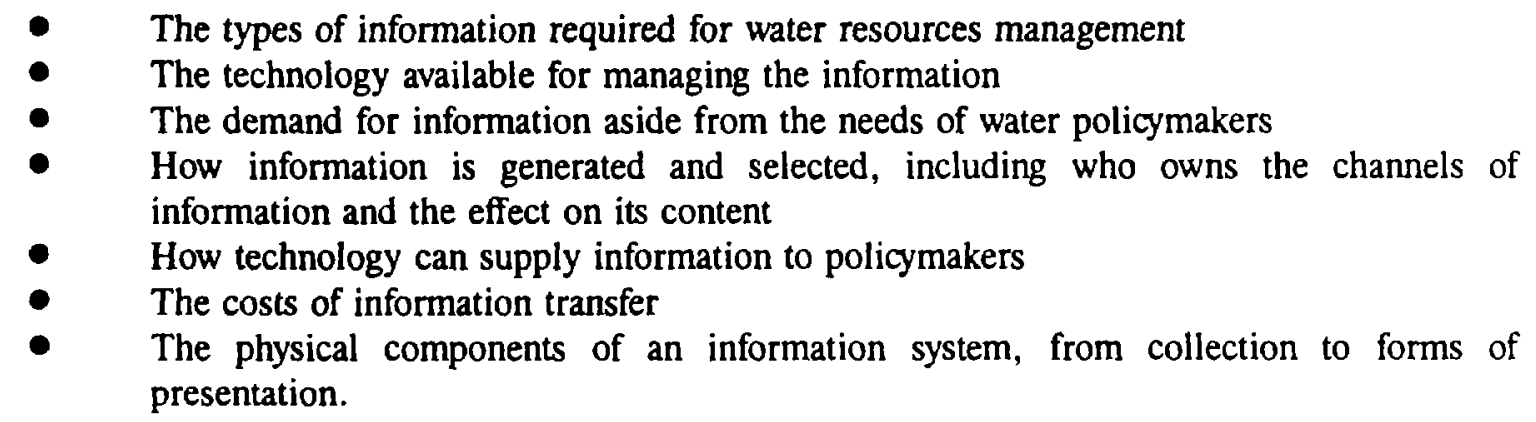

The expert team might assign to one group or consultant the task of studying the present and future role of information technology in water resources development and management.

1.81 Based on experience, recommendations for improving information about hydrometric and water supply services are likely to fall into six areas. These are: network rehabilitation, capacity-building, improving transportation conditions, data processing, establishing a hydrological cycle observing system, and monitoring water users, companies, and associations.

\section{Economic Analysis}

1.82 Countries are increasingly recognizing that water is not only a social and environmental good, but an economic good as well, one that must be managed in terms of both quantity and quality. Economic efficiency-the ability to produce the same or more goods with fewer resources-is a key policy in most countries, one that is directly linked to the conservation of water. Price and other economic incentives are required to conserve water and increase the efficiency of its use. Also, since the least-cost forms of water development have largely been used in most countries, further major investment in water will in most cases be in the area of water conservation and demand management. Economic analysis is an essential tool to choose among projects.

1.83 The task of valuing water among competing uses is complex in most countries. Most do not or cannot rely on the automatic reaction of market forces to determine prices; water has generally not been allocated by market forces alone because of its common good characteristics and externalities that distinguish it from other commodities. Pricing water based on its opportunity cost (the value of goods or services-including environmental services-foregone by using water for one purpose instead of another) is an ideal method, but this is not always possible because of both a lack of appropriate information and because of uncertainties inherent in water resources management. Quantity restrictions are generally a less efficient allocation method than prices, but can provide a shadow price. Even measuring the volumes or units of water on which to base either pricing or quantity restrictions is not

\footnotetext{
${ }^{10}$ Guidelines for the evaluation of the existing information system are also detailed UNESCO/WMO 1988.
} 
possible in all circumstances or could itself call for a massive capital investment. In domestic and industrial water systems, the price elasticity of demand is often small and hence even penal tariffs can have limited long-term effects. For this reason most countries favor the use of a combination of devices and direct water pricing, plus economic incentives such as fuel taxes, pumping quotas, or subsidies.

1.84 Countries should try to determine the value of water in different uses during formulating a strategy, or perhaps use the notion of opportunity cost to value water (see chapter 5). Determining the value of water can be a difficult task, depending on the existing economic data, for example, commodity prices, labor costs, and input prices (projecting such data over the long-term is also very difficult). Nevertheless lack of such data should not compromise strategy formulation. In fact, assessing data availability is the first of the tasks the strategy formulation team should consider undertaking in the area of water-related economic considerations. The others include

- $\quad$ Projecting water demand (and the country's capability for making such projections)

- Assessing the economic efficiency of existing water allocation

- Evaluating analytical methods used for water resource enquiries

- Reviewing and evaluating the ability of water pricing and cost recovery policies to meet country objectives

- Assessing the availability and adequacy of private and public capital for investment in water systems

- Reviewing institutional, legal, and regulatory systems.

1.85 If economic concepts and considerations are important in phase 1 of the strategy process, they are absolutely crucial for sorting through the issues and making recommendations in phase 2 . The strategy team will need economic analysis techniques (along with application of social and environmental techniques) to make projections, generate options, analyze impacts of various options, and choose which to recommend to policymakers.

1.86 Another important aspect of the economics of water resources strategies lies outside the process of formulating a strategy that is outlined in the guide. The costs of water investments are rising and the competition for public funds in developing countries is increasing. Greater attention will be needed concerning just how investments or projects are to be financed and sustained with adequate funding for O\&M. This is particularly true for irrigation and drainage projects and for sanitation facilities; O\&M for these have been neglected in the past.

\section{Environmental and Health Aspects}

1.87 During phase 1 (water resources assessment), the expert will identify problems and needs related to the water environment for major river basins and for sensitive ecosystems. Existing environmental policies, legislation, regulations, and institutions should be reviewed. In phase 2, the expert team should identify and rank issues related to the environment and incorporate them in the formulation of strategic options.

1.88 One environmental component of the development and management of water resources is the effect on human health. One of the major issues in most developing countries is the quality of drinking water and how it affects public health. National standards for drinking water can be assessed in phase one, while establishing or revising standards or providing for their enforcement could be some of the 
options offered to decisionmakers. Projects to develop water resources can lead to an increase in the number of organisms (vectors) that depend on water, or they can increase the contact between human communities and vectors, resulting in increased incidence of disease. The strategy formulation process should identify water-related health issues and consider the affect of strategic options on public health." For example, data on drinking water quality or waterborne disease can be used to suggest a level of water supply and sanitation investments.

1.89 There are two broad kinds of human activities that affect the water environment: water resources development projects that directly affect stream flows, water quality, and groundwater (for example projects for water supply, wastewater treatment, irrigation and drainage, hydropower, navigation and flood control), and water use and other activities that affect catchment basins (for example forestry, mining, and urban development). The assessment should examine the impact of these activities on sensitive ecosystems (such as estuaries, coastal zones, and inland wetlands), on human health, and on groundwater conditions. Among important elements are:

- Variation in water flows because of diversion, storage, and control of water

- Increased water runoff because of urbanization, deforestation, soil erosion, and land use changes

- Water quality changes because of pollution at point and non-point sources

- Over-pumping, which depletes water and causes land subsidence and salt water intrusion

- A high level of groundwater water storage (sometimes caused by over-irrigation), which often leads to waterlogging and salinization

- Water quality changes, which may have human or natural causes.

1.90 A review of environmental policies, legislation, regulation, and institutions should consider factors influencing administrative effectiveness. These factors may be a political mandate, financial resources, expertise, data and information, and coordination. More specifically, such a review should include careful examination of the effectiveness of environmental policies (such as answering questions of "how well are they articulated?" and "are they practical and achievable?"), legislation (water act, water pollution control act, and other environmental regulations), and environmental institutions. The latter includes reviewing the role of, for example, sectoral agencies, river basin authorities, specialized environmental agencies and groups, donors, and NGOs. Good coordination of these agencies could ensure the enforcement of environmental regulations and the successful integration of complex, crosssectoral environmental issues and the views of stakeholders in strategic decisionmaking. An examination might identify issues concerning coordination among agencies, effectiveness of regulations and water quality standards, procedures for controlling nonpoint source pollution, or environmental provisions associated with water allocation decisions.

1.91 Water allocation and pollution control will probably be the most prominent issues in developing a water resources management strategy. The analysis of the first issue should adopt the basin approach to making allocation decisions on optimum use of water. Dealing with the latter will require identification of major point and non-point pollution sources and loads, including information on water and land uses, and on hydrological data, which require input from the assessment of other areas. The assessment should identify priority river basins and geographic areas to be addressed in the short and long

\footnotetext{
"Two recent documents sponsored by WHO, FAO, and UNEP that provide guidance on health issues are Tiffen 1993 and Birley 1993.
} 
term in water strategy, and priority investment needs for pollution control infrastructure and techniques. Other non-physical control measures, such as standards, permits, penalty, courts, and incentives should be sought or evaluated for waste discharge control and monitoring. The priority environmental and institutional issues identified in the country water resources assessment and strategy should then be integrated into the country's environmental action plan.

\section{International Aspects}

1.92 The sharing of international waters and collaborative programs between riparian states to develop them is becoming of great importance almost throughout the world. For example, the principal surface water resources practically all countries in continental sub-Saharan Africa are international. In the former Soviet Union several major rivers have become international with the partition of that country into numerous independent states.

1.93 Water resources assessment for international rivers can be carried out by each riparian using a set of boundary conditions. Eventually, however, the several assessments of each riparian have to be integrated into an overall river basin assessment, hence the merit of joint assessments. In some situations such as in countries that embody only a small part of the total catchment area of the basin or in adjoining countries where the river forms the boundary, separate assessment may have little value.

1.94 The need for a good data and information base is even more important in international river basins if disputes are to be avoided and the environment is to be protected. The quality of data is particularly critical in arid zones that are subject to periodic droughts where the operational arrangements for sharing shortages between states needs clear definition.

1.95 It is usual to form some kind of jointly owned river basin organization (RBO) to act as a central clearing house for a number of activities but notably for planning, water sharing, and the preparation and execution of jointly-owned projects ("common works"). In such cases it should be the mandate of the $\mathrm{RBO}$ to carry out the type of assessment described in this guide.

1.96 The uses of the waters of international rivers is governed by the now widely-adopted Helsinki rules that embrace the concept of a drainage basin as an economic and geographical spatial unit within which the water resources are treated as the common property of all basin states. Furthermore, each state is entitled, within its territory, to a reasonable and equitable share of the water and is obliged not to develop projects that would cause appreciable harm to another riparian state. In some circumstances transboundary aquifers can also be treated as international drainage basins.

\section{REFERENCES}

Alaerts, G.J., T.L. Blair, H. Savenije, M.W. Blokand, and P. van Hofwegen. 1991. "Procedures and Partners for Capacity-Building in the Water Sector," in A Strategy for Water Sector Capacity Building. Delft: IHE and UNDP.

Birley, M.H. 1993. Guidelines for Forecasting the Vector-Borne Disease Implications of Water Resources Development. PEEM Guidelines Series 2. Geneva: WHO/FAO/UNEP. 
The Delft Declaration. 1991. Reprinted in A Strategy for Water Sector Capacity Building. Delft: IHE and UNDP.

The Dublin Statement. 1992. Reprinted in The Dublin Statement and Report of the Conference. Geneva: WMO.

Earth Summit. 1993. The Earth Summit: The United Nations Conference on Environment and Development (UNCED). London: Graham \& Trotman/Martinus Nijhoff.

Fox, I. K. 1976. "Institutions for Water Management in a Changing World," Natural Resources Journal, 16(4):743-58.

Grover, Brian. 1992. Institutional Arrangements for Water Resources Management in Developing Countries. Quebec: Canadian International Development Agency.

Hennessy, John. 1993. "Water Management in the 21st Century," address by John Hennessy at the fifteenth conference of the International Commission on Irrigation and Drainage, September 1993, The Hague, Netherlands.

Jaycox, Edward V. K. 1993. "African Capacity Building: The Missing Link in Development," excerpts from a speech by Edward V. K. Jaycox, World Bank Vice President for the Africa Region, The African Mirror, June, p. 15.

Kindler, Janusz. 1990. "Planning and Decision-Making Framework." in N. C. Thanh and A. Biswas, eds., Environmentally Sound Water Management. New York: Oxford University Press.

Noordwijk 1994. Political Statement and Action Program from the Ministerial Conference on Drinking Water and Environmental Sanitation, March 22-23, Noordwijk, the Netherlands. New York: UNDP.

Okun, D.A. and D.T. Lauria 1991. "Capacity-Building for Water Sector Management: An International Initiative for the 1990s," reprinted in A Strategy for Water Sector Capacity-Building. Delft: IHE and UNDP.

Postel, Sandra. 1992. Last Oasis. New York: W.W. Norton \& Company.

Sandstrom, S. 1994. Excerpts from an address in Canada. Bank's Wbrld, (April):13-15.

Tiffen, Mary. 1993. Guidelines for the Incorporation of Health Safeguards Into Irrigation Projects Through Intersectoral Cooperations. PEEM Guidelines Series 1. Geneva: WHO/FAO/UNEP.

UN, Economic and Social Commission for Asia and the Pacific. 1989. Guidelines for the Preparation of National Master Water Plans. Sales No. E.89.11.F17. New York.

UNDP. 1990. Report of the Global Consultation on Safe Water and Sanitation for the 1990s. New York.

UNESCO. 1987. Communication Strategies for Heightening Awareness of Water. Paris. 
UNESCO/WMO. 1988. Water-Resource Assessment Activities. Paris and Geneva.

WMO. 1992. Hydrological Data for Water Resources Management. Geneva.

World Bank. 1990. The African Capacity Building Initiative. Washington, D.C.

World Bank. 1993a. Water Resources Management. World Bank Policy Paper. Washington, D.C.

World Bank. 1993b. Water Resources Management in Asia. Washington, D.C.

World Bank. 1993c. A Strategy for Managing Water in the Middle East and North Africa. Washington, D.C.

World Resources Institute. 1993. World Resources 1992-1993. New York: Oxford University Press. 



\section{Part II}

\section{ISSUES IN COMPREHENSIVE WATER RESOURCES MANAGEMENT}





\section{CHAPTER 2 INSTITUTIONAL AND HUMAN RESOURCES ISSUES}

2.1 In this paper, the term "institutions" refers to both the set of rules governing water development use and the specific organizational arrangements involved in the formulation and implementation of water resources laws, policies, strategies, and programs. Together, these rules (that is, the laws and regulations) form the "enabling environment" for water resources management. Changes in the rules, organizational arrangements, and means of human resources development may be required to effectively translate water resources management policies into an action program. These changes should help to implement policies and should provide incentives for improved performance in terms of water resources planning, allocation, and operations management. Sound institutions along with high-quality human resources are the best assurance of achieving water sector objectives.

2.2 The strategy formulation process is an opportunity to evaluate whether institutions and human resources programs in a country effectively serve the country's water resources management goals. An evaluation of the set of rules is an opportunity to consider both the social norms that govern water supply and use as well as whether explicit policies, laws, and regulations are sufficient. A review of organizational arrangements can reveal whether existing or recommended rules can be enforced; it is also a chance to consider ways of involving community organizations, water users, or professional associations in the planning and management of water resources. Finally, human resources development is an opportunity to look at supply and demand for key personnel as well as elements such as education and training, employment, career structures and incentives. Because strategy formulation must remain a manageable process, all of these issues will probably not be addressed in great detail but a direction may be set. Examining organizational arrangements and human resources development above all directly address the issue of capacity-building in developing countries.

2.3 Water resources management strategy is country-specific. Analysis of institutional and human resources should pay special attention to a country's culture in terms of its legal framework, the mix of public and private sectors, educational and manpower development policies, and traditional modes of organization. In some cases, religious beliefs direct a certain code of conduct with regard to society's management of natural resources. Therefore, in the analysis of institutions, particular care should be paid to social and cultural practices governing the use of the resource.

2.4 Institutional analysis should lead to:

- An inventory of information

- Identification and analysis of key issues

- Development of options in terms of the legal and regulatory framework, and organizational arrangements and human resources requirements to achieve desired policy goals.

\section{ASSESSMENT AND INSTITUTIONAL ANALYSIS}

2.5 The starting point for institutional analysis is a country's water resource policies. Such policies, for instance, could include strengthening public regulatory functions (especially regarding the environment), developing rational pricing of water, or decentralizing operations management of water 
resources to the level of a river or drainage basin. Certain broad directions reform are visible in the developing world. For example:

- The roles of the government and the private sector are being redefined. In the past, governments generally have provided many water planning and management services. Increasingly, countries are experimenting with a wide array of organizational arrangements where the government retains overall planning and regulatory functions as well as management of major water structures (such as reservoirs and dams). Delivery of services, however, is being decentralized to the lowest level possible. The Philippines has experimented with a semi-autonomous national agency for irrigation management. More recently, Indonesia has initiated a process of transferring O\&M (O\&M) functions in small irrigation schemes to users. Mexico has launched an ambitious program of transferring the management of entire irrigation districts to water users. Chile and Peru are contemplating or have implemented policy reforms to transfer water rights for users and legal trade of those rights. Cote D'Ivoire, Guinea, and Argentina, among others, have experience with private water supply companies for major cities. A number of East European countries have also recently privatized water supply services in a number of medium-to-large towns.

- The need to incorporate environmental considerations in the planning and management of water resources both at the sectoral and at the project levels is being widely recognized. This implies efforts to introduce legal, regulatory, and organizational changes to address concerns related to water flows, land and water quality, aquifer monitoring, and pollution control. Chapter 6 on environmental and public health aspects and human resources discusses some institutional factors.

2.6 The following institutional aspects should be addressed during strategy formulation.

- Laws and customs governing water rights, principles of water allocation among various uses, water pricing, and private sector participation

- Regulations concerned with surface water, aquifer and groundwater management, (especially pollution control and reuse of these resources)

- Organizational arrangements such as mechanisms for coordination at the national, provincial, and local (basin) levels, These should specify the responsibility, authority and accountability for planning, regulation, and operations. Such arrangements should also include a system of human resource development incorporating education, training and incentives for improved service.

\section{WATER RIGHTS AND LEGISLATION}

2.7 Water rights have generally originated from historical use and have been sustained over time by custom, sometimes confirmed by specific legislation or constitutional decree. In many cases, the nature of water rights is vague. In some cases, government orders or notifications may substitute for law, as in the case of operating rules of a reservoir that may determine water allocation for different uses. The question of whether a formal establishment of rights is warranted is a question for the strategy 
formulation process. It must be remembered that once rights are conferred it is not easy to withdraw them. Any new system of conferring rights should also pay attention to equitable allocation among users, including their access to relevant information.

2.8 The system of rights may include the right to trade water. Irrespective of whether formal rights exist, informal markets for water can be observed in various countries. Specific written or verbal contracts may govern water trading; this is often the case of trades between irrigation organizations or between such organizations and other users. Lack of extensive irrigation infrastructure restricts conveyance capacity and may restrict the tradability of water. In the case of drinking water supply in the cities, however, there is extensive evidence of the population's willingness to pay for water supplied by private vendors. The assessment portion of the strategy formulation process is an opportunity to record the existence and spread of such practices and to determine whether they help meet a country's goals and water-related policies.

2.9 Laws also will usually specify the entity responsible for managing water resources and assets in the sector. Usually, a range of ownership and management entities will be found in a country; these include the central and provincial governments. Other managers of water resources and infrastructure include semi-autonomous public agencies (such as river basin commissions), private companies, cooperatives, and user organizations. The nature and type of governance and administration of these legal entities, including their accounting and audit procedures, should be of central interest to institutional assessment. For instance, in some cases, existing laws of incorporation may hinder the transfer of ownership or management from government to other agencies.

2.10 Conflicts and conflict resolution are inherent in any sharing of resources. Conflicts may be resolved by interpersonal means, local community organizations, government agents, or the courts. In the case of international or interprovincial waters, allocation rights and conflict resolution procedures would be part of agreements and treaties, an aspect dealt with in chapter 7. Identifying mechanisms that will not only resolve conflicts but also prevent them could be important. In this regard, existing community practices for dispute resolution would be an important area of inquiry. Experience with water rights in some developed countries suggests that it is important to forestall an expensive litigious process of dispute resolution through the courts, where cases may be tied up for long periods of time.

\section{REGULATIONS, ADMINISTRATION, AND ENFORCEMENT}

2.11 The enforcement of water legislation and policies depends on the relevance of the regulations and on the administrative machinery required to ensure compliance. For instance, in many countries, the regulation of groundwater is weak. Siting restrictions for pumps are either absent or poorly enforced. Aquifer monitoring to alert decisionmakers about the drawdown levels is often absent. Special attention will be needed during the assessment to collect and analyze information about groundwater regulation and its enforcement. A principle to remember in this context is that regulatory functions should be separated from operations. The same agency should not implement a program and regulate it.

2.12 Water regulations might cover land use rights related to water management, watershed development, environmental quality and pollution control standards, dam safety standards, service standards for water supply, and financial and management standards. 
2.13 The administration and enforcement of these regulations depends on adequate institutions. A study of the effectiveness of the present enforcement capabilities is a necessary part of the assessment. A reconsideration of regulations may follow such an analysis. For instance, in one case, it was discovered that the recruitment of additional personnel to pursue regulatory compliance would result in a net loss since the additional benefit was estimated to be less than the additional staff costs that would be incurred for monitoring and collection. In such instances, innovative mechanisms such as pollution permits may be required (where market conditions prevail). International experience of basin-level environmental management through a system of levies and subsidies may be worth careful study.

\section{ORGANIZATIONAL ARRANGEMENTS}

2.14 There are five broad areas of organizational responsibility for water resources management: (a) planning and coordination, (b) design and construction, (c) regulation, (d) social and environmental action; and (e) operations management. The government can use a range of instruments to discharge responsibilities in these areas. It is impossible to prescribe the best formula for organizational arrangements for all contexts. The ultimate organizational form will have to suit the country's own political, cultural, and administrative norms and practices. However, three major considerations should be kept in mind:

- Do present organizational forms violate some principles such as separation of operations from planning and regulation?

- Does government involvement in all of the areas above lead to effective management? If not, what are the priority areas for government involvement?

- Are financing arrangements for capital and operations of water services appropriate?

2.15 Planning at different levels is needed for effective water resources management. Planning involves (a) collecting data on water quantity and quality, (b) properly analyzing and disseminating the data, (c) establishing water supply and demand balances, (d) identifying areas for long-term water development and management at the national, provincial, or basin level, and (e) determining drought and flood protection needs. Chapter 4 on information systems elaborates on the requirements in several areas. Chapter 3 on stakeholder participation describes the need to involve key participants in the water sector in the planning process. For institutional analysis, the focus should be on assessing the effectiveness of planning agencies and mechanisms for ensuring technical inputs, economic analysis, and stakeholder participation. Institutional assessment would also focus on evaluating the capacity of existing institutions to undertake water planning exercises on a continuous basis to update and analyze basin and other levels of data.

2.16 Design and construction has been a major activity of many water resources agencies. This is a specialized technical function that has long been a source of power and pride for these agencies. Increasingly, however, emphasis is being placed on management of resources rather than on new construction. This specialty is being de-emphasized in many water departments. The transition from a civil works to a water management agency is difficult and is fraught with political and organizational pitfalls. The water resources assessment should carefully evaluate the future direction of water agencies. 
2.17 Coordination is a key aspect of planning and management. Several economic sectors and many water users are involved in water allocation and their actions needs to be coordinated within an overall water resources management framework. The question is how to bring the sectors together. Some countries have established inter-ministerial water councils for planning purposes, with leadership from planning or finance ministries to avoid the bias of a particular user sector (such as irrigation, which is the dominant sector in many cases). These councils also include representatives of the community at large to ensure participation of nongovernment organizations and trade and professional associations. Similar mechanisms can also be established at the level of river or drainage basins. These mechanisms are essential also for water regulation to ensure, for instance, that groundwater exploitation is not to the detriment of the overall basin.

2.18 Effective means of regulation and enforcement are required at local and higher levels so that the interests of all parties are protected and reconciled. For instance, timing of water delivery is a crucial question for irrigators and water release dates would have to be agreed to in consultation with irrigators, power utilities, and municipalities. Coordinated management action is important with respect to surface and groundwater.

2.19 Many recent critiques of the water sector have pointed out the poor attention to operations management and maintenance of water resource systems. As a result of this lack of attention, water services are unreliable, often inequitable, and inflexible. Some of the reasons for poor performance are technical and financial. In the developing world, capital development often is financed by the treasury, and water-related operations fees are collected by another arm of the government and channeled to the treasury. Separately, resources are allocated for the operations budget of the water agency. This results in a dichotomy between payments for water services and expenditures on them. When this link is tenuous, the incentive to improve system operations is limited. Also, the overall lack of emphasis given to O\&M because of the preoccupation with new construction contributes to poor performance.

2.20 The question of restructuring incentives in the irrigation and municipal water supply and other water-related sectors is, therefore a crucial institutional question. A number of alternatives to government provision of service are available. The "utility" model is one which focuses on a single purpose of delivering a measurable service to users. The water supply agencies in the developed and in some developing countries come close to this model. Various types of private sector participation are possible. Service contracts empower a contractor to provide a specific service. Management contracts ensure that the contractor assumes responsibility for managing, operating, and maintaining all or part of a water system. Lease contracts provide rent for the facilities with the contractor assuming full responsibility for operations. Concessions add a level of responsibility to the contractor in that he invests in additions to capital facilities and is responsible for associated debt service. "Build, operate, and transfer" programs require a public or private agency that builds and operates the facilities after commissioning, and then hands over the management to a designated, often community, agency. A variant on this is the "build, own, operate, and transfer" program, where temporary ownership of the facility by the builder may have favorable financial consequences. User organizations that contract with a government agency or manage a certain part of the water system are another option.

2.21 Institutional analysis during the water resources assessment phase of strategy formulation affords an opportunity to examine the participation and roles of nongovernment organizations in water resources planning and implementation. Representatives of these organizations should be included among the stakeholders consulted during the strategy formulation process, because they may ultimately be involved 
in strategy and project implementation. Two types of NGOs with a useful role to play are community organizations and professional associations.

\section{Community Organizations}

2.22 Economic development is rife with projects that were clearly needed, adequately financed, welldesigned, and entirely serviceable but that were eventually abandoned because the stakeholders (particularly customers) who were ultimately responsible for the viability of the project felt no "ownership." Often, this is because they were not involved in any stage of the planning process. Success stories almost always involve tales of active local community leadership and participation.

2.23 It is appropriate for water projects to include funds for the institution in charge of the project to support one or more consumer or user organizations that would institutionalize the assessment of customer needs, ability, and willingness of potential customers to pay, and ascertain their preferences with regard to levels or reliability of service. An understanding of the readiness of water users to support a project is essential, and the establishment and financial support of a consumer organization would pay for itself by avoiding costly missteps at the outset.

2.24 The role of women in user organizations has been shown to be instrumental in the success and in the sustainability of water supply and sanitation projects. The reasons are easy to understand: in the absence of water supply and sanitation facilities it is women who spend substantial portions of time carrying water and whose quality of life in the home and in the field is most affected by the availability or lack of water and sanitation facilities. Women have a stake in the improvement of water supply and sanitation facilities and in irrigation facilities as well. Capacity-building at the local level cannot succeed without the full participation and leadership of women.

2.25 While most other interventions in capacity-building have been appreciated, if not often implemented as fully as they should be, a responsibility for the establishment and utilization of community or user organizations is relatively new and requires new insights and, what initially may be uncomfortable, new practices. If fiscal responsibility is to be expected, users need to be involved early in the planning.

\section{Professional Associations}

2.26 National and international nongovernment professional associations have long played an important role in enhancing the capacity of industrialized countries in the water sector. They have contributed in many ways:

- They provide a forum for reporting and updating technical knowledge in the sector and making it available to professionals in the field through publications, conferences, and short courses.

- They work with national decisionmakers in defining policy and setting standards of all types. 
They can provide a link between public agencies, consultants, manufacturers, industry, and the public.

They promote national and international exchange and cooperation in training, research, technology, and in sector development.

2.27 While well-established in the industrialized countries, professional associations are weak in most developing countries. Important contributions to national capacity-building in the water sector can come from initiatives by international professional associations that in general are dominated by representatives from the industrialized countries.

2.28 National associations in the industrialized countries reach out to assist like types of associations in the developing countries by making special arrangements for distributing their publications which, because of foreign exchange difficulties, are generally not easy to obtain. External support agencies can assist financially in the distribution of publications by working through their own national professional associations in reaching associations in developing countries.

2.29 Examples of professional associations include the International Water Resources Association, which deals mostly with irrigation and drainage issues, the International Water Supply Association which operates on technical issues in the water supply subsector, and the International Association for Water Quality which covers the sanitation subsector. The International Commission on Irrigation and Drainage assists national associations involved in agricultural irrigation.

\section{International Support}

2.30 Institutions can enhance their capacity through active participation with the many specialized UN agencies that offer technical assistance as well as financial support in the water sector. These include the UNDP, The World Bank, the UN Department of Economic and Social Development, UNEP, UNESCO, the Food and Agriculture Organization (FAO), WHO, and WMO.

2.31 In addition, the regional development banks, the many bilateral agencies, and the large number of private voluntary organizations can assist countries developing their water resources.

\section{HUMAN RESOURCES DEVELOPMENT}

2.32 Capacity-building depends on adequate institutions and institutions depend on human resources. An ideal institutional structure with poor personnel has less potential than an ungainly structure with highquality people. Both success and failure have come from all types of institutions but high-quality human resources staffing and sound institutions are the best assurances of a country's capacity to achieve water sector objectives.

2.33 Estimates of both available and required skills should be made during the water resources assessment. Training needs should be geared to long- and short-term institutional objectives. General skill areas that could be evaluated include technical (for example, fisheries specialists, hydrologists, and toxicologists), managerial, and cross-disciplinary skills (for example, ecologists). 
2.34 Education and training of personnel at all levels are essential elements of a human resources development program. The worth of training may be eroded, however, if individuals are placed in an environment that does not utilize or support their education. Human resources development involves employment practices, career structures, and professional and financial incentives.If better performance as a result of commitment or training is seen to be rewarded by increased pay and by an invitation to a higher level of training and then greater responsibility, the individual will make much greater effort than if the training and its rewards are perfunctory. Staffing patterns must be well understood and opportunities for promotion enlarged, commensurate with merit. Expertise in human resources development could be employed on the permanent staff of large institutions or as consultants to smaller organizations.

2.35 Many water-related educational, research, and other tasks can be commissioned to local universities and other educational institutions. This helps the educational institutions obtain and retain staff in the water sector. A common practice is to have a utility provide the university with funds for professional students to undertake tasks important to the utility. The university, the student, and the utility all benefit.

2.36 Also among education and training resources is the International Training Network (ITN), which provide resources that can assist countries in their own training efforts. The ITN is a product of the UNDP-World Bank Water and Sanitation Program; it currently has nine members in Asia, Africa, and Latin America.

\section{FURTHER INFORMATION}

The Delft Declaration. 1991. Reprinted in A Strategy for Water Sector Capacity Building. Delft: IHE and UNDP.

Frederickson, Harald. 1992. Water Resources Institutions. Technical Paper no. 191. Washington, D.C.: The World Bank.

Kinnersely, David. 1992. "Privatization and the Water Environment in England" in Le Moigne and others, eds. Country Experiences with Water Resources Management. Technical Paper no. 175. Washington, D.C.: The World Bank.

Okun, D.A., and D.T. Lauria 1991. "Capacity-Building for Water Sector Management: An International Initiative for the 1990s," in A Strategy for Water Sector Capacity-Building. Delft: IHE and UNDP.

Small, Leslie, and Ian Carruthers. 1991. Farmer-Financed Irrigation. Cambridge: Cambridge University Press.

Triche, Thema. A. 1990. Private Participation in the Delivery of Guinea's Water Supply Services. Policy, Research and External Affairs paper no. WPS 477. Washington, D.C.: The World Bank.

World Bank. 1992. World Development Report. Washington, D.C. 
3.1 Stakeholders are people and organizations that are concerned with or have an interest in water resources. Water users, water providers, and those with an interest in water-related issues (for example, professional and nongovernment organizations) all have a stake in the decisions made in formulating a water resources strategy. The participation of such people and organizations in the process of designing and implementing water policy, strategy, and projects is very important. Including stakeholders from the very beginning of strategy formulation can help to gather information, to clarify the goals of policy, and to create a sense of commitment or "ownership" that can help to implement water policy and projects. While policies or processes seldom satisfy everyone, stakeholder participation lowers the risk of a large gulf occurring between the design and the implementation of water sector policies or projects; without it, the risk of policies and projects operating in a suboptimal or ineffective manner grows.

3.2 This chapter suggests principles and techniques as well as minimal and ideal approaches to stakeholder participation that can be used in and tailored to specific countries. Forming a strategy for water resources should be undertaken within the context of a country's broad development goals, and each country will of course have its own cultural norms and political accountability. Participation will display different characteristics in each culture.

\section{DEFINITION AND BENEFITS OF STAKEHOLDER PARTICIPATION}

3.3 Many water resources policymakers and project managers are familiar with the concepts and techniques of community involvement in water resources projects, at both the design and implementation stages. Stakeholder participation in formulating a strategy for water resources management has many similar aspects. The variety of stakeholders in national water resources policy is of course broader than the interested parties in a local community, as is the variety of issues. Stakeholder participation is the process of involving those who are affected by and who have an interest in water resources in the formulation of water strategy. It is a two-way communication process that explicitly seeks to identify and to clarify the interests at stake in decisions with the ultimate aim of producing a well-informed water management strategy that has a good chance of being implemented. Stakeholder involvement should not be simply an adjunct to the analytical aspect of water sector strategy development. It should be a integral part of the process of developing a strategy mainly because it would

- Assure that alternatives serving a broad range of interests are considered

- Help to gather data or information, identify gaps in data or information, and identify those who might provide data or information in the future

- $\quad$ Provide transparency and accountability regarding both decisions taken and the process by which those decisions were taken

- Accustom stakeholders to the fact that some difficult choices may have to be made in order to manage water resources effectively 
- Build a broad base of commitment to options by creating an environment that rewards the realistic discussion of benefits, risks, and costs of options and that provides a meaningful basis for informed consent to recommendations

- Help to identify options that are foreclosed and those to be maintained at critical decision points

- Increase the probability that projects can be implemented and that they will bring the desired return on investment.

3.4 At least two activities are involved in stakeholder participation: identifying stakeholders, and securing stakeholder participation in the work of producing a water resources strategy. These are both analytical and procedural activities; one without the other would probably be ineffective. Building commitment to and ownership of water strategies will depend on satisfying interested parties in several ways: substantive, procedural, and psychological. There is the substantial risk that involving stakeholders can turn into a politicized confrontation of interests, but if the process is well managed (that is, if stakeholders have an appropriate level of involvement, and if the emphasis is on developing joint options instead of only choosing among predetermined options) this risk can be avoided.

\section{WHO ARE STAKEHOLDERS?}

3.5 Stakeholders can be individuals, organizations, or groups. Stakeholders include (but are not limited to): (a) public sector agencies involved in water resources (for example, departments of agriculture, industry, transportation, and recreation), (b) various levels of public sector agencies in the water sector (state, regional, local), (c) private sector organizations and companies with water interests, (d) environmental and other professional nongovernment organizations, and (e) representatives of those people likely to be effected, specifically including people who may have little knowledge of the effects of strategy and who may lack the means to participate.

3.6 A variety of methods can be used to identify stakeholders. Three of the simplest approaches are self-identification, third-party identification, and identification by the strategy team. Self-identification simply means that individuals or groups step forward and indicate an interest in participating. Third-party identification uses knowledgeable parties such as existing advisory committees, informal or formal community leaders, and representatives of known interests to suggest people or organizations that should be included. Identification by the strategy team relies on the team systematically identifying and approaching stakeholders. Social impact assessments, environmental assessments, financial analysis, and gender analysis can all help to identify stakeholders. The team should identify those parties essential to implementing projects, those who are benefitting or will benefit from water projects, and those who are bearing project costs. Most important, people who would be affected by water strategy but do not yet know they will be affected should be identified. Stakeholder participation is a means of giving them a voice. 


\section{LEVELS AND TECHNIQUES OF PARTICIPATION}

3.7 Different stakeholders will seek different levels of involvement. The water sector strategy team must discern what level of participation is appropriate to the various decisions that must be made in formulating a strategy. Stakeholders with substantive knowledge or professional competence might be members of the strategy team itself. Not all stakeholders need to be involved or can be involved in the same way or at the same intensity during the entire formulation of a water resources strategy; levels of involvement may change during the during the process. The levels of participation can be seen on an increasing scale as

Having knowledge about a decision (listeners, observers)
- Being heard before a decision (reviewers, advisors)
- Forming and agreeing to a decision (originators and decisionmakers).

Listeners are those who need to be informed but do not feel a need to be actively involved in policies and projects. Observers, while not actively involved, are watching the policy assessment process and may become active if access to information is cut off or if they are surprised by events in the assessment. Reviewers actively watch the assessment process and will review ideas and materials. Advisors contribute their own time and energy and are willing to be actively involved. Their high level of interest and concern must be matched by equally high commitment and efforts by the water strategy team. Originators are so involved that they help create options. This is a high level of involvement and may be difficult to sustain. Decisionmakers are stakeholders who seek a level of involvement where they have a vote in or some control over the decisions made.

3.8 Figure 3.1 displays levels of involvement with examples of participation techniques appropriate to each level. The lower levels of participation are characterized by traditional public information programs and public hearings. These are typically techniques that emphasize one-way communication. Moving up, techniques such as task forces, workshops that may involve a neutral person to keep them focused (a facilitator), and collaborative problem-solving are emphasized. Typically these are techniques that emphasize two-way communication and often use the neutral assistance of facilitators to help shape the process, but not the substance, of dialogue. The high end of the scale includes structured techniques designed to produce consensus, agreement, or resolution, such as conciliation, mediation, and arbitration. Using a technique at the low end of the scale, such as providing public information, should not necessarily be expected to produce the results indicated at the high end, such as significant interaction or agreement.

\section{STAKEHOLDER PARTICIPATION DURING STRATEGY FORMULATION}

3.9 The strategy team might consider using citizen advisory and technical advisory committees. The team should be clear about the role of such committees. The team could easily rely too much on committees and not attempt to reach directly more stakeholders. Also, such committees can begin to function beyond the control of the water strategy team. One interesting form of citizen committees is a planning group (also known as a planning cell). Like advisory committees, planning groups may be expensive. In a planning group, a cross-section of stakeholders is chosen randomly. These people come together to work on a problem or policy issue for a short period. They are often paid and should have 
Figure 3.1 Levels of Stakeholder Participation and Examples of Participation Techniques

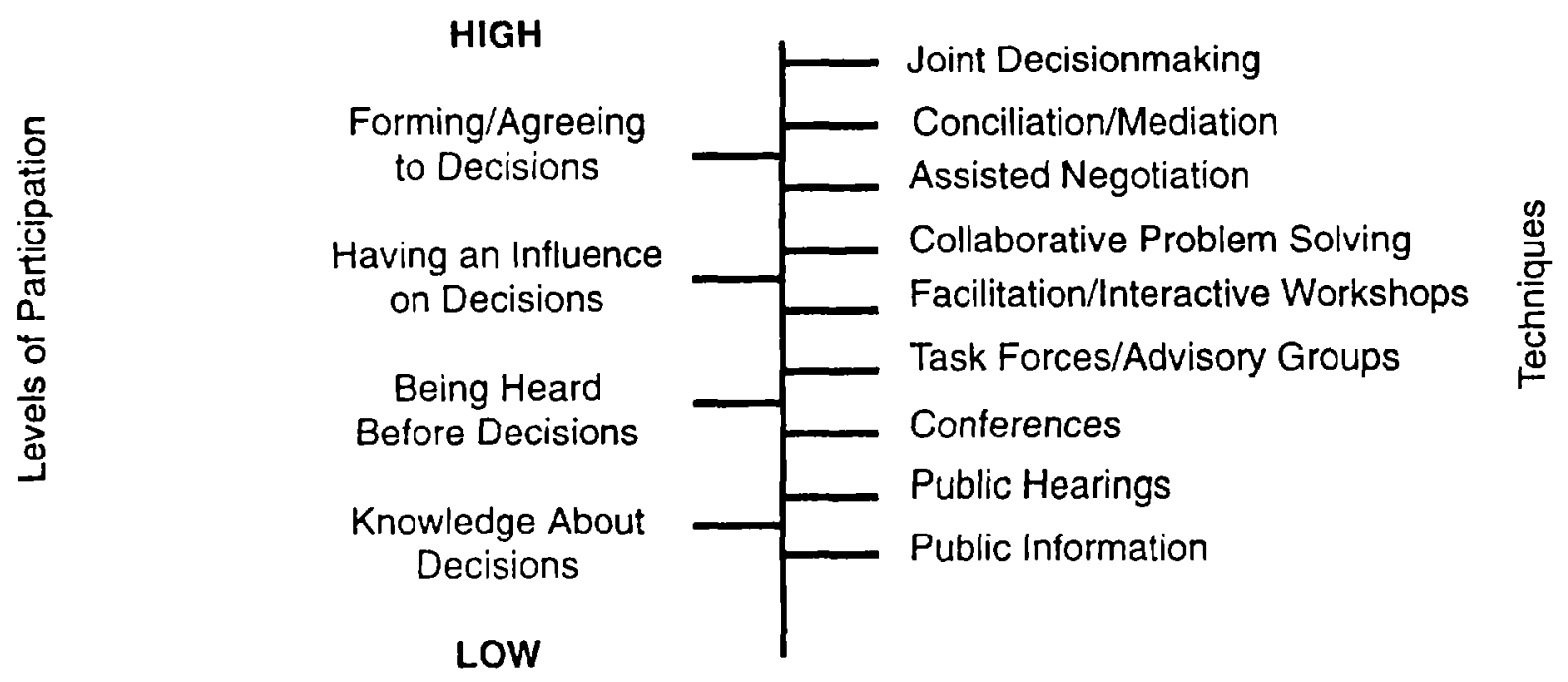

Source: Authors

full access to key information and to decisionmakers. Their activities are highly visible; at the end of the process they may produce a report to be considered by decisionmakers.

\section{Phase 1}

3.10 Phase 1 of formulating a water sector strategy is preparing an inventory of information and experience while identifying and analyzing the major issues in the water sector. In general, this phase should also include examining the interests and positions of the various stakeholders as well as their perceptions of the issues. To help this process, the strategy team may wish to prepare a grid or chart with the identified stakeholders listed in one column and four other columns reserved to outline each stakeholder's issues, positions, interests, and options. These terms can be defined as follows.

- Issues are matters or questions stakeholders disagree or agree about that can usually be stated as problems. Issues may be substantive (related to time, budget, or compensation, for example), procedural (concerning the way discussions are handled and the way decisions are made), or psychological (related to the effect of a proposed action).

- Positions are statements by a stakeholder about how an issue can or should be handled; they can also be proposals for particular solutions. 
- Interests are specific needs or conditions that must be met in an agreement for a particular party to be satisfied. Interests may refer to content, to specific procedural considerations, or to psychological needs.

- Options are possible solutions that address the interests of one or more stakeholders. There may be more than one way to satisfy interests.

3.11 If positions become the early or primary subject of discussion, too much effort may go into defending them. If interests are the main focus, stakeholders and the strategy team are more likely to develop options jointly, which is critical to fostering ownership. As the water strategy process moves into phase 2 (identifying, evaluating, and choosing options), the key to building agreement may lie in expanding options and moving beyond trade-off analysis. This is best achieved with collaborative techniques that ask stakeholders to examine the interests behind positions.

3.12 At minimum, the water sector strategy team should go through the exercise of deciding what information is needed from and what information should be given to various stakeholders. Also, public awareness should be generated at the start of the process.

3.13 An ideal way to begin the water resources assessment process would be to hold a series of meetings to identify public needs. Such meetings would be a cost-effective means for the strategy team to map the range of issues, interests, and positions they must examine; the meetings could also help form a positive relationship with stakeholders. They also often identify data and studies not readily available.

3.14 The water sector strategy team might think about stakeholder assessment in the terms outlined in table 3.1. Working through an outline of participation similar to table 3.1 would not only clearly define the levels and techniques of stakeholder involvement; it could help team members to clarify and agree to strategy objectives and to define the process to achieve those objectives. Thinking about stakeholder participation carefully at the beginning of the strategy process can also define indicators of progress that the water strategy team will be able to use as it proceeds. In table 3.1, the columns headed "Information from Stakeholders" and "Information to Stakeholders" will help to define what is needed. The last two columns will help to identify stakeholders and techniques of involvement. More information about such techniques can be found in the volumes listed at the end of this chapter.

3.15 Stakeholder involvement can be particularly valuable in providing and reviewing available data and determining priorities for data-gathering. Stakeholders are the best judges of their interests, and are thus often the best sources of data about their interests. Since they will ultimately have some say in the viability of water policy options and since that discussion will to some degree revolve around data issues, early stakeholder agreement about the information base will be critical. Even if stakeholders produce data similar to that from other sources, their involvement will produce some affiliation with the data base. Because an ideal data base can be fashioned only rarely, stakeholder participation will help to decide which gaps in the data base are most important to fill. This approach is likely to produce conflicting data. Conflicting data can provide an incentive for explicit interest-based negotiations that can help avoid to avoid the illusion of building an objective or neutral data base only to find it attacked at the end of the water sector strategy process. 
Table 3.1. Information and Stakeholder Participation

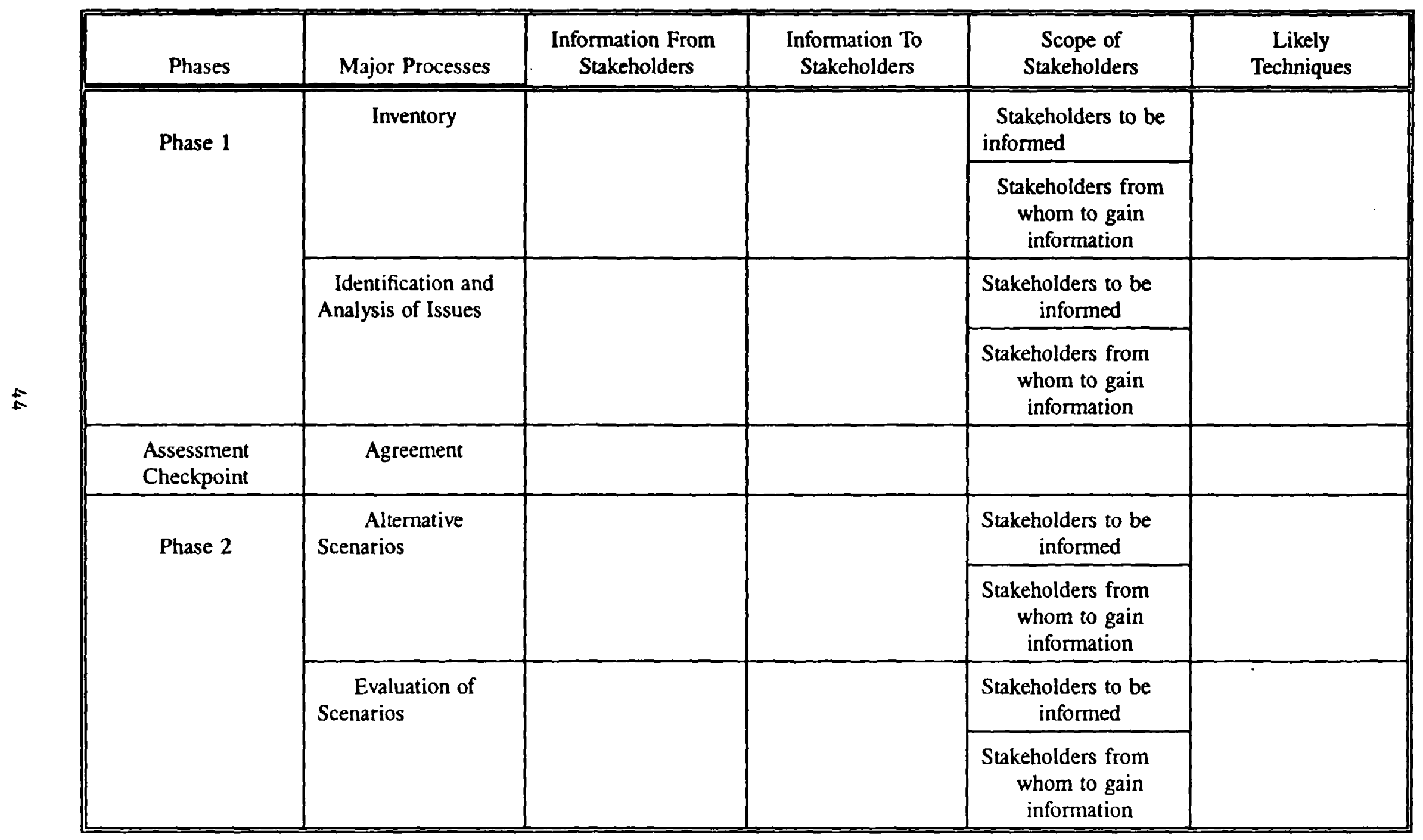

Source: Author. 
3.16 In the identification and analysis of issues, it is important to go beyond a list of needs and to understand the interests behind those needs. While representatives of stakeholders can provide a list of issues, needs, and priorities, the assessment should go further and try to reach stakeholders directly. The most effective method at this stage is focused workshops that are attended by the water sector assessment team. At least one workshop where ideas are exchanged should be held during both phase 1 and phase 2 of the strategy process. If time and resources do not permit, some form of focus group can be effective. Analytical tools such as questionnaires and surveys can be helpful but are fraught with danger. They are expensive and give only a "snapshot" of attitudes; also, they can encourage the idea of finding an empirical majority view at a moment when the sector assessment team needs to discern the intensity of feelings and not just a majority view. Surveys and questionnaires can be most effective when used together with more direct participatory techniques.

\section{Between Phases 1 and 2}

3.17 Between phase 1 and phase 2, the strategy team and decisionmakers must take stock of results and decide whether they should proceed with the water sector assessment. This is an important juncture for stakeholder participation. The team should seek clear direction, if not agreement, from stakeholders about the path of the assessment. Public meetings or workshops (possibly using mediators or facilitators) attended by the sector strategy team, decisionmakers, and stakeholder representatives are most effective at this point. Between phase 1 and phase 2, the water strategy team could also hold a series of evaluation workshops. These could help the team determine if the strategy process should proceed and whether more information is needed, as well as giving some early indications of what type of options and scenarios should be used. In addition to water sector strategy team members, government officials should participate in such workshops. Between phases one and two some public announcement should be made about the decision to proceed and why the decision has been made.

\section{Phase 2}

3.18 Phase 2 begins by developing options. This is a phase where stakeholders could contribute creatively. Stakeholders and team members should review what they have learned. They should then develop options. In this fashion the number of strategic options can be reduced, but the range of values represented by those options can be increased. This can be done using small workshops and selected stakeholder representatives.

3.19 Once options have been developed, they should be evaluated using both process and analytical techniques. Delphi techniques-where stakeholders are asked to independently create and evaluate options, which are given back to them for reevaluation-could be used to narrow the range of opinions about options. This process should continue until some areas of agreement emerge. Selected interviewing of stakeholders in conjunction with other analytical approaches can be effective. Also, focus groups are good routes for stakeholder participation at this stage. Simulations and other decision-support tools have opened new possibilities for meaningful stakeholder participation. These tools will offer some of the best ways to evaluate a variety of options. Assisted negotiation techniques (mediation, facilitation, and collaborative problem-solving) can also be used at this point.

3.20 Public meetings or hearings are appropriate at the conclusion of phase 2 . If there has been effective participation, few surprises should emerge at this stage; perhaps there will be agreement on 
proposed actions. At minimum, these meetings would affirm areas of, and reasons for, agreement and disagreement.

\section{PRINCIPLES FOR PARTICIPATION}

3.21 The various participation techniques mentioned in this paper and in the sources at the end of this chapter can of course be used in both phases of the water sector strategy process. Obviously, several techniques can be used in all or many phases. Stakeholder participation is as much an art as a science, and considerable judgement is required. The following are principles or lessons learned that can help choose appropriate techniques of participation.

- If people share the process of generating alternatives, they are more likely to make realistic decisions among alternatives.

- Frequently, the way something is done builds trust and legitimacy. It is not just the final answer but the way the answer was obtained that can make a difference. To arrive at strategies that people will implement, individuals must be satisfied procedurally, psychologically, and substantively. Participation is an attempt to build trust and communicate openness and concern throughout the strategic assessment process.

- A participation program must be visible at all times. Sometimes this is difficult when there are long periods between meetings and workshops. With new technical data, interactive computers and decision support systems, the time between actions can be shortened. The main point, however, is that some appropriate level of publicity without over-saturation should be maintained. Public access to databases should be considered.

- Professionals, scientists, and experts should know the limits of their expertise. Too often, political and value judgments are presented as objective, value-free, opinion. When this occurs or when "value-free" numbers change frequently, professional legitimacy and expertise will be questioned. Stakeholder participation processes encourage the professional and scientific community to move beyond such adversary science.

- Professional expertise should be used to create options, not to eliminate them. Participation tries to foster contact between technical expertise and values expressed by stakeholders. A properly designed participation process can produce alternatives that are technically sound and that had not been conceived by either the technical experts or other participants.

- Technical jargon can be exclusive rather than inclusive. Technical people must use language that can be understood. This simple advice is often ignored.

- Professionals need to understand how to read the feelings and to discuss the relations between facts and feelings. Feelings offer critical information. 
One of the aspects of participation programs can be the lack of understanding of which decision is going to be made by whom at what time. It is therefore a good idea to identify clearly those decisions that need to be made. A prerequisite to good participation is that an agency or professionals understand which decisions are going to be made by whom and in what fashion, and then to communicate this to stakeholders.

- It is important to look at the range of values represented, not just at the number of people. Too frequently the design of a participation process degenerates into a numbers game. The key is to identify the basic values at stake, to understand the conflicts that have emerged, and to find technical alternatives to problems.

\section{FURTHER INFORMATION}

Bleaker, Hanns and Annemarie. 1990. Citizen Participation Handbook for Public Officials and Other Professionals Serving the Public. 6th ed. Library of Congress \#88-082713. Washington, D.C.: GPO.

British Columbia Ministry of Forests, Information Branch. 1981. Public Involvement Handbook. Ottowa: Environment Canada.

Canada. Federal Environmental Assessment Review Office. 1988. Manual on Public Involvement in Environmental Assessment: Planning and Implementing Public Involvement Programs. Ottowa.

Connor, Desmond M. 1981. Constructive Citizen Participation. Victoria, British Columbia: Development Press.

Creighton, James L. 1981. The Public Involvement Manual. Cambridge, Mass.: ABT Books.

Creighton, James L. 1983. Public Participation Manual. Washington, D.C.: The Edison Electric Institute.

Creighton, James L., Jerome Delli Priscoli, and C. Mark Dunning. 1983. Public Involvement Techniques: A Reader of Ten Years' Experience at the Institute for Water Resources. Ft. Belvoir, Virginia: U.S. Department of the Army, Corps of Engineers, Institute for Water Resources.

Creighton, James L., C. Mark Dunning, and J. Delli Priscoli, eds. 1992. Public Involvement and Dispute Resolution: The Second Decade. Ft. Belvoir, Virginia. U.S. Department of the Army, Corps of Engineers, Institute for Water Resources.

Delli Priscoli, Jerome, and Christopher Moore. 1986. Executive Seminar in Alternative Dispute Resolution (ADR) Procedures. Ft. Belvoir, Virginia: U.S. Department of the Army, Corps of Engineers, Institute for Water Resources.

Fazio, J. R., and D. L. Gilbert. 1988. Public Relations for Natural Resource Managers. Bethesda, Maryland: Society of American Foresters. 
Institute for Participatory Management and Planning (IPMP). 1989. Citizen Participation Handbook. Monterey, California.

International Association of Public Participation Practitioners (IAP ${ }^{3}$ ) 555 Bryant St. Suite 712, Palo Alto California.

Lyra, Srinivasan. 1990. Tools for Community Participation: A Manual for Trainers in Participatory Techniques. PROWESS/UNDP Technical Series. New York: UNDP.

Toth Nagy, Magdolna and others, eds. 1994. Manual on Public Participation in Environmental Decisionmaking: Current Practice and Future Possibilities in Central and Eastern Europe. Budapest: Regional Environmental Center.

U.S. Department of the Agriculture, Forest Service, and U.S. Department of the Interior, Bureau of Land Management. 1981. Public Participation Handbook. 3 vols. Washington, D.C.:GPO. 
4.1 A water resources information system plays an important role in estimating the quantity and quality of water available as well as the current and prospective water use and demand patterns. Each country or drainage basin has its own hydrological and economic characteristics. Strategy should be tailored to meet specific national or basin characteristics and development priorities. There are issues common to all countries, however; it is therefore useful to present ways of approaching common issues in water resources information systems and how to address certain matters in order to develop a water resources management strategy. The goal of this chapter is to assist developing countries in preparing an assessment of their information system in order both to develop a water resources management strategy and to design or improve a system.

4.2 The information system covers not only the collection and analysis of data but how it is disseminated. Water strategy formulation should include an examination not only of which data is available, but how it is collected, analyzed, and shared. Information is an issue in many of the aspects of comprehensive water resources management, particularly institutional, international, and economic areas.

\section{JUSTIFICATION AND RATIONALE}

4.3 A clear need to allocate water more efficiently to meet specific national objectives elevates the importance of information systems for water resources. The need to modernize an information system normally arises at a stage in the development of water resources when some of the following characteristics manifest themselves: (a) there is an increasing scarcity of water, resulting in unacceptable competition and conflict, (b) riparian rights are becoming a major issue, (c) costs of developing new water supplies are rising (there are diminishing returns from water control by storage, and rising opportunity costs of storing, diverting, or transferring water), (d) the economic values of stream flows are increasing, (e) national budget deficits are high, (f) environmental and health concerns are increasing, (g) floods and droughts are prevalent, (h) an unstable climate puts sustainable economic development at risk.

4.4 When the efficient allocation of water depends on the analysis of more information than the government has, there is an acute need to evaluate and improve the water resources information systems. Uninformed or inadequate decisionmaking will eventually paralyze both the public and private sectors as different economic sectors or different countries compete fiercely for water. In such circumstances, economic development cannot be sustained. In addition to helping form a strategy to manage water, information technology with its "decision-aiding systems" can assist the efficient management and allocation of water in rapidly changing supply and demand conditions.

4.5 Decisionmakers will be able to form better sustainable water resources management strategies if they are provided with credible historical information on water resources. Implementing strategies will depend on timely information for day-to-day management decisions. Water information, blended interactively with information from other areas (for example, the environment, health, industry, energy generation, agriculture, urban) will help build consensus among all those areas. 


\section{ELEMENTS OF AN ASSESSMENT OF A WATER RESOURCES MANAGEMENT INFORMATION SYSTEM}

4.6 In order to develop a water resources management strategy, the ultimate requirements for an information system as well as many other elements of the system should be examined. The six main physical components of an information system are: (a) a data collection system, (b) a data transmission system, (c) data storage, analysis, and transformation into "user-friendly" information, (d) an information transmission system, (e) an information dissemination system, and (f) an interactive system to aid decisionmaking. The areas that should be addressed together with questions that should be asked in each area are listed below. Some of these questions pertain to a water resources assessment, others to evaluating options and recommending a strategy.

4.7 Types of Information. What are the information requirements for water resources management?

4.8 Information Technology. What information technology is available for water resources management? What are its present and future roles? What are the advantages and disadvantages of information technology? What are present patterns of ownership of information technology?

4.9 Information Demand. Aside from water resources managers, who else needs information (for example, policymakers, researchers, educators, private enterprise, water resources stakeholders)? What kind of information is most urgent, and how can information technology help?

4.10 Information Supply. Where is information generated or selected? Who owns the channels of information? What does that mean for the content? Could user groups set the agenda for information generation and transfer? Who controls the development and availability of interactive information technology?

4.11 Systemic Approach to Information. What could be the role of information technology in providing water-related information to managers, users, and policymakers?

4.12 Costs of Information Transfer. Who pays for the information? How does that differ from payment for the information carrier (for example, radio, telephone, or television)? What are typical public good aspects of information (such as water quality), and what are private aspects (such as water rights)? What does that mean for information technology? Is information technology cheaper than direct contact, and can it achieve the same results?

4.13 The questions asked above can be used to create terms of reference for the improvement of an information system. Based on these questions, an example of terms of reference that could be used as a guide for the design of an information system specific to water resources management is presented in the next section.

4.14 Those undertaking an information system assessment should interview representatives of the government ministries responsible for water resources development and management, representatives of the ministry of health, the director of the national hydrological service, and representatives of the water resources stakeholders, such as the power generation authorities, irrigation farmers, industries, fishermen, poor neighborhoods, water supply companies, and navigation companies. In addition, other interests such as health care and social workers and conservationists should be interviewed. 
4.15 The role of hydrological and meteorologic services is to assess the quantity, quality, and availability of water and to make the data on these issues available. Tables $4.1,4.2$, and 4.3 suggest some of the key areas where hydrological data are needed. In many cases, individual country circumstances will determine how important each item of data is; the tables have been intentionally left blank so that those undertaking the assessment can rank data in terms of importance (for example, vital, important, useful, or not necessary). In addition to traditional uses, hydrological data are becoming vital in areas such as preserving ecosystems, maintaining the aquatic environment, preventing both deforestation and soil erosion, maintaining or improving public health, controlling pollution, maintaining or improving recreation and tourism, and predicting the climate.

4.16 Because many decisionmakers (and the general public) are normally unaware of the economic value of water and the vital role it plays in the development process, it is not likely that water resource data is adequately assessed and used in decisionmaking at any level of the community. Since an information system is about the management of data in all its forms, those responsible for information system assessment might recommend that the sources of both water supply and demand data be improved. This means working with the institutions responsible for generating this data, usually the national hydrological and meteorologic services, and the water users, companies, and associations.

\section{AN EXAMPLE OF TERMS OF REFERENCE FOR THE DESIGN OF WATER RESOURCES INFORMATION SYSTEM}

4.17 Since addressing the information system is an important part of formulating a strategy, many of the elements below are included in the terms of reference presented in the annex of this guide. The following terms of reference for the design of an information system go a step further than formulating strategy, however, and address the design of an information system. The design of an information system is most likely to occur after a national or international strategy is in place, but the kinds of information available and needed should be examined during strategy formulation.

4.18 Although this example refers to a "consultant," those undertaking an assessment or developing a water resources information system may actually be a group of people. The aim of building local capacity to assess water resources and formulate strategy should be kept in mind. Again, parts of the terms of reference will be associated with a water resources assessment, parts with recommending a strategy, and parts with the design and implementation of an actual system.

\section{Overview of Work}

4.19 The consultant will study the present and future role of information technology in water resources development and management. The areas of investigation and system components will be based on a desk study and interviews with water resource development and management specialists, information technology specialists, environmentalists, and public, private, and non-government institutions. 


\section{Areas of Investigation}

4.20 The following paragraphs present general comments on each area of investigation, and possible elements of the physical management information system to be considered.

4.21 Types of Information. Water managers require information on supply and demand as well as financial, legal, and technological information. Other information may also be necessary.

4.22 Information Technology. This should be a list of available information technology systems and equipment that has been specifically designed for (or can be easily adapted to) water management.

4.23 Information Demand. Since almost all socio-economic and environmental activities have a demand for water, the potential demand for water-related information is enormous. The first step is to determine which information is most urgent. The water suppliers will also request the same information for management purposes; in addition they will demand information about sources of natural water supply, both surface and subterranean.

4.24 Information Supply. Some of the same sources that demand water-related information will be able to supply water-related information. Again, the priority of this information must be determined.

4.25 Systemic Approach to Information. What should be the role of information technology in the development and management of water resources? Should it support (a) decisionmaking at all levels of the community, (b) education of the general public about the role of water in their day-to-day lives and activities, (c) monitoring water law compliance, (d) water-related research, (e) disaster management, (f) institutional capacity-building, within the water sector and other sectors, and public and private institutions in general? Are there other roles for information technology?

4.26 Costs of Information Transfer. Is the application of water information management technology cost effective in terms of the overall benefits to the community? Is there another way of managing this information that would be more appropriate?

4.27 Physical Components. Examples of each of the system components that might be included are: (a) data collection systems (sensors, data collection platforms, meters (b) data transmission systems: (radio, meteorburst, satellite), (c) data storage, analysis, and transformation systems, (d) information transmission systems (radio, satellite, cable), (e) information dissemination systems (local area networks, e-mail), and (f) interactive systems to aid decisionmaking (expert systems, computer simulation software).

\section{Report Outline}

4.28 The report to be prepared by the consultant should first describe the present information management system, the present use of information technology, and state-of-the-art information technology. It should explain the present and potential use of information technology for water resources development and management, including the positive and negative aspects of responsiveness, flexibility, relevance, situation specificity, participation, and accountability. It should predict changes in the use of information technology (covering the aspects of both information and technology) that could further enhance or detract from information management systems for water resources. Analysis should include: 
- The ability of the present information management system to meet both the short- and long-term development objectives, including the legal, technical, economic, institutional, and policy framework within which the system operates (this should include analysis of strengths and weaknesses of the present information management system)

- The strengths and weaknesses of greater use of information technology within the same framework mentioned above

- Possible changes to the framework that would enhance overall performance of the information system, with and without greater use of technology

- Institutional capacity-building required to obtain improved performance of the information system, with and without a greater application of information technology.

4.29 In view of local conditions, the report should asses the relevance of information technology for the country or for the specific hydrological basin. This should include reviewing the possibilities of cost reduction for information transfer, the systemic nature of information demand, and the role of information technology in international competitiveness.

4.30 A key part of the report should be estimates of cost and of cost-sharing possibilities for information technology, together with indications of the robustness of the equipment. The latter should cover how well the equipment can be used in harsh environments and by untrained people.

4.31 Finally, the report should draft terms of reference for the design of an information system for water resource development and management using information technology.

\section{LIKELY RECOMMENDATIONS}

4.32 There are eight recommendations for improving the water resources information system that are common to many assessments. They are:

4.33 Network Rehabilitation. This includes repairing and upgrading hydrometeorologic networks for measuring many factors (for example, water quantity and quality, rainfall, evaporation, humidity, air temperature, and wind) through the installation of basic equipment. Network rehabilitation often involves improving the operation and maintenance of equipment and establishing telemetric systems if necessary. Studies often propose that the authorities consolidate and rationalize the existing hydrometeorologic network rather than expand it.

4.34 Institutional and Human Resources Development. Carefully tailored training programs should emphasize in-service training, using the agency's own facilities to the extent possible. They should help the national hydrometeorologic agencies to become ultimately self-sufficient. The training programs should aim to broaden the scope of courses, with particular emphasis on practical training. It may be appropriate to provide this kind of training by expanding the activities of established training centers within existing academic or training institutions. Many hydrometeorologic agencies need to change attitudes regarding management. In many countries, for example, two or more agencies run hydrometeorologic networks in parallel, with minimal coordination of efforts and reluctant exchange of data. The issue is not who operates the stations. It is vital that one agency be responsible for handling 
the data and that all field data be sent to the concerned office to minimize delays in data processing. Perhaps there is a need to re-organize the hydrometeorologic services and their financing to generate incentives and to offer better careers. Many hydrometeorologic agencies are part of government departments, subordinate to various ministries. Governments may wish to examine institutional arrangements to make agencies more dynamic and product-oriented, in order to enable them to serve the needs of water resource planners and managers in both the private and public sectors. The human resources needs of an information system will also probably merit significant mention (see chapter 2 ).

4.35 Improving Transportation Conditions. Transportation is an important element of water resources information systems, including hydrometeorologic services. Field visits are needed to take measurements and to detect and repair malfunctioning equipment. Often, field agents need new vehicles or a reliable source of spare parts. Hiring or renting transportation during peak demand, or otherwise involving the private sector in providing transportation, can be explored.

4.36 Improving Data Processing. More effective monitoring of water resources can be achieved by computerized data management and processing. Hardware support is a problem in many parts of the world, however, because the selection of hardware is often determined by donors, who do not always take the compatibility of existing equipment or the availability of repair facilities into account. User-friendly data processing and effective dissemination of hydrological information are often both needed. More attention should be paid to improving equipment compatibility, increasing the use of automatic monitoring systems, and installing information technology that can analyze data to provide specific user-friendly information needed for planning, management, and operational decisionmaking.

4.37 Establishing a Hydrological Cycle Observing System (HYCOS). There is a growing need in many countries to collect and process data in a cost-effective and sustainable manner for a reliable data base. This means blending and reinforcing the conventional systems with modern technology and equipment, which would offer greater coverage on a regional and sub-regional basis than most current systems. Regional organizations can play an important role in achieving agreements between countries on joint activities in a region or river basin. A HYCOS system using telemetry and satellite communication would transmit hydrometeorologic and environmental data from automatic data collection platforms. The data would be collected, transmitted, stored, processed, and disseminated by the hydrometeorologic services daily via an information system linked to decisionmakers in both the public and private sectors. The decisionmakers could transform data into information of knowledge that has a high economic value; this is the science of hydroinformatics. The HYCOS system would complement conventional hydrometeorologic networks, but involve data less subject to manual input or manipulation, thus offering additional reliability. Such a system would also strengthen the institutional capacity of local hydrological services. It would establish real-time monitoring of water resources through telemetry. It would encourage regional and international collaboration among governments, organizations, and donors, particularly where international river basins are involved. It would promote the exchange of hydrological and environmental information between nations and regions. Since many rivers and lakes are shared by more than one region or country, sharing information is crucial to the optimal development and management of water resources. Eventually, HYCOS could be linked to other continents to form a global hydrological network.

4.38 Water Users, Companies, and Associations. Water users, companies, and associations should keep detailed accounts of the water they receive, treat, and distribute. This entails metering all customers, including government agencies, and maintaining a financial accounting system. All of this 
information will be vital in order to improve demand management, efficiency analysis, and general overall performance of the water distribution system to all sectors.

\section{THE EFFECT OF TECHNOLOGY ON INSTITUTIONS}

4.39 Innovation in information technology has presented a challenge to all institutions, including the hydrometeorologic services. New technologies have given information a much greater role in economic development, especially in water resources and environmental management. New technologies have brought change because of the speed and scale of information processing and dissemination, the new markets for data applications, the costs and revenues of data collection, and the economic value of water resources information. More important, technologies are changing the way people think, manage, and use information to design, monitor, evaluate, and manage water resources on a day-to day basis.

4.40 To successfully form and implement a strategy for water resources management, cooperation with other sectors is crucial. As technologies improve, information availability and use will also require improved organization and management. Human resources and administrative support must be good enough to overcome what typically exists: inadequate coordination between suppliers and users, insufficient technical competence of users, and inappropriate analytical frameworks or models used in some analysis. As technologies advance, organizational structures may change. At their best, changes should engender more dynamic and effective data collection and wider information dissemination. Change may not be immediate, but its direction should be clear to decisionmakers.

\section{FURTHER INFORMATION}

WMO. 1992. Hydrological Data for Whter Resources Management. Geneva. 
Table 4.1. Need for Selected Meteorologic and Climatologic Data for Water Resources Management

\begin{tabular}{|c|c|c|c|c|c|c|c|}
\hline Management Area & $\begin{array}{l}\text { Sunshine/ } \\
\text { Radiation }\end{array}$ & Wind & $\begin{array}{r}\text { Air } \\
\text { Temperature }\end{array}$ & Humidity & Evaporation & $\begin{array}{r}\text { Storm } \\
\text { Rain }\end{array}$ & $\begin{array}{r}\text { Daily } \\
\text { Rainfall }\end{array}$ \\
\hline
\end{tabular}

\section{Hydropower}

Reservoir

Irrigation

Surface water

Groundwater

Drainage

Surface

an Subsurface

Floodplain zoning

Flood

Control

Protection

Warning

Potable water

Surface

Ground

Industrial water supply

Fishery

Navigation

Pollution control

Salinity control

Catchment management

Note: This table is intentionally left blank; the strategy team may wish to rank information needs for each management area 
Table 4.2 Need for Selected Hydrometric Data for Water Resources Management

\begin{tabular}{|c|c|c|c|c|c|c|c|c|}
\hline \multirow{2}{*}{ Management Area } & \multicolumn{4}{|c|}{ Lake Data } & \multirow[b]{2}{*}{$\begin{array}{l}\text { Flow } \\
\text { Level }\end{array}$} & \multicolumn{3}{|c|}{ River Data } \\
\hline & $\begin{array}{l}\text { Lake } \\
\text { Level }\end{array}$ & $\begin{array}{l}\text { Water } \\
\text { Quality }\end{array}$ & $\begin{array}{l}\text { Water } \\
\text { Temp. }\end{array}$ & $\begin{array}{r}\text { Surface } \\
\text { Evap. }\end{array}$ & & $\begin{array}{r}\text { Water } \\
\text { Quality }\end{array}$ & $\begin{array}{r}\text { Flow } \\
\text { Discharge }\end{array}$ & $\begin{array}{r}\text { River } \\
\text { Sediment }\end{array}$ \\
\hline
\end{tabular}

Hydropower

Reservoir

Irrigation

Surface water

Groundwater

Drainage

Surface

Subsurface

Floodplain zoning

Flood

Control

Protection

Warning

Potable water

Surface

Ground

Industrial water supply

Fishery

Navigation

Pollution control

Salinity control

Catchment management

Note: This table is intentionally left blank; the strategy team may wish to rank information needs for each management area 
Table 4.3. Need for Selected Groundwater Data for Water Resources Management

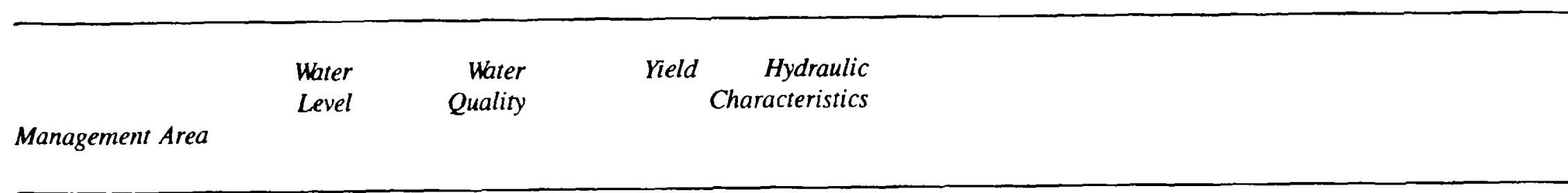

\section{Hydropower}

Reservoir

Irrigation

Surface water

Groundwater

Drainage

Un Surface

Subsurface

Floodplain zoning

Flood

Control

Protection

Warning

Potable water

Surface

Ground

Industrial water supply

Fishery

Navigation

Pollution control

Salinity control

Catchment management

Note: This table is intentionally left blank; the strategy team may wish to rank information needs for each management area 


\section{CHAPTER 5 THE ROLE OF ECONOMICS}

5.1 Although many countries have long recognized the importance of securing a reliable water supply, only recently have they recognized water as an important economic good that must be carefully managed in terms of both quantity and quality. In most countries water has an economic value that varies over time and among uses. In general, competition for water among various uses has increased and its value has risen. Economic concerns have become increasingly important in water resources management.

5.2 Economics will play an increasingly important role in water resources decisions because (a) economic efficiency is a key development objective for most countries, (b) opportunity costs ${ }^{12}$ will need to guide future water allocation decisions, (c) price and other economic incentives will be required to increase water conservation and efficiency, (d) investment decisions will require economic analysis, (e) as water becomes more scarce, investments in water resources development will become more costly (which means that capital resources will be a key constraint to future water resources development). Also, water can be seen as a key production factor, the availability of which can govern many aspects of planning (Falkenmark 1994).

5.3 In establishing their water resources management strategy, countries must assess the economic value of water resources. The role of water pricing and economic incentives for efficient water use will be critical in guiding water use and allocation decisions. Not enough attention has been paid to this issue in the past. Economic analysis will offer important guidance in choosing among various water resources investment and management options. Here both the costs and benefits of alternative courses of action should be assessed where possible. Finally, project financing and cost recovery will constrain future water resources development. Project financial requirements and sustainability concerns suggest that greater emphasis will be needed on private sources of capital and strategies to increase cost recovery.

5.4 This chapter examines the major economic concepts in the valuation of water and in methods to evaluate water strategies, costs, and investments. In formulating a water resources strategy, countries should try to establish economic values for water, however broad. This will require gathering information mentioned later. Economic analysis of possible courses of action will depend on establishing this value.

\section{APPLYING ECONOMIC CONCEPTS IN STRATEGY FORMULATION}

5.5 During phase 1 of strategy formulation (essentially a diagnostic inventory or assessment of water resources), the strategy team should undertake several tasks related to economic analysis that will be essential for developing and evaluating options in phase 2 . The concepts behind some of these tasks are described in succeeding sections of this chapter. The activities include:

- Data Availability. Assess existing sources of economic data and the country's capability of collecting and maintaining a data base of key economic information, for example, commodity prices, labor costs, and input prices. In addition,

\footnotetext{
${ }^{12}$ Opportunity cost is the value of goods or services (including environmental services) foregone by using a scarce resource for one purpose instead of for its next best use.
} 
existing information on water response functions for key agricultural and industrial products should be assessed along with domestic water use rates.

- Demand Projections. Review and evaluate projections of water demands by various sectors as well as evaluating the country's ability to continue making such projections (an institutional issue).

- Water Allocation. Assess the economic efficiency of existing policies and procedures used for allocating water resources within and between sectors and country capabilities in implementing appropriate water allocation procedures.

- Analytical Methods. Review and evaluate the analytical methods used to assess water resource issues and investments and the possibility of using new or different methods. Assess the country's ability to evaluate alternative combinations of supply and demand measures including both single and multipurpose options.

- Pricing and Cost-Recovery Policies. Review and evaluate water pricing and cost recovery policies and the record in water fee collections.

5.6 The ability to perform demand projections will be crucial in generating scenarios and evaluating the effects of different choices in phase 2 . Existing projections of water demand might be inadequate; it may be necessary for the water strategy team to make new projections based on population growth, urban development, agricultural policies (for example, if existing policy calls for crop diversification, what effect will that have on water demand?), water quality considerations, and supplying enough water for the preservation and protection of ecosystems.

5.7 One of the important options that should be considered in phase 2 is implementing a water pricing and cost recovery program that at least covers the operation and maintenance costs of water, and that (if possible) reflects the opportunity cost of water.

\section{Characteristics of Water}

5.8 Water is characterized by several features that affect the way it is handled by markets and governments, and that limit the ability of countries to relay on the automatic reaction of market forces to determine prices. Some of the major features relate to whether water should be treated as a public or a private good for pricing and regulatory purposes and whether existing market prices can fully reflect all aspects of using water. These features are summarized below. ${ }^{13}$

5.9 Water's mobility has made it difficult to establish enduring and secure water rights that are necessary for efficient market transactions. In addition, the bulky nature of water generally makes it expensive to move significant quantities upstream or outside many river basins. This expense has inhibited the development of national water markets, except for bottled water.

\footnotetext{
${ }^{13}$ This section is an excerpl from World Bank $1993 \mathrm{pp} .81-92$. For a more detailed discussion of these aspects, including concepts such as subtractibility and excludibility, see this reference and see Kessides 1993.
} 
5.10 Many water investments involve large capital investments with long periods before payoff. Many cite this as the reason for a distinct lack of private investors (especially in developing countries). Another reason for this dearth of private investment could be that governments historically have controlled water resources development in order to further policy aims such as agrarian reform or populating certain regions. Regardless of the reason, water supply and irrigation projects typically exhibit increasing returns to scale and therefore are prone to natural monopolies. Consequently, without government intervention, there will be underinvestment in water supply and monopoly pricing. Furthermore, many water resources and water resource investments produce joint products, such as recreation, electric power, and irrigation, which complicates water pricing and allocation decisions.

5.11 Inadequate information concerning water supply and demand, which can vary widely within and between years, as well as poor information concerning who actually receives water and how much is used has, in many cases, made it difficult to effectively manage and price water.

5.12 In some of its uses, water is a public good, where one person's use does not decrease nor subtract from its value to others who use the same good, for example water used for fishing and navigation. As long as they are not damaged or congested, public goods are not consumed (in the traditional sense) when used; they can continue to provide the same benefits to everyone. Moreover, as long as there is no cost to society for the added use or subtraction from benefits to other consumers (the marginal cost of serving another user is zero), increased use of water adds to total economic welfare.

5.13 Because water activities have many physical interactions within the ecosystem and with other economic activities, they are often characterized by externalities; the benefits and costs of production and consumption affect individuals or entities other than those involved in a transaction. Related to the issue of externalities is the limited amount of information available to consumers of water and to consumers and producers of water-related services. The complexities of the ecosystem, the variability of the water supply and the intricacies of the hydrological cycle make it difficult for those transacting with water to consider all aspects; consequently, market prices do not necessarily reflect all these interrelations.

5.14 Unregulated market systems may generate outcomes that do not satisfy environmental concerns or a country's social goals in terms of poverty alleviation, food security, income distribution, and public health. In cases where water resources are transnational or involve transnational environmental effects, water allocation decisions are necessarily made by transactions among governments.

\section{Economic Efficiency and the Value of Water}

5.15 Economic efficiency is an important development objective in most countries. Everything else equal, countries would like to produce the desired goods and services with the minimum amount of resources. In fact, it is the ability to produce more with fewer (or the same amount of) resources that helps create economic development and gives a country a comparative advantage in producing certain goods and services. For water, this means that economic incentives are needed to encourage efficient allocation of the resource to those uses that provide the greatest socio-economic benefits for society.

5.16 Water values vary widely among different uses as well as within uses. For example, Gibbons (1986) estimated the direct economic value of 1,000 cubic meters of water in Tucson, Arizona, in the summer to be $\$ 302$, while the same amount of water used for navigation on the lower Mississippi River had a value of $\$ 3$. Within uses, she estimated that 1,000 cubic meters of water used to irrigate land 
producing wheat in the Salt River Irrigation project in Arizona had a value of about $\$ 33$; if that water were used to irrigate land for growing carrots, it would have a value of $\$ 261$. Sometimes this is due to the differences in conveyance costs or the costs of transacting a sale or exchange while in other cases differences exist because water is generally not sold or traded like other goods especially among sectors. Most trades or sales of water occur within the agricultural sector, usually among farmers in the same village or irrigation system. In a number of situations water use is determined by its first legally recorded use (prior appropriation doctrine), and its allocation may be difficult to change over time in response to the changing economic and social conditions, unless provisions are made to facilitate water trades. In other cases water is allocated by government administrative decisions; in still others no one is given a secure and sustainable allocation of water. Where water rights are uncertain or where existing allocation mechanisms cause a misallocation of water resources, higher socio-economic benefits could be obtained through the development of new institutional arrangements that allow a reallocation of water based on its economic value in different uses. This is particularly important among sectors where differences in the economic value of water may be substantial, as in the example above.

\section{Opportunity Cost and Pricing}

5.17 The task of valuing water is particularly complex owing to the limited ability of countries to rely on the automatic reaction of market forces to determine prices (see above section on the characteristics of water).

5.18 Since competitive water markets are generally localized, water allocation especially amorig regions and sectors could be improved by using an estimated economic value of water to guide water allocation decisions and to set administrative price levels for water. In those cases where localized water markets exist, there is a ready basis for valuing water when pollution or return flow externalities are not important. When water markets do not exist or significant externalities are present, other valuation techniques must be used. Near many major urban areas, the opportunity cost of water used for irrigation is its value for domestic or industrial consumption. Water users should be required to pay the opportunity cost of water, especially where water is scarce and water use is critical. This provides them with a clear economic incentive to use water efficiently. The opportunity cost of water could be used as an economic signal to improve water allocation decisions and encourage water conservation.

5.19 Where there is a concern about providing water to the poor at a low cost, block or graduated prices can be used. A low charge is set for the volume or block of water that is needed to meet a minimum basic health requirement. For the next volume or block of water, a much higher price is charged. Also, different prices can be charged for office and industrial uses that do not provide society with the same health benefits as does clean water used in the household. In this way, the poor can be cross-subsidized by industry.

5.20 When it is not possible to charge users a price based on the economic value per unit of water consumed, then quantity restrictions can be used to improve water allocation and use. Although quantity restrictions are less efficient allocation methods than water prices per volume of water used, they do create a shadow price or implicit price for water. The implicit price forces consumers to use water more efficiently than if there were no restrictions on quantity. An economic incentive or implicit price is created by the fact that consumers would like to have more water than they receive at the existing charges. 


\section{Other Economic Incentives}

5.21 Economic incentives may also be needed to achieve the desired level of pumping and conservation of groundwater when the rights to groundwater stocks are not well defined. Where there is overexploitation of groundwater resources, fuel taxes or pumping quotas can be used to achieve the desired level of extraction. The fuel tax should be raised sufficiently so that the cost of pumping equals the opportunity cost of water.

5.22 Government may want to use economic incentives to encourage the adoption of water-saving and reuse technology and the use of water-saving crops. This can be done by direct subsidies, tax credits for the purchase of certain technology, or credit subsidies to purchase water-saving technologies. The amount of subsidies or tax credits should not exceed the economic value of the water saved. Subsidies and tax credits could also be used to promote private sector research and development for new watersaving technologies. In addition, water pricing based on opportunity costs will encourage water users to adopt water-saving technology.

\section{Economic Analysis of Alternative Courses of Action and Investments}

5.23 Economic analysis of alternative courses of action is important for economically efficient decisions (Easter and others 1991). It is critical that decisionmakers have the facts concerning their possible courses of action. They should know the costs and benefits of other strategies or investments before the decision is made. This does not mean that the decision should be made only on the basis of economics (Hufschmidt and others 1983). Other social and environmental objectives should be considered when appropriate. While in many cases, not all costs and benefits can be measured effectively, decisionmakers should have an idea of what it will cost society if they decide to build a hydropower project or allocate water to irrigation instead of industry.

5.24 Two types of economic analysis are commonly used to evaluate strategies or investments. First and most complete is "benefit/cost" analysis where the discounted costs and benefits of investments are compared to determine which is the most likely to achieve the highest rate of return. If the project is not large relative to a country's economy and it doesn't create nonmeasurable costs and benefits then benefit/cost analysis provides a good basis for economic decisions. However, the measurement problems in this form of analysis can be severe, particularly for environmental and health effects, and may force decisionmakers to use other evaluation techniques (Dixon and Hufschmidt 1986).

5.25 The second method is "cost effectiveness" analysis, which ascertains the least cost method of achieving predetermined objectives or targets. It does not provide an economic rate of return or any information concerning benefits, but cost effectiveness analysis identifies the lowest cost method of meeting the objective or target. It is less time-consuming and not as expensive to estimate the least cost solution compared with conducting a full benefit/cost analysis. Furthermore, this type of analysis provides a good cost-based decision rule if the decision has already been made that something should be done. Providing a sewer or water supply system for a given area or group of people is a good example. Cost-effective analysis would be used to determine what type of system to build. Yet in some cases even the least-cost method may be too expensive to justify construction. 


\section{The Economic Value of Water}

5.26 For benefit/cost analysis one of the key variables that must be measured is the value of water or the benefits from using water since it is both an input into production and a good directly consumed. Estimating the value of water is not easy because its value varies with quality, use, location, and time. During dry periods of the year or during drought years, water values will be much higher than in other periods. Moreover, certain seasons or times of the year may also be important (high water values) because of critical water demands for crop growth, heating, cooling, industrial production, or shipping.

5.27 One means to determine the value of water is to use competitive market prices where they exist, such as prices set by sales of well water for irrigation or by water vendors in urban areas. However, since such market prices are generally not available except in certain localized markets, other procedures have to be used to estimate water values. One direct procedure is to use the marginal cost of pumping water from an open access aquifer. This only works under competitive water supply conditions where users pump to the point where their marginal value of water equals marginal pumping costs (Easter and Waelti 1980). Under these conditions the marginal cost of pumping can be a proxy for the marginal value of water.

5.28 The value of water to domestic consumers can be estimated based on willingness-to-pay surveys of potential water users that are aggregated to measure the demand (Altaf and others 1992; Whittington and others 1992). The problem is to construct a survey that elicits actual consumer willingness to pay. Demand estimates based on willingness to pay can also be made from observations concerning what people pay for domestic water supplies including the time cost involved in collecting the water. A recent World Bank study of rural water demands in seven developing countries found a larger than expected willingness to pay for private water connections to the house or yard (World Bank 1992).

5.29 For irrigation projects the residual return to the crops grown (gross returns minus all costs ${ }^{14}$ other than water costs) provides an estimate of the maximum farmers can pay for the water. This is an upper bound for the value of water used in producing the crops in question and can be used as an estimate of the value of water when it is the limiting resource. When the data are available direct estimates can also be made of the value marginal products of water in different uses. By varying the quantity of water applied while holding other inputs constant, a schedule of input/output relationships (marginal products) can be obtained. These marginal products when multiplied by the product price provide an estimate of the derived demand schedule for water. Which procedure or combination of procedures should be used will depend a great deal on the data and time available for the analysis.

\section{Cost Estimate}

5.30 The other important side of analysis and the key part of cost effectiveness analysis is the estimation of costs. For any decision regarding water use and allocation, costs must be estimated. For water strategies or investments, decisionmakers need to have information concerning the costs (including environmental costs) of alternatives. Without this information the decisionmaker cannot determine what the economic implications are of different choices. Decisionmakers should also know what costs will be imposed on areas or users that do not receive the water. For example, what is the cost to society of

\footnotetext{
${ }^{14}$ Costs include enough profit to keep farmers in business.
} 
allowing agriculture to use a stock of groundwater that a city would like to have available for domestic consumption in the next ten to twenty years? This is a good illustration of why it is important to have information concerning the opportunity cost of water.

\section{COST RECOVERY}

5.31 Another important aspect of the economics of water resource strategies involves the financing of water investments and practices. With the rising costs of water investments and the increased competition for public funds, greater attention will be needed concerning just how investments are to be financed and sustained with adequate funding for O\&M. This is particularly true for drainage and sanitation facilities that have been neglected in the past and that will have to be emphasized in future water investments. Questions of cost recovery will become increasingly important as a source of funds to sustain projects. Aside from finding funds to improve the system, innovative ways must be found to break the old cycle of poor service, low willingness to pay user fees and inadequate funds for O\&M. Current strategies to break this cycle involve turning over the O\&M (in some cases ownership) of water projects to financially autonomous entities, either public or private, and to water user groups. For example, through increased user participation and ownership of water facilities, the Philippines increased cost recovery to an average of 75 percent of O\&M. Water users are generally in a better position to monitor and use social pressure to collect water fees from association members. They know what crops their neighbors have grown and who obtains water. This information can help reduce the cost of monitoring and enforcing water fee collections if water users have the authority and responsibility for collections.

5.32 Before cost-recovery levels can be established for multipurpose projects, joint costs (costs of infrastructure that serve more than one purpose) must be allocated to the different purposes (for example flood control, irrigation, or hydropower). How the joint costs are allocated will have a major effect on how much must be recovered from each aspect of a project. In the United States, for example, there is always substantial political pressure on the U.S. government to allocate most of the joint costs to "nonreimbursable costs" (which are paid by the federal government) so that water charges to users are kept low. Unfortunately, economic theory has little to say about cost allocation. This means that joint costs are allocated by rather arbitrary procedures such as the separable cost-remaining benefits method or the allocation of costs in inverse proportion to the elasticity of demand for outputs of the various purposes.

5.33 Cost recovery will also depend on a country's overall pricing policy. If a country pursues a cheap food policy and keeps agricultural product prices well below world market prices it will be difficult to expect farmers to pay the full cost of water projects. Furthermore, if a project was built to serve other country objectives (food security or national defense) and is at best only marginally profitable for users, farmers cannot be expected to pay the full cost of irrigation. In contrast, when agricultural prices are high, and the system profitable, then cost-recovery is much easier as seen by the case of Korea where cost recovery reached 93 percent of the $\$ 210$ per ha cost of O\&M in 1983 (Small and Carruthers 1991).

5.34 In addition to the problems associated with cost recovery, during the next decade the financial requirements for water resource investments will probably be beyond the capabilities of many developing countries and additional sources of capital will be necessary (World Bank 1993). The mix between private and public capital will need to change; the share of investment from the private sector will need to increase sharply. The move toward greater reliance on financially autonomous entities, private firms, and water user organizations should help to open up new sources of private capital. Some of the 
autonomous entities and holders of operator contracts, once they prove to be financially viable, will be able to borrow through local and international capital markets. The availability of private capital will depend to an important extent on the general level of local capital market development. Moreover, water users' associations should be able to obtain some investment funds from their members (in addition to achieving higher levels of cost recovery than government agencies). Thus, a mix of user charges, beneficiary taxes, central government transfers (grants and loans), and municipal and utility bonds will be required to meet future investment demands.

\section{REFERENCES}

Altaf, Mir Anjum, Haroon Jamal, and Dale Whittington. 1992. Willingness to Pay for Water in Rural Punjab, Pakistan. UNDP-World Bank Water and Sanitation Program, Water and Sanitation Report 4. Washington, D.C.: The World Bank.

Dixon, John A., and Maynard M. Hufschmidt. 1986. Economic Valuation Techniques for the Environment, A Case Study Wbrkbook. Baltimore: The John Hopkins University Press.

Easter, K. William. 1993. "Economic Failure Plagues Developing Countries: An Assurance Problem." Water Resources Research 29:7, pp. 1913-22.

Easter, K. William, and John J. Waelti. 1980. The Applications of Project Analysis to Natural Resources Decision. Bulletin no. 103, the Water Resources Center, University of Minnesota, Minneapolis.

Easter, K. William, J. A. Dixon, and M. M. Hufschmidt. 1991. Watershed Resources Management Studies from Asia and the Pacific. Singapore: Institute of Southeast Asian Studies.

Falkenmark, Malin. 1994. "Integration of Land and Water," Stockholm Water Front, No. 1 (April).

Gibbons, Diana, C. 1986. The Economic Value of Water. Washington, D.C.: Resources for the Future.

Hufschmidt, M. M., D. E. James, A. D. Meister, B. J. Bower, and J.A. Dixon, 1983. Environment Natural Systems and Development An Economic Valuation Guide. Baltimore: The John Hopkins University Press.

Kessides, Christine. 1993. Institutional Options for the Provision of Infrastructures. Technical Paper no. 72. Washington, D.C.: The World Bank.

Small, Leslie E., and Ian Carruthers, 1991. Farmer-Financed Irrigation, The Economics of Reform. New York: Cambridge University Press.

Whittington, Dale, Donald T. Lauria, Albert M. Wright, Kyeongae Choe, Jeffrey A. Hughes, and Venkateswarlu Swarna, 1992. Household Demand for Improved Sanitation Services: A Case Study of Kumasi, Ghana. Water and Sanitation Report no 3, UNDP-World Bank Water and Sanitation Program. Washington, D.C.: The World Bank.

World Bank. 1992. World Development Report 1992. New York: Oxford University Press. 
World Bank. 1993. Water Resources Management: A Policy Paper. Washington, D.C.

\section{FURTHER INFORMATION}

Bhatia, Ramesh, and Malin Falkenmark, 1992. "Water Resources Policies and the Urban Poor: Innovative approaches and Policy Imperatives." Background paper for the Working Group on Water and Sustainable Urban Development, International

Conference on Water and the Environment: Development Issues for the 21st Century, Dublin.

Gittinger, J. Price. 1982. Economic Analysis of Agricultural Projects. Baltimore: The Johns Hopkins University Press.

Hashimoto, M., ed., 1991. Guidelines of Lake Management. Vol. 2: Socio-Economic Aspects of Lake Reservoir Management. International Lake Environmental Committee, United Nations Environment Programme. New York.

Munasinghe, M. 1992. Water Supply and Environmental Management. Boulder, Colorado: Westview Press.

Ward, William A. and Barry J. Deren, 1991. The Economics of Project Analysis. Economic Development Institute, The World Bank.

OECD. 1989. Water Resources Management: Integrated Policies. Paris.

O'Mara, Gerald T. 1988. Efficiency in Irrigation: The Conjunctive Use of Surface and Groundwater Resources. Washington, D.C.: The World Bank.

Rodriguez, Fritz, ed. 1990. Water Projects: Selected Readings. The Economic Development Institute of the World Bank. 



\section{CHAPTER 6 ENVIRONMENTAL AND HEALTH CONSIDERATIONS}

6.1 Economic development can only be sustained if a country's renewable resources (including its population) are protected and maintained. Aside from any inherent worth of natural ecosystems, protecting them can ensure the availability of resources in the future and can avoid serious consequences of neglect in the present. Such neglect in the management of water resources has resulted in depleted water sources, contaminated supplies, and public health hazards, aside from the significant economic costs of lost benefits from adequate water resources. The water needed to protect ecosystems should be considered a use along with the use of water for human consumption, agriculture, energy, and industry.

6.2 This chapter discusses major health, water quality, and environmental issues that should be considered in developing a water resources management strategy. Activities in many sectors of the economy affect public health and the environment, of course, and protecting them adequately involves developing policies, legislation, regulations, and institutions that will serve this goal. The first part of this chapter briefly outlines some of the health considerations and issues in formulating a strategy. The next two sections review substantive matters pertinent to the water resources assessment during phase 1 of the process of formulating a strategy. Although the legal and institutional framework for water resources is discussed in chapter 2, these aspects are such an important part of environmental protection that they are included here. This chapter is only a guide; discussion is limited to major environmental quality issues and should not be considered a complete treatment of environmental issues in water resources management.

6.3 The chapter assumes that water resources will be assessed and issues evaluated within a river or drainage basin. For groundwater management, the groundwater basin bounded by geohydrological features may be more appropriate.

\section{PUBLIC HEALTH AND WATER RESOURCES}

6.4 Public health is intimately linked with adequate water supply and quality and with adequate sanitation. Of eight major diseases or disease groups found in developing countries, four are linked to water supply and sanitation or to organisms (vectors) that breed in water (World Bank 1994, p. 90). ${ }^{\text {is }}$ Many water projects alter the environment so as to either increase the number of vectors or increase the amount of contact with disease-causing organisms (Tiffen 1989a and 1989b).

6.5 Good health is a basic human need and desire, and improving public health can have impressive economic benefits. Attaining a certain standard of public health is often a government objective. Improved public health can be the outcome of government programs that are not intimately linked with water, such as general education programs, particularly the education of women (World Bank 1994). Of course, many government health programs concern water directly, for example programs that are aimed

\footnotetext{
${ }^{15}$ These are diarrhea-related diseases (including dysentery, cholera and typhoid),trachoma, tropical cluster diseases (including schistosomiasis, South American trypanosomiasis, and Bancroftian filariasis), and intestinal worms. The other four diseases or disease groups are tuberculosis, respiratory infections, chronic respiratory diseases, and respiratory tract cancers.
} 
at improving personal hygiene. Public health objectives should be included among the government objectives identified by the water resources strategy formulation team.

6.6 The strategy formulation team could include public health professionals, but in any case the team should consult and include such professionals in the course of strategy formulation.

6.7 Identifying the major water-related diseases should be part of the water resources assessment. The assessment should include estimation of the levels of incidence of such diseases, their relationship to water, and some identification of the capacity of the existing health service to overcome such diseases (Tiffen 1989a). Projections could include the economic benefits of improved public health. Specifically, this could mean a reduction in work time lost because of disease. It is extremely difficult to make reasonable projections of the economic benefits of improved public health, however, and the strategy formulation exercise must remain above all a manageable activity. As with other issues, addressing the issue of public health at the strategy level does not mean that projections or estimations of benefits should attempt to be unduly precise.

6.8 In general, water-related diseases in developing countries fall into two major categories: those arising from the ingestion of food or water contaminated by excreta, and those that are vector-born diseases. Vector-borne diseases such as malaria and bilharzia are closely related to problems of environmental sanitation; in general, water-related diseases are related to water quality. Control programs for vector-borne diseases in many countries emphasize preventive or curative measures to the neglect of environmental management and community-based preventive measures (Thomas and others 1993).

6.9 The remainder of this chapter includes the biological contamination of water that damages human health among the measures of water quality. Protecting the environment should be regarded as a means of sustaining and enhancing human health.

\section{EXISTING ENVIRONMENTAL ISSUES FOR WATER RESOURCES ASSESSMENT}

6.10 Human intervention in existing water resources can be divided into two sets of effects. The first set is from direct use or management of surface water and groundwater; the second is from all sectors of the economy that use water or affect catchment waters. Water resources management activities include investments for urban, rural, industrial, and agricultural water supply, sewage treatment, flood control, irrigation and drainage, power, and navigation projects. Such activities directly modify streamflow, groundwater basin conditions, and water quality. Activities in other sectors that affect catchment waters include, for example, forestry, mining, and construction (which have an indirect influence on flow regimes and sediment loads carried in surface water), and industrial discharge and agricultural runoff (which influence the chemical, biological, and physical properties of water) (United Nations 1979).

6.11 The water quality and hydrological modifications caused by water management and other activities may in turn have other physical, biological, and social effects. Understanding the causes and consequences of the "first order" modifications (those caused initially) is vital for formulating environmentally sound and sustainable water resources management strategies.

6.12 The following paragraphs discuss some of the main causes and consequences of surface and groundwater use, overuse, and quality degradation as well as the effects of surface and groundwater use and pollution on sensitive ecosystems and public health. The expert team formulating a water resources 
strategy will want to examine the aspects discussed below to determine if there is or will be a major problem or issue.

\section{Surface Water}

6.13 The chief aspects of surface water that affect the environment or public health are stream flow variability, runoff, and water quality.

6.14 Stream Flow Variability. Stream flow variation is a function of the rate, amount, form, and distribution of rainfall, and the rate of evapotranspiration, infiltration, and runoff. The variation in streamflow affects the amount of organic and inorganic matter that is deposited and the rate of its deposition. Such matter includes, for example, sediments, silts, nutrients, plankton, and benthos, which are carried as dissolved, suspended, and bed loads. This matter is eventually deposited. Variation in stream flow also affects the rate at which oxygen is added to the water through surface aeration. Natural variation in stream flows is one of the chief factors governing the kind of ecosystem that will develop and survive in a given watercourse (Jain and others 1993).

6.15 Projects for controlling, storing, or diverting water modify streamflows in different ways. Flood control projects reduce peak flows, power generation projects minimize low flow conditions, and diversions of water for consumptive use reduce the overall amount of flow. Reducing flows decreases the rate of nutrients, organic matter, and substrates carried and deposited by moving water. Low flows diminish the stream's ability to dilute and breakdown pollution and make downstream reaches more vulnerable to entering pollution. Reduced silts and sediment loads and adsorbed nutrients may affect the productivity in downstream areas such as deltas. Lower stream flows also may affect replenishment of groundwater.

6.16 Increased Runoff. Land use activities can alter the surface and topography of a basin and profoundly affect important components of the hydrological cycle. Urban development (with buildings, parking lots, and roads) reduces the pervious surface of the land, decreasing the rate and amount of water infiltrating as groundwater. Urbanization also tends to even the land surface. Smooth surfaces reduces the resistance to flow and the time for flow to concentrate, resulting in higher peak flows and greater flood damage. Land use planning can be used to minimize damage from higher peak flows. Flood damage from uncontrolled land use, such as squatter settlements, can be significant. Agricultural activities also alter soil cover and affect the rate of runoff and percolation in the catchment.

6.17 Higher flows may increase soil erosion and the amount of sediments transported downstream. Upland erosion is accelerated by processes that reduce vegetative cover in the catchment such as agriculture, deforestation, overgrazing, and forest fires. Stream channel erosion is accelerated with increased flows. The amount of sediments delivered to downstream locations depends on the fluvial transport system's ability to entrain and hold on to the sediment particles (Ponce 1989). Fine particles are carried more readily than course particles. Sediment deposition is likely to be greater when flow velocities are reduced, for example when streams enter impoundments or lakes. Deposition is also greater when gradients are smaller, for example, in deltas and floodplains. Areas experiencing frequent flooding and excessive sediment deposition should be delineated in the water resources assessment.

6.18 Surface Water Quality. All natural water bc dies have the capacity to assimilate some level of waste without apparent damage (Jain and others 1593). This capacity is the result of physical and 
biochemical processes occurring within the aquatic environment that break down waste into harmless substances. The effect of waste discharge on a stream becomes more significant once the water's capacity to assimilate waste is exceeded.

6.19 Waste discharge comes from "point" or "nonpoint" sources. Point sources are direct discharges through discrete conveyance systems to water bodies. Examples include municipal and industrial wastewater discharges into streams, lakes, and oceans. Nonpoint sources are diffuse discharges that occur over large areas, such as runoff from urban areas, agriculture, forestry, and mining. The characteristics of major point and nonpoint sources are explored below (much of the following draws on Robins and others 1991).

6.20 The main point sources of pollution are municipal wastewater and industrial wastewater. Municipal wastewater from urban and community centers or squatter settlements can be treated, partially treated, or untreated. Partially treated and untreated discharges are a major source of nutrients like nitrogen and phosphorus, bacterial pathogens, viruses, parasites, and organic contaminants. Nutrients can accelerate algae growth and eutrophication (the process of becoming rich in nutrients but often shallow and seasonally deficient in oxygen) in water bodies. Water supplies contaminated with bacteria, parasites, and viruses may affect downstream users and require higher treatment costs. Industrial wastewater characteristics vary according to use and level of treatment received. Cooling water effluent can elevate the temperature of water in receiving streams. Processing plant effluent contains a wide variety of waste byproducts. For example, food processing can produce organic wastes that generate high biochemical oxygen demand and tanneries may generate toxic chromium wastes. Industrial effluent can affect water in many ways, from changing the temperature (thereby altering sensitive biochemical processes), to harming and even destroying aquatic ecosystems.

6.21 Major nonpoint sources of waste include urban runoff, agricultural runoff, forestry management, and mining. Urban runoff may contain sediments, suspended solids, heavy metals, and organic contaminants (U.S. 1969). Agricultural runoff can carry sediments, salts, nutrients, organic loads, pesticides and pathogens to receiving water. Sediments are the largest pollutant category to affect surface water, and many of the aforementioned pollutants may be adsorbed in soil particles and thus be carried to surface waters (Robbins and others 1991). Irrigation return flows may contain high concentrations of silts and sediments, dissolved solids, pesticides, and trace elements. Irrigation-related salinity is a serious problem in arid and semi-arid areas. (El-Ashry and others 1985). Salts become concentrated in soils when the applied irrigation water is lost through evaporation and transpiration. They can be concentrated in water, also, when relatively high-quality water is diverted from a basin, reducing the amount of water available to dilute downstream discharges. Salt loading occurs when the applied water percolates through soils and dissolved salts are carried to receiving waters (Robbins and others 1991). Other agricultural nonpoint sources of pollution include grazing areas, ranches, feedlots, and poultry farms. Forestry management activities affect downstream flow and water quality (see Brown 1976). Logging and clear cutting may increase surface runoff and reduce groundwater replenishment. Mining often causes soil erosion. Mining soils often contain metals and other substances that can increase the acidity of surface water and dramatically harm sensitive species.

\section{Effects of Surface Water Issues on Sensitive Ecosystems}

6.22 Modifications in water flow regime and quality may have the greatest effect on wetlands, which are sensitive ecosystems whose existence is dominated by water. Wetlands include marshes, estuaries, 
coastal zones, and inland lakes (see Dugan 1990). Wetlands are productive ecosystems, and are vital for preserving biological diversity. They also serve as natural water purification systems and as buffers against floods. Low flow conditions decrease wetland areas and as previously mentioned, decrease the capacity of natural waters to assimilate pollution-making wetlands susceptible to damage from waste loads.

6.23 Estuaries are sensitive ecosystems located at confluences of freshwater streams entering salty waters of a bay, sea, or ocean. They are important nurseries and staging areas for many species of shrimp, fish and waterfowl. Estuaries are influenced by tidal action and freshwater flows. Low upstream flows can concentrate discharges and deteriorate downstream water quality and affect estuarine species. Low flows can also shift the freshwater and saltwater balance in the estuary and increase the chance of salt water intrusion in fresh water supplies.

6.24 Coastal zones are narrow stretches of water and land along shores of coastal and inland waters. They form important habitats for shellfish and are also used as locations for seaports, industrial and commercial operations, and residential and recreational areas. They also provide vital services such as shoreline stabilization, protection from storms, flood control, fish nurseries, nutrient cycling and waste treatment (World Bank 1991). Coastal zone ecosystems can be affected by municipal and industrial waste discharges, nonpoint pollution from urban and agricultural runoff, destructive fishing practices (for example, using dynamite), dredging, or other destructive commercial operations.

6.25 Inland lakes are vital sources of water supply, and they provide benefits such as fishing, navigation, and recreation. They can also influence the local climate and the groundwater regime. Waste discharges can have dramatic effects on the populations of fish and other aquatic species, and plants. Nutrients from municipal wastes and agricultural runoff (from fertilizers and pesticides) can accelerate algae growth and the aging process in a lake (eutrophication). Algae increase turbidity levels, create taste and odor problems, and can make significant demands for dissolved oxygen. Oxygen depletion can create anoxic conditions in the deeper parts of the lake and can affect many types of fish and other species.

\section{Effects on Public Health}

6.26 Streams receiving municipal wastewater discharges, for example from urban or squatter settlements, can be very vulnerable to flow changes. Compared with treated water, untreated or partially treated municipal effluent contains higher levels of faecal deposits, bacteria, parasites, and viruses. Such effluent can harm downstream users, especially when downstream supplies are not treated adequately before use. High levels of waste in water can cause diarrhea, cholera, or other waterborne diseases. Such public health hazards can be exacerbated under low flow conditions when wastes become more concentrated. Also, the reduced assimilative capacity of streams with low flow slows the breakdown of organic wastes, prolonging the survival and growth of pathogens. Data on occurrences of waterborne

diseases in different regions of a country can help set priorities for action. Available health data can be incorporated in the country's water resources assessment. 


\section{Groundwater}

6.27 Among the tasks in a water resources assessment will be to assess whether groundwater basins are overdrafted, whether there are effects on groundwater from increased storage, and whether there are problems with groundwater quality.

6.28 Groundwater Use Groundwater use is typically greater in areas where surface water supplies are scarce (for example, arid and semi-arid areas) and expensive. Also, use of groundwater generally increases during dry periods when surface supplies become limited. Excessive pumping over an extended period can "overdraft" a basin-a condition where depletion exceeds aquifer safe yield. Safe yield is the average amount of water that can be extracted without impairing the basin in the long run. It can be estimated as the sum of inflows from adjacent areas, deep percolation of the applied irrigation water, infiltration from precipitation, and recharge from streams minus the sum of outflows into adjacent areas and total extraction (pumping). Overdrafted basins should be delineated in the water resources assessment.

6.29 Overdraft reduces groundwater storage in a basin and causes water level decline. The economic and environmental consequences of excessive pumping can be severe. The most obvious economic impact is the increased cost of the additional energy needed for lifting water from lower elevations. A large decline in water level may even dry out shallow wells and result in a total loss of supply. Excessive water level decline may even cause land subsidence and affect groundwater quality.

6.30 Land subsidence from groundwater pumping is influenced by changes in water level or piezometric head and the compaction characteristics and thickness of aquifer deposits (Poland and Evenson 1966). ${ }^{16}$ The dynamics of land subsidence because of groundwater pumping is different for different aquifers. ${ }^{17}$ The economic consequences of subsidence may include the costs of releveling land, repair or replacement of deep-water wells (because of ruptured casings) and unexpected flooding from changed gradients and the courses of streams and creeks. Subsidence can also cause serious problems in the construction and maintenance of highways and water and wastewater conveyance structures (Ireland 1986).

6.31 Salt water intrusion occurs when saline waters migrate into fresh water. Excessive groundwater pumping in basins located near saltwater, such as basins along coastlines, estuaries, or inland lakes, may be susceptible to salt water intrusion if they are not managed carefully. Salty water can be unfit for potable and even agricultural supplies.

6.32 Groundwater pumping can also induce the migration of poor quality waters from adjacent vertical areas. Interaquifer movement of poor-quality water can occur when there is a difference in the hydraulic

\footnotetext{
${ }^{16}$ Factors other than groundwater pumping can cause land subsidence. These include the oxidation of organic soils, hydrocompaction of moisture-deficient soils, and changes in aquifer dynamics resulting from oil and gas pumping.

${ }^{17}$ In unconfined aquifers, water level declines decrease the buoyant support of aquifer material and increase the gravitational stress on the underlying material. In confined aquifers, piezometric head change also induces vertical hydraulic gradients across the confining bed and produces seepage stress (Lofgren 1968). Both gravitational and seepage stresses increase the effective stress on overlying deposits.
} 
head across aquifer boundaries through well screens, perforated casing, or open boreholes. Overpumping from freshwater aquifers overlying salty waters may also cause upwelling of connate saline waters from under the base of the freshwater (Everett 1990).

6.33 Effects of Increased Storage. In areas where the water table is high, the applied irrigation water can create a different set of problems: waterlogging and salinization. Waterlogging is the saturation of surface or near-surface soils. It occurs in areas with a high water table which are not drained adequately. The absence of pumping tends to exacerbate waterlogging in such areas. In dry climatic zones, waterlogged soils concentrate salts in the plant root zone. Irrigation accelerated salinity buildup, which can be an acute problem in arid and semi-arid areas where soils tend to be saline and surface evaporation rates are high (El-Ashry and others 1985). Many of the irrigation-induced salinity problems currently faced by communities are outlined in Umali 1993.

6.34 Groundwater Quality. Groundwater systems have some ability to purify themselves; this depends on the material and properties of the aquifer. Self-purification occurs largely through the filtering action of water infiltrating the aquifer material and also through biochemical processes that may be controlled by the available oxygen and substrate material.

6.35 Generally, the properties of an aquifer and the length of time the water is in contact with the aquifer material have the most influence on quality. For alluvial deposits, the quality of the water infiltrating (from precipitation and applied irrigation water) as deep percolation and recharging from streams into the aquifer is also an important influence on groundwater quality. Recharge mechanisms are different in confined and unconfined aquifers. Since confining layers reduce the volume and rate of direct recharge, the effect of recharge on groundwater quality in confined aquifers is less than in unconfined aquifers.

6.36 A variety of chemicals can contribute to groundwater contamination. Salts, fertilizers, and pesticides (including insecticides, herbicides, and fungicides) used in agriculture may dissolve in water and leach into groundwater. Other sources of contamination include surface disposal of liquid wastes, septic tanks, leaking sewers and underground storage tanks, industrial wastes, and oil field brine disposed through injection wells, as well as mining wastes (Everett 1990). Remediating groundwater contamination is generally more difficult and therefore more expensive than treating surface water pollution because the properties of aquifer materials and their transport mechanisms are more difficult to understand and define. The effects of pumping on groundwater quality are discussed in the next section. Contaminated areas and aquifers that are highly vulnerable to pollution should be noted in the water resources assessment.

\section{WATER RESOURCES ASSESSMENT: ENVIRONMENTAL INSTITUTIONS}

6.37 Environmental aspects of water resources management are diverse, complex, and cross-sectoral. Protecting and preserving the environment can only be accomplished with effective institutions backed by adequate legislation and policies. The effectiveness of environmental institutions should be examined as part of the country water resources assessment.

6.38 Environmental policy articulates principles to ensure that economic development occurs in an environmentally sound and sustainable manner. It could be based on broad principles or on pragmatic concerns recognizing that prevention of adverse effects is less costly than restoring damage. Policy may 
be implemented through procedures for recognizing environmental consequences of a proposed action (for example a flood control project) early in the planning process and for considering such consequences in decisionmaking.

6.39 A policy's success may depend on how well it is articulated and the extent to which is practical and achievable. Addressing the goals of development and environmental sustainability and the tradeoffs between them, especially in the context of a nation's social and cultural traditions, will be central to the success of economic development (Ahmad and Sammy 1985).

\section{Legislation}

6.40 Legislatively mandated policies are more likely to be implemented successfully than those that are not. Examples of legislation for managing water resources are discussed below.

6.41 Water Act. This type of legislation provides a framework for a rational utilization of a nations's surface and groundwater resources. Typically, it may define the ownership of a nation's waters, the powers of the responsible ministry for controlling its utilization, protection, and setting rates, the types of beneficial uses and procedures for obtaining use permits, and the responsibility for watershed protection and provisions for conflict resolution.

6.42 Water Pollution Control Act. Pollution control legislation may be used for controlling point and nonpoint source discharges. Enforcing controls for point source discharge is generally easier than for nonpoint sources. Direct regulation based on effluent standards, including perhaps permits or licenses (or both) is often used for controlling point source discharges. Zoning regulations have been used for controlling nonpoint sources from land use activities in urban areas. Controlling nonpoint sources from agriculture and forestry management activities may require watershed management programs in which soil and water conservation is an explicit objective.

6.43 Environmental Legislation. Broad-based environmental legislation can provide a framework for an integrated approach for regulating development activities that affect environmental quality. Such legislation may specify an environmental impact assessment requirement for integrating environmental considerations in major development projects and programs.

6.44 Public Health Standards. While often not strictly a matter of legislation, such basic requirements as drinking water standards may however be included in, for example, a water pollution control act.

\section{Euvironmental Impact Assessment}

6.45 An environmental impact assessment (EIA) is a policy instrument that has been used in many countries for fostering sustainable water resources management. An EIA is also a means of improving decisionmaking and planning by anticipating adverse physical, biological, and social effects of project alternatives and by opening up the decisionmaking process to include diverse inputs from communities, agencies, and nongovernment organizations potentially affected by the development.

6.46 An EIA comprises five basic steps: identification, prediction, evaluation, mitigation, and monitoring. The first entails detailing the components of a project, the affected area, and baseline 
conditions. The second step consists of screening significant environmental factors and forecasting their dimensions of change. The third step evaluates project alternatives using technical, economic, environmental, and social factors. Step four defines the preventive, mitigatory, and compensatory measures for the preferred alternative. Step five outlines the program for monitoring changes in environmental components.

6.47 EIAs can be used for project, regional, or sector-specific water resources activities. (The World Bank's Operation Directive 4.01: Environmental Assessment describes the Bank's requirements in this area.) Project-specific EIAs could be required for most investments for water supply, flood control, irrigation and drainage, sewerage treatment, and power generation. Regional EIAs can be used for multiple projects, such as a series of dams, planned or proposed in a localized geographic area or for river basin development planning. Regional EIAs may be an efficient use of resources for identifying major issues in an area, compiling existing and baseline data which could expedite future project-specific ElAs. They may also be useful for identifying conflicting demands on resources imposed by different projects (for example, the combined effects of receiving water quality of effluent of several municipal and industrial treated wastewater discharges), and for designing mitigation measures (World Bank 1991). In this way the EIA process can be used to (a) incorporate cross-sectoral actions needed to properly manage the water environment, (b) spur consultation and coordination among sectoral ministries, and (c) achieve restoration and protection of the water environment.

6.48 Sectoral EIAs may be suited for reviewing investment options and for evaluating new policies, for example water conservation programs. Their advantages in terms of efficient and expedient use of resources may be similar to regional EIAs. Sectoral EIAs may also be used for assessing the institutional requirements for performing environmental reviews, environmental management, and developing monitoring programs (World Bank 1991).

\section{Institutions}

6.49 Environmental management entails a wide variety of tasks such as data collection, monitoring, regulation, enforcement, advising, and EIA implementation, coordination, and oversight, each of varying complexity. Different types of agencies are suited to perform some or more of these tasks.

6.50 Sectoral Agencies. Sectoral agencies such as a ministry of water development may be suited for regulating and controlling the use of a nation's water resources and for watershed protection as defined by the water act, for example. Their tasks might include collecting data and performing hydrological analysis for determining available supplies, monitoring surface water and groundwater quality for domestic supply (perhaps in conjunction with the ministry of health), and issuing permits for beneficial uses. Pollution control might be the responsibility of a department within the ministry of water development; this department might be responsible for regulating municipal and industrial wastewater discharges (through monitoring and the issuance of permits) and enforcing sanctions using fines and other penalties for noncompliance. While it is probably wise for one institution to bear the responsibility of general water data collection, monitoring, and regulation, standards should be developed together with other sectoral agencies such as the ministry of health.

6.51 Control of nonpoint source pollution might best be achieved through enforcement of structural measures and nonstructural measures by different agencies. Ministries of agriculture and forestry might 
be responsible for monitoring and regulating soil erosion and farm chemicals in surface waters. Zoning regulations enforced by local councils may be an effective way of controlling urban runoff.

6.41 Specialized monitoring (such as of aquatic species in priority rivers, lakes, or coastal zones) might be undertaken by sectoral agencies (for example, a fisheries department in a ministry of natural resources). A department of public health may gather data and administer programs on water-related health matters.

6.52 River Basin Authorities. River basin authorities may be well suited for coordinating cross-sectoral activities and their effects on basin water resources. Such authorities may be responsible for collecting hydrologic, land, and water use data, performing hydrological investigations, and coordinating point and nonpoint source pollution monitoring in the river basin.

6.53 Environmental Agencies. National environmental agencies would be suited for setting policy, advising on complex cross-sectoral and cross-media issues, and implementing or coordinating the implementation of environmental impact assessments.

\section{Coordination}

6.54 The effective management of water resources will depend on the capability of the government to bring together diverse interests and integrate them in decisionmaking. Such integration should begin with strategy formulation and continue to project planning, design and implementation. Coordination between project proponents, and those affected by them will be especially vital for integrating the complex crosssectoral environmental issues.

6.55 Affected Groups and NGOs. Coordination with communities and NGOs may be vital to the success of most major developments affecting their interests. ${ }^{18}$ Communities affected by reservoir inundation, for example, may need to be resettled or compensated (or both) for dislocation, loss of income-generating capability and other socio-cultural disruption. While the actual dimensions of most such disruption may never be fully realized, incorporating the views of these communities in the planning process would assist in understanding the nature and extent of the potential socio-cultural impacts as well as the suitability of the preventive, mitigative, and compensative measures proposed for unavoidable impacts.

6.56 Donor Community. Coordination with donor agencies and NGOs involved in water resources and environmental management programs may be also beneficial. Some donor agencies and NGOs may already have data and other information available on specific regions of a country or on specific sectors of the economy. ${ }^{19}$ Having access to such information reduces the time-consuming and costly baseline

${ }^{18} \mathrm{~A}$ detailed discussion of community involvement and the role of nongovernment organizations is in World Bank 1991s, pp. 191-208.

'UNEP mair 'ains databases on major environmental issues covering many areas of the world. Nongovernment organizations such as the World Resources Institute and the International Union on the Conservation of Nature maintain significant environmental information on many areas of the world 
data collection effort. Other donor agencies have often carried out major investigations useful for formulating project alternatives.

6.57 Donor agencies may have access to recent technologies (such as new software for groundwater or reservoir water quality modeling) as well as literature and information about their use and limitations. Having access to such information can be useful for selecting planning methodologies. National environmental agencies, river basin authorities and the ministry of water development can benefit from such access. Some nations have donor coordination groups focusing on environmental and water resources programs. Such organizations should be identified in the water resources assessment and the problems of coordination should be explored.

\section{WATER RESOURCES MANAGEMENT STRATEGY}

6.58 The major environmental and public health issues and the existing institutional framework that should be reviewed as part of a water resources assessment have been covered in the first two sections of this document. Based on international experience, the following sections review what are likely to be the major overall issues in these areas.

\section{Priority Environmental Issues}

6.59 Over-allocation of water resources and water pollution are the two principal causes of conflict among competing uses of water. Such conflicts invariably affect the poor and the environment. Excessive surface water diversions and groundwater pumping result in low downstream flows and basin overdraft respectively. Both conditions often result in significant adverse environmental impacts. Pollution from point and nonpoint sources affects most beneficial uses.

6.60 Allocation of Water Resources. Over-allocation of water is often a result of poor planning, misallocation of resources, or poor management decisions. All basin supplies and uses including instream flows and flow requirements for maintaining sensitive ecosystems and projected demands should be considered when making planning decisions. Environmental uses should be given equal considerations as other beneficial uses, otherwise sensitive ecosystems may be the first to suffer during conflict. Using basinwide considerations for making management decisions may be an optimal use of water resources. For example, operating a basin on a conjunctive use basis can optimize both surface and groundwater use. During wet periods, surface water use can be increased and surplus supplies intentionally recharged and during dry periods groundwater use can be increased. Such an operation, for example, could permit the maintenance of higher flows for instream uses during the critical, dry periods. Strategies for addressing water allocation issues should be included in the water resources management strategy.

6.61 Pollution Control. Pollution from point and nonpoint sources affects all beneficial uses. Polluting water may render it unfit for potable supply or it may require costly treatment. Pollution may limit the use of water for environmental purposes (for example, thermal pollution may affect fish populations, organic loads may deplete dissolved oxygen levels, and toxic wastes may damage entire ecosystems). Controlling waste discharges from point and nonpoint scurces should be a priority objective for protecting surface water and groundwater quality. This would first require identifying major point and nonpoint sources and loads, then using the various techniques (standards, permits, or incentives) for 
controlling waste discharges, and finally monitoring changes in pollutant loads to enforce compliance and determine the effectiveness of the controls.

6.62 Source identification would require information on water use. land use (chemical inpurs, waste discharges, sediment data, and hydrological data). Flow and water quality and waste discharge data collected during low and high flow periods at major tributaries and streams can be used to estimate the proportion of pollutant loads originating from different sub-basins or point sources.

6.63 Priority basins or geographic areas to be addressed in the short term should be identified in the country water resources management strategy. In addition. priority investment needs for pollution control infrastructure should be identified.

\section{Priority Institutional Issues}

6.64 Effective environmentai management will require agencies capable of administering well-defined regulations. Regulations mandated by legislation are often easier to enforce and are more likely to be complied with. Strengthening existing legislation and institutions could be two options presented to policymakers.

6.65 Strengthening Legislarion. The country's water act, for example, could be strengthened by explicitly defining environmental uses as important beneficial uses. Specific methods and procedures for determining instream flows, for example, might be incorporated. For groundwater management, new well field development should be based on the concept of aquifer safe yield as a way of controlling basin overdraft. Procedures for adjudicating overdrafted basins should also be clearly defined in a water act or similar legislation. Surface water diversions and groundwater water pumping could be regulated using penalties (for example, monetary fines and imprisonment) for sanctioning uncontrolled diversions and pumping.

6.66 A water pollution control act or similar legislation could be strengthened by defining control techniques such as standards, permits, or incentives for managing pollution control. Direct regulation for controlling point source discharges based on effluent standards could require dischargers to treat their effluent to acceptable levels before discharging into receiving waters. Restrictions in terms of the timing and locations of discharge may also need to be specified for cases where dischargers are concentrated geographically or along vulnerable streams. Penalties such as fines, imprisonment, or orders to halt operations could be specified for sanctioning violators.

6.67 Nonpoint sources may be controlled using various management practices. Procedures for identifying, monitoring, evaluating, and controlling the various types of nonpoint sources should be developed. Responsibility for controlling each type of nonpoint source should be defined clearly and enforced through incentives, permits, and regular monitoring. Any monetary penalties in the water act or the water pollution control act may need to be updated to reflect existing economic conditions or else they may not provide sufficient deterrent or motivation for meeting the needed waste discharge requirements.

6.68 Environmental legislation is also important and necessary for promoting an integrated approach for regulating all activities that affect environmental quality. Broad-based legislation may symbolize and reflect public acceptance and political commitment for environmental protection and management. This 
legislation should mandate an EIA requirement for major project, regional, and sector-specific actives. The legislation should specify procedures for EIAs, types of activities (for example, flood control, water supply and power generation) requiring an EIA, contents of an EIA, and responsibility for implementing an EIA and enforcing EIA compliance. Legislative priorities for addressing these issues should be included in the country water resources management study.

6.69 Strengthening Institutions. Effective regulation and enforcement of environmental legislation depends on the administrative capability of the institutions to perform their tasks. Although the effectiveness of different institutions such as the ministry of water development, pollution control department or national environmental agency varies, there are some common factors that govern administrative effectiveness. These include political mandate, resources, data, expertise, and coordination.

6.70 A political mandate will be important for successful environmental management. A strong mandate not only legitimizes the role of an institution but it also provides the necessary clout to perform the regulatory and administrative tasks that frequently entail conflict resolution (Hirji and Ortolano 1991a and 1991b) Regulatory tasks may include setting standards for supplies and effluent standards, issuing permits, setting charges, conducting monitoring and site inspections, enforcing compliance and imposing penalties.

6.71 Adequate funding is important for successfully performing tasks efficiently and effectively. Funding will be needed for hiring trained manpower, for collecting data, for purchasing laboratory equipment, for performing complex hydrological and water quality analysis, and for transportation and administration.

6.72 Data is central to all types of environmental analysis and evaluation. Baseline data are frequently used for most analysis of past, ongoing, and future projects. Well-designed surface and groundwater monitoring programs are necessary for collecting baseline data and for measuring changes in ambient conditions in water supplies and qualities. Monitoring land and water use, hydrologic, biologic, and social data are also necessary for a variety of environmental analysis, evaluation, and decisionmaking.

6.73 Trained personnel are crucial to performing various tasks involved in environmental management. Technical and managerial capability is needed for policy and program planning, implementation, coordination, and administration. The water resources assessment might examine skill and training requirements in this area.

6.74 Funding Priority Pollution Control Efforts. Immediate steps should be taken to address the priority pollution control issues identified above. The primary bottleneck will be funding. Revenues from both taxes and services provided by the government could possibly fund a sectoral ministry. There are several other options for supporting immediate water pollution control.

Charges or tariffs could be imposed on pollution discharges. The revenue generated could be used for pollution control. This is sort of a pollution control program may have a wide public appeal, since polluters would have to bear the cleanup burden. However, a question of equity may arise. Since point sources are easier to regulate than nonpoint sources, point-source dischargers may end up paying a disproportionate cost of pollution control compared with nonpoint-source dischargers. Setting charges for point-source discharges is also complicated. Charges set on the basis of volume or concentration of 
waste each have their advantages and disadvantages, which would need to be considered carefully.

- Pollution control costs could be built into the price of products and services generating the wastes. For example, the price of finished paper or finished leather could include the cost of waste treatment incurred by the pulp and paper industries or the tanneries. This option may even be extended to control nonpoint sources even though its regulation and enforcement may be more complicated. Zoning regulations for controlling erosion may include additional fees as part of permit fees for land use or construction activities, for example.

- Securing multilateral and bilateral funding may be more appropriate for addressing priority issues needing immediate attention or for developing and initiating the longer term water pollution programs.

\section{REFERENCES}

Ahmad, Y.J., and G. K. Sammy. 1985. Guidelines to Environmental Impact Assessment in Developing Countries. London: Hodder and Stoughton.

Brown, G. W. 1976. Forestry and Water Quality. Corvallis, Oregon: Oregon State University School of Forestry.

Dugan. P. 1990. Wetland Conservation - A Review of Current Issues and Required Action. IUCN - The World Conservation Union: Gland, Switzerland.

El-Ashry, M. T., J. van Schilfgaarde, and S. Schiffman. 1985. "Salinity for Irrigated Agriculture," Journal of Soil and Water Conservation 401(1):48.

Everett, L.G. 1980. Groundwater Monitoring. Schenectady, N.Y.: General Electric Company.

Hirji, R. and L. Ortolano. 1991a. "Strategies Used by Kenya's National Environment Secretariat to promote Environmental Protection." The Environmental Professional 13:154-65.

Hirji, R. and L. Ortolano. 1991b. "EIA Effectiveness and Mechanisms of Control." The International Journal of Water Resources Development. 7(3).

Ireland, R. L. 1986. "Land Subsidence in the San Joaquin Valley, California as of 1983." U.S. Geological Survey Water Resources Investigations Report no. 85-4196.

Jain, R. K., L. V. Urban, G. S. Stacey, and H. E. Balbach. 1993. Environmental Assessment. New York: McGraw Hill.

Lofgren, B. E. 1968. "Analysis of Stresses Causing Land Subsidence in Geological Survey Research." U.S. Geological Survey Professional Paper no. 600-B. 
Robbins, R.W., J. L. Glicker, D. M. Bloem, and B. M. Niss. 1991. Effective Watershed Management for Surface Water Supplies. Denver: American Water Works Association and AWWA Research Foundation.

Poland, J.G. and R. W. Evenson, 1966. "Hydrogeology and Land Subsidence, Great Valley, California," in E.H. Bailey, ed., Geology of Northern California. California Division of Mines and Geology Bulletin no. 190.

Ponce, V. M. 1989. Engineering Hydrology: Principles and Practice. Englewood Cliffs, New Jersey: Prentice Hall.

Tiffen, Mary. 1989a. Guidelines for the Incorporation of Health Safeguards into Irrigation Projects through Intersectoral Cooperation. PREEM Guidelines Series 1. Geneva: WHO.

Tiffen, Mary. 1989b. Guidelines for Forecasting the Vector-Borne Disease Implications of Water Resources Development. PREEM Guidelines Series 2. Geneva: WHO.

Thomas, Robert, Michael Colby, Richard English and others. 1993. Water Resources Policy and Planning: Towards Environmental Sustainability. Arlington, Virginia: Irrigation Support Project for Asia and the Near East (ISPAN).

Umali, Dina. 1993. Irrigation-Induced Salinity. Technical Paper no. 215. Washington, D.C.: The World Bank.

United Nations. 1979. Economic Commission for Latin America. Water Management and Environment in Latin America. Oxford, U.K: Pergamon Press.

U.S. 1969. United States Department of Interior, Federal Water Pollution Control Administration. Water Pollution Aspects of Urban Runoff. Washington, D.C.

World Bank. 1991. Environmental Assessment Sourcebook. Vol I. Technical Paper no. 139. Washington, D.C.

World Bank. 1994. World Development Report 1993: Investing in Health. Washington, D.C.

\section{FURTHER INFORMATION}

Tolentino, A. S. 1986. "Review of Environmental Legislation and Administration and its Application in Selected DMCs," in Environmental Planning and Management: Proceedings of a Regional Symposium on Environmental and Natural Resources Planning. Manila: Asian Development Bank.

Ayers. R.S. and D.W. Westcott. 1989. Water Quality for Agriculture. Food and Agriculture Organization Irrigation and Drainage Paper 29 rev. 1 FAO: Rome, Italy. 
Biswas, A.K. and Q. Geping, eds. 1986. Environmental Impact Assessment in Developing Countries. Tycooly International: London, UK.

Federal Water Pollution Control Administration. 1969. Water Pollution Aspects of Urban Runoff. United States Department of Interior: Washington, D.C.

Gordon, N.D., T.A. McMahon, and B.L. Finlayson. 1992. Stream Hydrology: An Introduction for Ecologies. John Wiley and Sons Ltd.: Chichester, UK.

Hirji, R., and L. Ortolano. 1991. "Controlling Industrial Pollution Using EIA: Case Study of a Kenyan Tannery Project." The Environmentalist. 11(4): 1-10.

Munasinghe, M. 1992. Water Supply and Environmental Management. Westview Press: Boulder CO.

Nemerow, N.L. 1991. Stream, Lake, Estuary, and Ocean Pollution. Van Nostrand Reinhold: New York, NY.

Ortolano, L. 1984. Environmental Planning and Decision Making. John Wiley and Sons: New York, NY. 


\section{CHAPTER 7 INTERNATIONAL ISSUES}

7.1 Water does not respect borders. When a significant amount of the water used in one country comes from another, or when sources (such as aquifers) span international borders, the entire process of formulating a national water resources management strategy can change. Similarly, obligations to provide water of a certain quality to downstream users can become a significant aspect of a country's national water resources management strategy. Over 200 river basins are shared by two or more countries. International conferences such as the 1992 Dublin Conference on Water and the Environment and the 1992 UNCED in Rio de Janeiro have stressed the need for comprehensive management of water resources using the river basin as the focus of analysis. Cooperation and goodwill among states sharing a drainage basin are essential for efficient development and utilization of international rivers and groundwater aquifers. In order to fulfil their own economic development goals, it is important that such states formally collaborate to exchange data, share waters, preserve the environment, and generate development programs that are of joint interest and benefit.

7.2 This chapter suggests how international considerations can be included in the process of formulating a national water resources strategy and presents some of the main considerations that arise in setting up of collaborative arrangements between basin states. It draws on international experience and on the various rules that have been published by the International Law Association (ILA) and International Law Commission (ILC) on the uses of the water of international rivers and of ground water aquifers. Finally, the chapter discusses types of river basin organizations (RBOs) and the factors that influence their success as well as the concept of joint commissions for managing water resources.

7.3 Many of the suggestions and principles in this chapter apply not only to international waters but to national waters that flow between provinces or regions.

\section{INTERNATIONAL ASPECTS OF WATER RESOURCES STRATEGY}

7.4 It should be immediately obvious to the group charged with formulating a national water resources management strategy whether the international aspects of the resource deserve significant attention. For those countries that receive a substantial portion of their water from international sources, the major focus of the strategy team's efforts may be international, especially when devising and choosing policy options. Other countries may wish to devote a portion of the strategy team's effort to international aspects or to devote a task force, working group, or workshop (perhaps even an international workshop) to these matters. It is also conceivable that some countries will want a process for examining international aspects that runs parallel to the national aspects of developing a water resources strategy. In general, however, the process of assessing water resources (phase 1) should be somewhat similar in most countries; for some, dependence on international sources will be a major issue, and how to most efficiently (and equitably) manage such resources will be the chief question in developing and choosing options (phase 2).

7.5 It may be that formulating a national water resources strategy without directly involving neighboring riparian countries would be fruitless. Perhaps several riparian countries will wish to undertake strategy formulation together or at the same time. This could certainly further comprehensive river basin planning. 
7.6 At minimum, the strategy team may wish to review existing international treaties during the assessment of water resources and suggest realistic options if change in such arrangements is required. The strategic plan might suggest areas of further collaboration by riparian states.

\section{INTERNATIONAL WATER LAW}

7.7 The main initiatives in international water law have been taken by the International ILA and the ILC. The ILA is an NGO and the ILC is a subsidiary organ of the General Assembly of the United Nations. Founded in 1873, the ILA became engaged in water resources in 1954. This led, in 1966, to formulation of the well-known Helsinki Rules on the Uses of the Waters of International Rivers. The ILA has remained very active in this field. It has published a number of corollaries to and clarifications or completions of the Helsinki Rules including some modifications to their application to groundwater. The ILC, founded in 1948, was initially oriented toward navigation and took up the study of nonnavigational use of international watercourses in 1970.

7.8 The Helsinki Rules are widely adopted as a basis for international negotiations and collaboration on river basin development. They embrace the concept of a drainage basin as an economic and geographic spatial unit within which water resources are treated as the common property of all basin states. Furthermore, they rest on the principle that each basin state is entitled within its territory to a reasonable and equitable share of the beneficial use of the waters of an international drainage basin. Among the relevant factors in a consideration of the measure of an "equitable share," the Rules list the geography, hydrology and climate of the basin in each concerned state, past and existing water users, social needs of each basin state, costs of development and, very importantly, the degree to which the needs of a basin state may be satisfied without causing substantial injury to another state in the basin.

7.9 There has been little serious criticism of the value of the Helsinki Rules as a basis for negotiation. Some feel, however, that the "drainage basin" is not always the appropriate spatial unit and others have suggested that the full application of the Rules can detract unduly from the autonomy of a basin state.

7.10 Groundwater did not have a prominent place in the Helsinki Rules and some experts have felt that the Rules were unclear on this subject, but the ILA's position was modified in 1986. Until that time isolated groundwater basins (those unconnected with the surface body of water) were not considered to be part of a drainage basin simply because they did not "flow to a common terminus" as described in Article II of the Rules. An important change in 1986 was that the "common terminus" requirement was effectively dispensed with in respect of transboundary aquifers that are not connected to the surface water body. An aquifer that is connected to the surface water body is deemed to flow to a common terminus and has therefore always been covered by the Helsinki Rules.

7.11 The ILC has not yet gone as far as the ILA and includes as international watercourses only those aquifers that are connected to the hydrological system of the river. International groundwater should be considered with care if only because it is usually very difficult to establish whether extracting water from a transboundary aquifer in one country can cause substantial harm to the interest of another. This is particularly so if the ILC position is followed for an aquifer that is not connected to a surface system. 
7.12 There are two substantive principles that emerge strongly from the Helsinki Rules and from the work of the ILC that now receive general acceptance in international rules. They are:

- A prohibition of appreciable harm by way of deprivation of water rights, pollution or other means

- The right of each basin state along an international waterway (drainage basin) to a reasonable and equitable share in the utilization of its waterway.

7.13 Regardless of the extent to which the aforementioned principles may be adopted by basin states, there is one principle of paramount importance. This is the principle of good faith and good neighborly relations that should govern the use of all international waters and matters connected with them.

\section{OBJECTIVES OF COLLABORATION}

7.14 The primary objective of international collaboration between basin states is often perceived to be the resolution of conflicts. This is, however, a position of last resort. The primary objective must be to develop the resources of a drainage basin for the mutual benefit of its several connected states. If that objective is achieved, potential conflicts can be avoided, or they resolve themselves.

7.15 Whatever objectives are set, they should fit into a carefully constructed strategic framework that includes realistic priorities from the standpoint of all participating basin states. Several international endeavors have failed to achieve their aims because their specific objectives were either too ambitious in the first place or they did not represent true priorities for the member state. Such failure can occur because basin states have not adequately prepared their own national plans or the river basin organization set up by the basin states has itself done inadequate overall planning and has attempted to move too rapidly to the project implementation stage. This can result in the need to halt project preparation because projects that do not fit into an integrated basin plan attract inadequate financial and political support. It is then necessary to return to the planning and strategic formulation stage before project implementation can be resumed. This has occurred in the case of the Gambia Basin Authority (the Organisation pour la Mise en Valeur du Fleuve Gambie).

7.16 There is evidence that the most successful endeavors in international collaboration are those that

- Focus on well-defined objectives such as water-sharing (for example, the Indus River Basin Agreement between India and Pakistan) or the construction of specific common works, such as the Kariba Dam on the Zambezi River

- Develop projects that are of joint benefit to several or all of the basin states and are not essentially national projects

- Develop projects that are related and form part of a long-term integrated river basin plan.

7.17 Comprehensive water resource strategic planning is a prerequisite to any successful collaborative program in international river basin development. It is perhaps even more important to the international than the national situation if only because international treaties offer less flexibility for later adjustments 
than do domestic arrangements. Of the various components of comprehensive water resource strategic planning-physical, technical, management, socio-economic, environmental, political, and legal-the first two are of particular importance in international situations. These concern among other things the need to:

\footnotetext{
- Integrate the several potential sources of water, namely surface, ground, reclaimed, and desalinized water as appropriate

- Integrate water supply and waste water disposal

- Control pollution at appropriate levels.
}

7.18 Until recent years, little attention was given to groundwater and its conjunctive use with surface water, but there are now moves to include it as part of the total resource of an international drainage basin (please see the section on international water law below).

7.19 In the irrigation of arid zones, disposal of saline drainage effluent is becoming a greater problem as the total resources of rivers approach full development. This has important international implications. The mixing and diluting of saline effluents with the water supplies of the general irrigation system is a crucial element in the overall management of the crop environment and in the levels of salinity in the river waters that pass to downstream states. International law on such transboundary water pollution is weak and poorly codified. The resolution of pollution problems depends very much on negotiation of agreements between countries. One example is the agreement between the governments of South Australia and Victoria in Australia.

7.20 As with national river basins, international basin planning involves comprehensive assessments of (a) available resources, (b) potential demands, (c) constraints-physical, social and environmental, and (d) feasible development options. Assessing feasible development options leads to the next stage-policy and strategy formulation and the preparation of an action program or similar development program.

7.21 Evaluation of any of the above four items can be done either on a national basis by each basin state or RBO, acting on behalf of all concerned states. In some cases all four activities have been pursued unilaterally and only at the subsequent stage of policy and strategy formulation do the various parties came together; this was the case in the Indus Settlement of 1960. The latter procedure has the advantage of creating a stronger sense of "ownership" and participation on the part of basin states. On the other hand, central planning by an RBO is theoretically more efficient and can lead to rapid results.

\section{ASSESSING THE DATA BASE}

7.22 A good data base including hydrology, land resources, demand projections, and inventories of potential development projects, and environmental conditions is essential to any international dialogue on water affairs. Unsound and inadequate data give rise to dispute and uncertainty that can seriously hinder progress and detract from the quality of project preparation. Most principles governing data measurement, retrieval, and processing (please see chapter 4) apply equally to national and international drainage basins. There is one important difference, however; for international rivers there is a distinct need for frequent exchange of data between basin states so that apparent discrepancies in either the raw data or its processing can be identified at an early stage. Such discrepancies need to be resolved as they 
become evident so that sources of error can be rectified without delay. Otherwise, disputes may occur and in some cases errors in data recording may be perpetuated. In several international river basins, there has been an unwillingness to exchange data and information unless exchange is established by formal agreement. In such circumstances, every effort should be made to reach agreement. Article XXIX of the Helsinki Rules recommends that "each basin State furnish relevant and reasonably available information to the other basin States concerning the waters of a drainage basin within its territory and its use of, and activities with respect to, such waters."

7.23 Data is generally collected on a national basis by each basin state. In some cases, specific data is collected regionally by a jointly formed river basin organization or other agency. The choice depends on local conditions and the nature of the data. For example, navigation data on the Mekong River was collected by the Mekong Secretariat, the RBO. Boundary surveys in Lake Chad have been carried out under the auspices of the Lake Chad Commission (an RBO), whereas hydrological data in the Lake Chad basin is collected as a national activity by the basin states.

\section{WATER SHARING AND ALLOCATION}

7.24 The data base and the planning process provide the information from which the available water resource and the potential demands on them can be evaluated by each basin state. That evaluation then provides the basis for negotiation of the shares of water that could be allocated to each state and that might be inscribed in a treaty between basin states.

7.25 Water allocations are made in various ways according to circumstances. In some situations, like the Indus basin, water may be shared by the allocation of the complete flow of a sub-basin. More usually such "block" allocations are not feasible and water sharing is on a proportional basis. This is the case with the Nile between Egypt and Sudan and the Komati River between Swaziland and South Africa.

7.26 For the purpose of international agreement there is a strong case to be made for measuring water allocations at a specific point (for example at Aswan for the Nile) and to adjust, by an agreed formula, for transmission and operational loss, either positive or negative, to the point of abstraction.

7.27 It is important to take into account all significant water uses and return flows in preparing the balance sheet that will form the basis of a treaty. These include not only the main direct uses of water for rural, urban, industrial, and recreational purposes and for irrigation, but also evaporation losses from reservoirs and return flows from irrigation and from urban and industrial uses.

7.28 In some situations, it is advisable to include the consumption of water by forests in the water balance and hence in allocations inscribed in a treaty, as in the treaty between Swaziland and South Africa regarding the Komati basin. This is done by stipulating the limits to forested areas and relating those areas to water demands based on estimated consumption.

7.29 Water allocations to different sectors are assigned different assurance levels. For example, urban supply may be 98 percent or even 100 percent against $65-75$ percent for irrigation. The right to convert one allocation to another by a predetermined conversion factor is often formally included in agreements.

7.30 General rules for water rationing during extreme droughts need to be incorporated in treaties, but the responsibility for detailed operations during such events may be more appropriately assigned to an 
RBO established specifically for the operation and maintenance of any common works, such as a storage dam (please see the following section).

\section{TYPES OF RIVER BASIN ORGANIZATIONS}

7.31 Creating some kind of $\mathrm{RBO}$ is a practical step toward international collaboration for the development of a river basin. The scope of the terms of reference of a RBO can cover all or any of the following activities:

$\begin{array}{ll}- & \text { Data collection } \\ - & \text { Planning } \\ - & \text { Water allocations } \\ -\quad \text { Implementation of projects } \\ \text { - } \\ \text { Operation and maintenance of projects } \\ \text { Monitoring water use, control of pollution and preservation of environmental conditions }\end{array}$

7.32 River basin organizations vary from joint commissions concerned with little more than water sharing to organizations that have major executive functions and are corporations. Examples of the former are the India-Pakistan and Sudan-Egypt joint water commissions, and of the latter the Senegal basin's OMVS which covers almost all of the functions listed above. It is desirable, if not essential, that an RBO operate continuously and not be ephemeral in its activities. It must exist as a point of reference at all times so that any issue among basin states can receive immediate attention.

7.33 It is advisable to establish river basin organizations in progressive steps so that they may evolve to conform as precisely as possible to the needs of each situation. As a first step, a provisional commission can draft a treaty and constitution for the creation of a permanent joint water commission. This process may call for specific studies initiated by the provisional commission. At a later stage, the permanent joint water commission can both create and regulate any further body that may be required, such as an RBO charged with the implementation of specific works and studies. Some RBOs (like the OMVS) may provide in one organization a wide range of functions from planning to project implementation and management of completed works. It is, however, usually more expedient and logical to separate the policy- and strategy-level responsibilities from the executive actions and implementation programs. For example, a joint water commission might be formed as the main policy body with a wide brief that may encompass all drainage basins shared by the member states. Another RBO might then be established in the form of a corporation with a full legal status with specific responsibilities to execute, operate, and manage specific projects. Normally, the executive RBO would be answerable for policy direction to the joint water commission. 
91

\section{FACTORS CONTRIBUTING TO THE SUCCESS OF A RIVER BASIN ORGANIZATION}

7.34 Four important requirements for the establishment of an effective RBO are:

- Political and financial commitment on the part of the member states

- Clear definition of what the member states require of the RBO

- Defined procedures for interaction between the RBO and the national agencies

- An organization, incentive structure, and staff for the RBO that are compatible with its responsibilities and its legal status.

7.35 Experience has shown that the most successful RBOs are those that have well-focused, if not narrow, objectives and that concentrate on projects that form common works beneficial to several basin states. There are cases, however, where not all states will benefit or be concerned with a particular common work. In such cases it is expedient to limit the arrangements for project implementation to the states concerned.

\section{FURTHER INFORMATION}

The International Law Association (ILA), 17 Russell Square, London WC1B 5DR.

The International Law Commission (ILC), The United Nations, New York, New York 10017. 



\section{Annex SUGGESTED TERMS OF REFERENCE FOR WATER RESOURCES STRATEGY FORMULATION}

A.1 This annex suggests terms of reference for the expert team that is chiefly responsible for water resources strategy formulation. These terms of reference have been taken from a number of actual or proposed water resources assessments or plans. They are meant to be general, however, and to serve as an outline for preparing specific terms of reference for particular situations. The terms of reference presented below will need to be adapted to reflect

- Country conditions, including political, social, economic, institutional, and hydrological circumstances

- $\quad$ Existing water resources management practices and policies, including the work that has been done previously to design policies, strategies, master plans, or resources assessments

- Different geographic coverage, where some aspects of the scope of work may need to be international, some national, and others local

- Varying time required for strategy formulation, which may be short (one year) in some countries and long (three years) in others.

Formulating a national or international water resources strategy must above all be a manageable process with achievable goals.

A.2 This annex is based on the strategy formulation process outlined in chapter 1 of this guide. Please refer to the chapters of the text for an explanation of the process and for brief discussions of the major subject areas in water resources management. That process assumes the existence of an interministerial committee (or other responsible body) to guide and oversee strategy formulation and an expert team to perform the necessary work, drawing upon partners (outside expertise) as necessary. One of the tasks of the expert team is to determine how the process of strategy formulation will unfold. The first job of the team or its leadership will probably be to develop or negotiate the terms of reference with its oversight body (the interministerial committee). This will involve financial considerations.

A.3 Chapters 2-7 of the guide discuss basic aspects of substantive matters that should be discussed in formulating a strategy; accordingly these terms of reference merely present a list of potential activities. These terms deliberately avoid making any recommendations or elaborating on any common benefits or disadvantages in certain aspects of water resources management.

A.4 Because water resources management overlaps in many areas, some of the terms below are repeated in different contexts. It is difficult to identify, for example, whether the adequacy of river basin arrangements between countries is primarily an "institutional" or an "international" issue or whether data on pollution falls into the category of "information" or "the environment." It is probably more important that the various issues be considered in strategy formulation than that they be classified correctly.

A.5 Both in the expert team's determination of process for its work and in the terms of reference finally agreed on, it is important to be specific about the tasks to be performed and the amount of time to be devoted to each. The final terms of reference should specify what reports should be prepared and when they are due. The reports might include an inception report once the process has been agreed, an 
the political organization of the country, there may be some discussion with the leadership and ministers before agreeing on a strategy, or the recommendations may need to be reviewed or passed by a legislature before a strategy is finally in place.

\section{CRUCIAL ELEMENTS}

A.6 A number of elements discussed in the main text of this guide are crucial to the success of the strategy formulation process and should be in place or occur before the work begins. Briefly, these are:

- An existing national economic and water or environmental policy framework

- Government commitment at the highest level to forming a comprehensive water resources management strategy

- Agreement that the process will be collaborative, consultative, and transparent

- Appointment of an interministerial steering committee or other body to oversee the process and possibly choose options

- Recruitment of a team of experts that should be composed chiefly of a country's own nationals

- $\quad$ Agreement on the team's terms of reference and budget

- Determination by the expert team of the partners and process for strategy formulation, including identification of major stakeholders in water resources decisions and determining their appropriate role in all phases of the process.

\section{SCOPE OF WORK}

A.7 Formulating a water resources management strategy will cover the following main tasks.

Phase 1

- Review of development objectives and key water-related policies

- Assessment of the availability of water resources in terms of both quantity and quality, covering surface water, groundwater, and nonconventional water sources (for example, desalinization, wastewater reuse, and water imports)

- Assessment of past and present water resources development and use, including an evaluation of existing infrastructure

- Identification and evaluation of the main issues faced in the water resources sector, including, but not limited to, issues of policy, planning, technology, institutional structure, the environment, and international relations

- Projections of future water supply and demand, and the presentation of alternative scenarios for the future water balance 


\section{Phase 2}

- Formulation of options that address the key issues emerging during inventory and analysis

- Evaluation of alternative strategies for managing water resources, including those relating to the management of supply (for example, investment, allocation, and real-time management) and those relating to the management of demand (for example, regulatory measures and controls, pricing, incentives, finance, and markets); these strategies should include considerations of both water quality and protection of the environment

- Presentation and recommendation of options to an oversight body (interministerial committee). The oversight body should either choose among these options or forward them, with endorsement, to decisionmakers.

- Detailing of further investigations and studies required to implement the strategy at the national, regional, international, and basin levels as appropriate.

A.8 The expert team will include water resources stakeholders as appropriate in both phases of the strategy formulation.

\section{PHASE 1: RESOURCES ASSESSMENT}

A.9 The first [indicate here a timeframe] will be devoted to assessing existing water resources and policies. This will cover the following areas.

\section{Examination of National Development Goals and Key Water-Related Policies}

A.10 This task should establish a list of a country's economic and social development objectives and water-related policies. The remaining tasks will be focused on the areas identified by those objectives.

\section{Inventory}

A.11 Assessment of Existing Information and Studies. Review from both a quantitative and qualitative standpoint of existing sources of data on water resources, including statistical sources, studies, documents, maps and ancillary reports, and identification of any data gaps.

A.12 Review of analytical methods currently used to assess water resources and water resource issues, together with an evaluation of their strengths and weaknesses.

A.13 Review of how data is collected and treated (including the interoperability of data bases) and how it is disseminated, including who has access to existing data bases.

A.14 Review of existing treaties and arrangements for international water resources management, including the availability and exchange of international data on climate, land use, and water. 
A.15 Assessment of the Physical Resource Base. General description and assessment of the physical resource base, including, climate, land, water, and other relevant characteristics.

A.16 Assessment of surface water availability allowing for re-use of drainage flows, and covering those resources fully available to the country and those shared with other countries, together with a review of present agreements concerning water allocation among the countries of the major river basins.

A.17 Assessment of the availability of groundwater, taking full account of actions between surface water and groundwater in the hydrological cycle, as well as of potential international aspects arising from shared groundwater aquifers.

A.18 Assessment of water quality and related issues having to do with surface and groundwater, including an evaluation of the point and non-point sources of pollution, and the nature of any trends over time.

A.19 Identification of sensitive ecosystems such as wetlands, estuaries, and coastal zones and assessment of how the aforementioned issues affect these ecosystems.

A.20 Water Resources Development and Use. Description of how water has been allocated between different consumptive and non-consumptive uses, together with an assessment of the basis for such allocations and priorities between them under normal and extreme conditions, for example at times of drought.

A.21 Evaluation of past and present development of single and multi-purpose water supply and control infrastructure, both within the country and in interconnected systems in neighboring countries, including water storage projects, water diversion, and inter-basin transfers, pump projects, flood control and river training works, and associated developments.

A.22 Assessment of past and present programs in water supply and disposal related to human consumption and industrial purposes, including trends in the coverage of water supply and sanitation services, the nature and development of industrial demands for water, and trends in other domestic and municipal uses.

A.23 Assessment of past and present programs in the irrigation and drainage sector, covering traditional settled areas as well as newly developed land reclamation and settlement schemes, and with reference to the nature of the supply and drainage system (for example, gravity or pumped, the performance of irrigated agriculture, the emergence of waterlogging, secondary salinity and other adverse environmental impacts in irrigated areas.

A.24 Evaluation of the impact of in-stream uses on the environment, evaluation of the environmental impacts of water development, notably those related to the development of hydrogeneration and the operation of the electric power systems.

A.25 Institutional Issues. Evaluation of the institutional system governing the development and management of water resources, including, but not limited to, legislation, the regulatory and administrative framework, management of the water resource, and provision of water services to endusers. 
A.26 Analytical review of existing legislation and preliminary identification of modifications to such legislation that may be desirable to address medium- to long-term goals.

A.27 Analytical review of the existing regulatory framework governing water and associated land use as it effects water use, water quality, and the control of the water resource, for example during droughts or floods, and the preliminary identification of modifications to the regulatory framework in support of sustainable economic development goals.

A.28 Analytical review of the agency functions and organizations with respect to the management of the resource. This includes review of functional links in agency responsibilities for water and associated land use, surface water and groundwater, and water quantity and quality. Functions relating to the management of the resource include

- Data collection, processing and dissemination

- National policy formulation

- Water resources planning

- Developing and enforcing water resources regulations

- Operations management of water resources systems

- Pollution control and enforcement

- Regional or hydrological basin planning and management

- Regulation and oversight of water resources institutions.

In respect of river basins in particular, the role and effectiveness of river basin organizations should be reviewed.

A.29 A critical review of agency functions and organization with respect to the delivery of water services (utilities, water users' associations) including

- The degree of autonomy and financially accountability of entities responsible for the provision of measurable water services that are organized as utilities delivering defined services to their customers for a fee

- Involvement of the private sector in the provision of measurable water services either in the form of cooperative or user groups, or where appropriate of private interests involved in ownership, management, or concession arrangements.

A.30 Consideration must be given to the delivery of water services in such areas as water conveyance and wholesaling, water supply and sanitation, and irrigation as they relate to other in-stream and environmental uses.

A.31 Consideration must be given to the government's role in strategic planning at the level of the individual sector, together with the provision of policy guidance and technical support to autonomous utilities and other entities.

A.32 Human Resources Development. Estimates of both available and required skills should be made during the water resources assessment. Training needs should be geared to long- and short-term institutional objectives. General skill areas that could be evaluated include technical (for example, 
fisheries specialists, hydrologists, and toxicologists), managerial, and cross-disciplinary skills (for example, ecologists).

A.33 Human resources development involves employment practices, career structures, and professional and financial incentives. Staffing patterns must be well understood and opportunities for promotions, commensurate with merits, assessed.

A.34 Economic Issues. Description of how water and its delivery is priced, including the analytical techniques used in pricing and economic analysis.

A.35 Review of current water pricing in view of the principles of cost recovery and equity. Review will include issues such as water price subsidies and indirect pricing or taxation methods (for example, fuel taxes).

A.36 Review of the methodology used to price water.

A.37 Review of the availability of data necessary to establish an opportunity cost or shadow price for water.

A.38 Environmental and Health Issues. Description of the state of water resources and of key portions of the natural environment that are closely related to water availability and quality. Review of the major water-related public health issues.

A.39 Inventory of matters related to the physical resource base and the environment, including the affects of water development on the environment (please see paragraphs A.15--A.24).

A.40 Description of the incidence and conditions associated with major water-related diseases, especially those related to water supply and sanitation.

A.41 International Issues. A review of the adequacy of existing international arrangements for water resources management.

A.42 Assessment of the physical resource base in terms of international river and hydrological basins (please see paragraph A.15).

A.43 Review of existing treaties and arrangements, including the terms of water supply agreements both as to quantity and quality, and data exchange (please see paragraph A.14).

A.44 Assessment of the effectiveness of treaties and of institutions such as river basin organizations or national institutions charged with fulfilling the responsibilities mandated by international treaties or agreement, covering whether treaty or agreement obligations have been met (by ail relevant parties) and identification of major international issues.

A.45 Consideration of whether, in view of a high proportion of international water resources, planning should be undertaken on a regional or international basis, or whether is possible or feasible to undertake strategy formulation for an entire river basin (assuming it crosses regional or international borders). 


\section{Key Issues: Selection, Analysis (Projections), and Ranking}

A.46 Selection. Choice of major immediate and long-term issues that must be addressed by a water resources strategy. The team should give consideration to those issues that may not be readily apparent, but that may have major long-term implications. The team should bear in mind that if the remainder of the strategy formulation process is to remain manageable, the number of issues will probably have to be limited.

A.47 Analysis (Projections). Estimation of past trends and the present position with regard to the water balance based on present levels of efficiency in water use in different sectors, accounting for re-use and other resource inter-actions, allowing for annual, seasonal, and regional variability in supply and demand, and, to the extent possible, reflect the impact of quality on the nature of the water balance.

A.48 Projection of future water supply and demand over the medium and long terms, and presentation of alternative future water balances based on differing assumptions concerning such factors as international agreements relating to water allocations and the need to augment flows to water bodies, population projections and the level of per capita consumption of water, industrial development and the effect of regulation on industrial and municipal demands, irrigation development and the impact of rehabilitation and modernization programs on the efficiency of irrigation use, the effect of drainage and related developments on the need to leaching water and the volume of return flows, demand management, including pricing and marketing issues, and any other significant developments as they may affect the water allocation and balance.

A.49 Assessment of alternative future trends and prospects with regard to water quality, taking into account the effect of irrigation, drainage, and municipal and industrial development, and the potential mitigating effects of investment, regulatory, and incentive measures on water quality.

A.50 Ranking Issues. In view of the projections and analysis, ranking issues in order of their importance in supporting development objectives and key water-related policies.

\section{Output}

A.51 [The terms of reference should specify what the products of phase 1 should be in terms of reports, summaries, presentations, and the like as well as setting dates for such output to be ready.]

\section{PHASE 2: STRATEGY DEFINITION}

A.52 Strategy definition comprises developing and evaluating options together with making firm recommendations to policymakers about which combination of options appears most suitable to achieve goals. [A timeframe should be suggested for phase 2].

\section{Developing Options}

A.53 This stage involves formulating alternative measures that address the issues identified in phase 1. Since each country is different, the options will be as varied as the major issues identified. The options might include: 
A.54 Water Supply. Options related to the management of supply, including those related to

- New surface water supply and control, both within the country and in connected systems in neighboring countries

- New groundwater sources, taking into account interaction with surface supplies in the hydrological cycle

- Non-conventional sources of water

- Rehabilitation and modernization of water supply and drainage storage and conveyance facilities and their effect on the efficiency of water use and water disposal

- Modifications in management of supplies to meet alternative allocation objectives or improve the efficiency of water use

A.55 Water Demand. Options and in the management of demand, including those related to

- Regulatory measures that mandate particular patterns of water supply and use, including quantitative restrictions, control of groundwater extractions, and rotational supply, for example in surface irrigation systems

- Regulatory measures that mandate particular quality standards, both to achieve environmental objectives and to encourage recirculation of industrial process and other water.

- Technical interventions in irrigation including canal lining and improved distribution technologies, land levelling, and advance on-farm irrigation practices, for example improved furrow irrigation, sprinkler, and micro-irrigation (notably drip), and irrigation scheduling and other operational improvements both on-farm (to meet crop water requirements more accurately and at the level of the main system

- Technical interventions aimed at conserving water in other contexts, for example rehabilitation of urban water systems

- Introduction of water tariffs and financial penalties and incentives designed to encourage investments in water-saving technologies such as those described above and to promote economically efficient levels of water use

- Public education and awareness programs designed to inform consumers of the real value of water and to promote desirable changes in behavior.

A.56 Water Quality. Options for establishing or maintaining water quality in terms of

- Institutions responsible for establishing, standards and for monitoring, and enforcement of those standards 
- Major geographic or functional areas requiring immediate attention, including ecologically sensitive zones and agricultural areas

A.57 Information. Options relating to the need to gather and distribute necessary information on both a discrete (i.e., how to obtain specific pieces of information) and systemic (i.e., how the information system should be set up) basis. Development of options concerning the latter will include suggestions for institutional arrangements for data handling and dissemination, including options for working within existing institutions where feasible.

A.58 Institutional Issues. Options related to institutional arrangements including those related to the regulatory measures described in paragraph A.25 as well as:

- Options for harmonizing or making consistent various laws and regulations within the framework of the legal regime for water resources management, including considerations of ownership of or use rights to water

- Options for a structure to enforce laws and regulations and to manage the process of water resources planning, as well as definite suggestions as to which organizations should have responsibilities for the functions of national resource policy and planning, data collection and dissemination, pollution control and enforcement, and regional or river basin planning and management

- Options for links between and among government areas and departments

- Options relating to the structure and management of water supply and sanitation and irrigation and drainage organizations, including consideration of decentralization to the extent feasible, cost recovery, financial autonomy, and the formation and use of water users' associations

A.59 Human Resources Development. Options on short and long term training requirements, including requirements for cross-disciplinary skills.

A.60 The options involve employment practices, career structures, and professional and financial incentives. The options should consider the possibility of employing expertise in human resources development on the permanent staff of large institutions or as consultants to smaller organizations.

A.61 Consideration should be given to having a utility provide a university with funds to participate in the development of options.

A.62 Economic Issues. Options related to the allocation of water on an economically efficient basis, including the need for data to determine such an allocation. Consideration of the institutions that will be responsible for gathering or maintaining requisite data.

A.63 Environment and Public Health. The former may comprise many water quality options in addition to 
- Options for protecting or reclaiming natural ecosystems, especially those that are economically important or that serve as important protection from natural or man-made problems

- Options for assessing the environmental impact (including the social impact)of water development projects

Options for improving public health including water quality standards, institutional options, and public education campaigns.

A.64 International Options. These may include options for joint or international river basin planning and management, for solutions to specific disagreements or disputes, or for negotiation (or re-negotiation) of international treaties.

\section{Evaluating Options}

A.65 Clear articulation of the criteria to be used for evaluating options, including the values of practicality and sustainability.

A.66 Evaluation of alternative combinations of supply and demand measures to achieve national goals and objectives, where possible using standard economic and other analytical techniques.

A.67 Evaluation of information system, institutional, economic, environmental, public health and international options.

A.68 Evaluation of cost recovery and other water pricing measures.

A.69 Evaluation of alternative options for bulding the capacity to deliver water and manage it, including examining decentralization of services and community involvement.

A.70 Evaluation of risks associated with options or combination of options.

\section{Recommendations}

A.71 Detailed recommendation of a set of options that the team considers best suited to best achieve development goals and support key water policies, together with identification of institutions to implement those options.

A.72 Presentation of options, together with the short and long-term implications of each (including potential risks) to the oversight body (interministerial committee).

\section{Output}

A.73 [The terms of reference should specify what the products of phase 2 should be in terms of reports, summaries, presentations, and the like as well as setting dates for such output to be ready.] 


\section{Distributors of World Bank Publications}

ARGENTINA

Galeria Guemes

Florida 165, 4th Floor-Ofc. 453/465

1333 Buenos Aires

Ofiana del Libro Internacional

Albert 40

1082 Buenos Aires

australia, papUa NEW GUiNEa, FIII, SOLOMON ISLANDS,

VANUATU, AND WESTERN SAMOA

D.A. Information Services

648 Whitehorse Road

Mitcham 3132

Victoria

AUSTRIA

Gerold and Co.

Graben 31

A-1011 Wien

BANGLADESH

Micro Industries Development Assistance Society (MIDAS)

House 5, Road 16

Dhanmondi R/Area

Dhaka 1209

BELGIUM

Jean De Lannoy

Av. du Roi 202

1060 Brussels

BRAZIL

Publicacoes Tecnicas Internacoonass Ltda.

Rua Peixoto Gomide, 209

01409 Sao Paulo, SP

CANADA

Le Dhffuseur

151A Boul. de Mortagne

Boucherville, Québec

J48 5E6

Renouf Publishing Co.

1294 Algoma Road

Ottawa, Ontano

KIB 3W8

CHINA

Chuna Financal \& Economic

Publishung House

8. Da Fo S1 Dong Jie

Beijung

COLOMBIA

Infoenlace Ltda.

Apartado Aereo 34270

Bogota D.E.

\section{COTE D'IVOIRE}

Centre d'Edition et de Diffusion

Afncarnes (CEDA)

04 B P. 541

Abıdjan 04 Plateau

CYPRUS

Center of Applied Research

Cyprus College

6. Dhogenes Street, Engomi

P.O BDo 2006

Nicosia

\section{DENMARK}

SamiundsLitteratur

Rosenoerns Alle 11

DK-1970 Frederiksberg C

DOMINICAN REPUBLIC

Editora Taller, C. por A.

Restauracón e Isabel la Católica 309

Apartado de Carreos 2190 Z-1

Santo Domingo
EGYPT, ARAB REPUBLIC OF

Al Ahram

Al Galaa Street

Cairo

The Muddle East Observer

41, Sherif Street

Cairo

FINLAND

Akateemunen Kinakauppa

P O. Box 128

SF-00101 Helsinki 10

FRANCE

World Bank Publications

66 , avenue d'Iéna

75116 Pans

GERMANY

UNO-Verlag

Poppelsdorfer Allee 55

53115 Born

GREECE

Papasotinou S.A.

35. Stoumara Str.

10682 Athens

HONG KONG, MACAO

Asia 2000 Ltd

46-48 Wyndham Street

Winning Centre

7th Floor

Central Hong Kong

HUNGARY

Foundation for Market Economy

Dombovari Ut 17-19

H-1117 Budapest

INDIA

Allied Publishers Private Ltd

751 Mount Road

Madras - 600002

INDONESIA

Pt. Indira Lumited

Jalan Borobudur 20

P.O. Box 181

Jakarta 10320

IRAN

Kowkab Publishers

P.O. Box 19575-511

Tehran

IRELAND

Government Supplies Agency

4-5 Harcourt Road

Dublin 2

ISRAEL

Yozmot Literature Ltd.

P.O. Box 5605

Tel Aviv 61560

ITALY

Licosa Commissionaria Sansoni SPA

Via Duca Di Calabna. 1/1

Casella Postale 552

50125 Firenze

JAMAICA

Ian Randle Publishers Ltd.

206 Old Hope Road

Kungston 6

JAPAN

Eastern Book Service

Hongo 3-Chome, Bunkyo-ku 113

Tokyo
KENYA

Africa Book Service (E.A.) Ltd.

Quaran House, Mfangano Street

P.O Box 45245

Nairobi

KOREA, REPUBLIC OF

Pan Korea Book Corporation

P.O Box 101, Kwangwhamun

Seoul

Korean Stock Book Centre

P.O. Box 34

Yeoerdo

Seoul

MALAYSIA

University of Malaya Cooperative

Bookshop, Limited

P.O. 80x 1127, Jalan Pantai Baru

59700 Kuala Lumpur

MEXICO

INFOTEC

Apartado Postal 22-860

14060 Tlalpan, Mexico D.F.

NETHERLANDS

De Lindeboom / InOr-Publikaties

P.O. Box 202

7480 AE Haaksbergen

NEW ZEALAND

EBSCONZ Ltd.

Private Mail Bag 99914

New Market

Auckland

NIGERIA

University Press Limited

Three Crowns Building Jericho

Prvate Mail Bag 5095

Ibadan

NORWAY

Narvesen Information Center

Book Department

P.O Box 6125 Etterstad

$\mathrm{N}-0602$ Oslo 6

\section{PAKISTAN}

Mirza Book Agency

65. Shahrah-equaide-Azam

P.O. Box No. 729

Lahore 54000

PERU

Editorial Desarrollo SA

Apartado 3824

Lima 1

PHILIPPINES

International Book Center

Suste 1703, Cityland 10

Condornunium Tower 1

Ayala Avenue, H.V. dela

Costa Extension

Makan, Metro Manila

POLAND

International Publishung Service

Ul. Piekna 31/37

00-677 Warszawa

For subscription orders:

IPS Joumals

Ul. Okrezna 3

02-916 Warszawa

PORTUGAL

Luvrana Portugal

Rua Do Carmo 70-74

1200 Lssbon
SAUDI ARABLA OATAR

Jaru Book Store

P.O. Box 3196

Riyadh 11471

SINGAPORE TATWAN

MYANMAR,BRUNEI

Gower Assa Pacfic Pte Ltd.

Golden Wheel Building

41, Kallang Pudding, $104-03$

Singapore 1334

SOUTH AFRICA, BOTSWANA

For single titles:

Oxford University Press

Southern Africa

P.O. Box 1141

Cape Town 8000

For subscription orders:

International Subscription Service

P.O. Box 41095

Craighall

Johannesburg 2024

SPAIN

Mundi-Prensa Libros, S.A

Castello 37

28001 Madrid

Libreria Internacional AEDOS

Consell de Cent, 391

08009 Barcelona

SRI LANKA AND THE MALDIVES

Lake House Bookshop

P O. Box 244

100. Sir Chittampalam A.

Gardiner Mawatha

Colombo 2

SWEDEN

For single titles:

Fritzes Fackboksforetaget

Regeringsgatan 12, Box 16356

S-10327 Stockholm

For subscription orders:

Wennergren-Willams $A B$

P. O. Box 1305

S-17125 Solna

SWITZERLAND

For single tutles:

Libraine Payot

Case postale 3212

CH 1002 Lausanne

For subscnption orders:

Libraine Payot

Service des Abonnements

Case postale 3312

$\mathrm{CH} 1002$ Lausanne

THAILAND

Central Department Store

306 Silom Road

Bangkok

TRINIDAD \& TOBAGO

Systematics Studies Unt

*9 Watts Street

Curepe

Trundad, West Indies

UNITED KINGDOM

Microinfo Ltd

P.O Box 3

Alton, Hampshure GU34 2PG

England

ZIMBABWE

Longman Zimbabwe (Pvt.) Ltd.

Tourie Road, Ardbennie

P.O Box ST 125

Southerton

Harare 



\section{RECENT WORLD BANK TECHNICAL PAPERS (continued)}

No. 226 Bindlish, Evenson, and Gbetibouo, Evaluation of TEV-Based Extension in Burkina Faso

No. 227 Cook, editor, Involuntary Resettlement in Africa: Selected Papers from a Conference on Environment and Settlement Issues in Africa

No. 228 Webster and Charap, The Emergence of Private Sector Manufacturing in St. Petersburg: A Survey of Firms

No. 229 Webster, The Emergence of Private Sector Manufacturing in Hungary: A Survey of Firms

No. 230 Webster and Swanson, The Emergence of Private Sector Manufacturing in the Former Czech and Slovak Federal Republic: A Survey of Firms

No. 231 Eisa, Barghout, Gillham, and Al-Saffy, Cotton Production Prospects for the Decade to 2005: A Global Overview

No. 232 Creightney, Transport and Economic Performance: A Survey of Developing Countries

No. 233 Frederiksen, Berkoff, and Barber, Principles and Practices for Dealing with Water Resources Issues

No. 234 Archondo-Callao and Faiz, Estimating Vehicle Operating Costs

No. 235 Claessens, Risk Management in Developing Countries

No. 236 Bennett and Goldberg, Providing Enterprise Development and Financial Services to Women: A Decade of Bank Experience in Asia

No. 237 Webster, The Emergence of Private Sector Manufacturing in Poland: A Survey of Firms

No. 238 Heath, Land Rights in Côte d'Ivoire: Survey and Prospects for Project Intervention

No. 239 Kirmani and Rangeley, International Inland Waters: Concepts for a More Active World Bank Role

No. 240 Ahmed, Renewable Energy Technologies: A Review of the Status and Costs of Selected Technologies

No. 241 Webster, Newly Privatized Russian Enterprises

No. 242 Barnes, Openshaw, Smith, and van der Plas, What Makes People Cook with Improved Biomass Stoves?: A Comparative International Review of Stove Programs

No. 243 Menke and Fazzari, Improving Electric Power Utility Efficiency: Issues and Recommendations

No. 244 Liebenthal, Mathur, and Wade, Solar Energy: Lessons from the Pacific Island Experience

No. 245 Klein, External Debt Management: An Introduction

No. 246 Plusquellec, Burt, and Wolter, Modern Water Control in Irrigation: Concepts, Issues, and Applications

No. 247 Ameur, Agricultural Extension: A Step beyond the Next Step

No. 248 Malhotra, Koenig, and Sinsukprasert, A Survey of Asia's Energy Prices

No. 249 Le Moigne, Easter, Ochs, and Giltner, Water Policy and Water Markets: Selected Papers and Proceedings from the World Bank's Annual Irrigation and Drainage Seminar, Annapolis, Maryland, December 8-10, 1992

No. 250 Rangeley, Thiam, Andersen, and Lyle, International River Basin Organizations in Sub-Saharan Africa

No. 251 Sharma, Rietbergen, Heimo, and Patel, A Strategy for the Forest Sector in Sub-Saharan Africa

No. 252 The World Bank/FAO/UNIDO/Industry Fertilizer Working Group, World and Regional Supply and Demand Balances for Nitrogen, Phosphate, and Potash, 1992/93-1998/99

No. 253 Jensen and Malter, A Global Review of Protected Agriculture

No. 254 Frischtak, Gozernance Capacity and Economic Reform in Dezeloping Countries

No. 255 Mohan, editor, Bibliography of Publications: Technical Department, Africa Region, July 1987 to April 1994

No. 256 Campbell, Design and Operation of Smallholder Irrigation in South Asia

No. 257 Malhotra, Sinsukprasert, and Eglington, The Performance of Asia's Energy Sector

No. 258 Willy De Geyndt, Managing the Quality of Health Care in Developing Countries

No. 259 Chaudry, Reid, Malik, editors, Civil Service Reform in Latin America and the Caribbean: Proceedings of a Conference

No. 260 Humphrey, Payment Systems: Principles, Practice, and Improvements

No. 261 Lynch, Provision for Children with Special Educational Needs in the Asia Region

No. 262 Lee, Bobadilla, Health Statistics for the Americas 
The World Bank

Headquarters

1818 H Street, N.W.

European Office

66, avenue d'Téna

Tokyo Office

75116 Paris, France

Kokusai Building

1-1, Marunouchi 3-chome

Telephone: (1) 40.69.30.00

Telephone: (202) 477-1234

Facsimile: (202) 477-6391

Telex: MCI 64145 WORLDBANK MCI 248423 WORLDBANK

Facsimile: (1) 40.69.30.66

Chiyoda-ku, Tokyo 100, Japan

Telex: 640651

Telephone: (3) 3214-5001

Facsimile: (3) 3214-3657

Telex: 26838 